\title{
WestVirginiaUniversity
}

THE RESEARCH REPOSITORY @ WVU

Graduate Theses, Dissertations, and Problem Reports

2001

\section{Fastener withdrawal resistance of wood-based composite panel products}

Steven M. Cook

West Virginia University

Follow this and additional works at: https://researchrepository.wvu.edu/etd

\section{Recommended Citation}

Cook, Steven M., "Fastener withdrawal resistance of wood-based composite panel products" (2001). Graduate Theses, Dissertations, and Problem Reports. 1334.

https://researchrepository.wvu.edu/etd/1334

This Thesis is protected by copyright and/or related rights. It has been brought to you by the The Research Repository @ WVU with permission from the rights-holder(s). You are free to use this Thesis in any way that is permitted by the copyright and related rights legislation that applies to your use. For other uses you must obtain permission from the rights-holder(s) directly, unless additional rights are indicated by a Creative Commons license in the record and/ or on the work itself. This Thesis has been accepted for inclusion in WVU Graduate Theses, Dissertations, and Problem Reports collection by an authorized administrator of The Research Repository @ WVU. For more information, please contact researchrepository@mail.wvu.edu. 
Fastener Withdrawal Resistance of Wood-Based Composite Panel Products

\author{
Steven M. Cook \\ Thesis submitted to the \\ College of Agriculture and Forestry \\ at West Virginia University \\ in partial fulfillment of the requirements \\ for the degree of
}

Master of Science in

Forest Resource Management

Dr. Elemer M. Lang, Ph.D, Chair

Dr. R. Bruce Anderson, Ph.D

Dr. James P. Armstrong, Ph.D

Division of Forestry

\author{
Morgantown, West Virginia \\ 2001
}

Keywords: hardwood flooring, composite panel products, fastener withdrawal, moisture content cycling 


\title{
Fastener Withdrawal Resistance of Wood-Based Composite Panel PRODUCTS
}

\author{
By \\ Steven M. Cook \\ Committee Chairman: Elemer M. Lang \\ Wood Industries
}

\section{(ABSTRACT)}

The purpose of this research project was to evaluate the performance of currently available wood-based panel products as sub-floor materials when used under quality oak strip flooring and exposed to cyclic EMC conditions. The critical evaluation criterion was the fastener holding capacity of various sub-floor materials. To accomplish this, investigation of the in-plane density variations of currently available panel products was performed, as was an investigation of the relationship between panel density and the fastener holding capacity of different panel materials. In addition, a comparison of the fastener holding capacity of six different panel products was investigated during and after a two and one-half year simulated moisture cycle. This allowed for a testing of the interaction between moisture content cycling, sub-floor materials, and fasteners on floor system performance. The results of this project were compared to results obtained in similar investigations done previously. 


\section{ACKNOWLEDGEMENTS}

Partial funding for this project was provided by the National Oak Flooring Manufacturers Association. Further support was provided by the West Virginia University Division of Forestry.

I would like to take this time to express my sincere appreciation to Dr. Elemer M. Lang for giving me this once in a lifetime opportunity. His guidance and patience throughout the duration of this project was paramount, as was his lenience towards my work habits. Without his assistance, none of this would have been possible. I would like to thank Jeremy Kerekes, whose countless hours of testing and data acquisition made my life easier. Appreciation goes out to the entire faculty and staff in the Division of Forestry, specifically those associated with Wood Science, for providing further guidance with matters of research or otherwise. I would also like to thank Paul Ludrosky, who provided me with the tools and the help necessary to complete this research project. A special thanks goes out to Charles "Mickey" Moore and Warren Spradlin of the National Oak Flooring Manufacturers Association, who provided not only the opportunity for this project, but much of the assistance critical in making this project a success.

Lastly, I wish to express my love and appreciation to my family, without whom I would not be here. Their encouragement and love over the past twenty five plus years means more to me than they will ever know. Their positive outlook provided me the desire to succeed, even when I may have wanted to give up. To them I am eternally grateful. 


\section{TABLE OF CONTENTS}

Page

CHAPTER 1: INTRODUCTION

OBJECTIVES

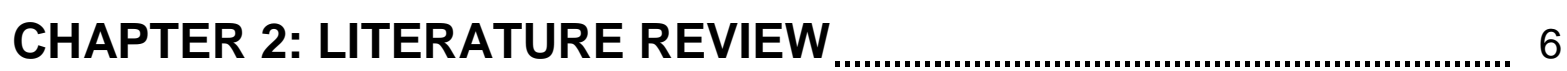

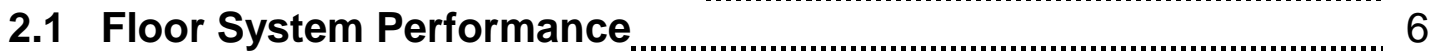

2.2 Wood/Moisture Relations $\ldots$

2.2.1 Floor Joists

2.2.2 Sub-flooring ...................................................................................... 8

2.2.3 Finished Flooring ................................................................................. 10

2.3 Fasteners

CHAPTER 3: EXPERIMENTAL METHODS $\ldots 14$

3.1 Introduction

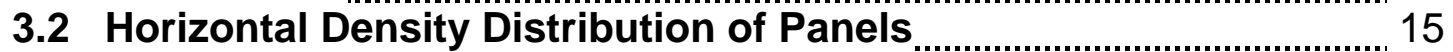

3.3 Floor Construction $\ldots$

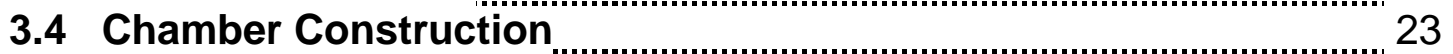

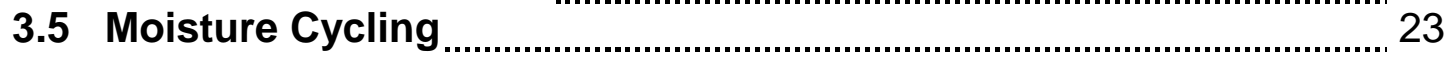

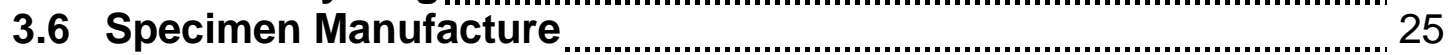

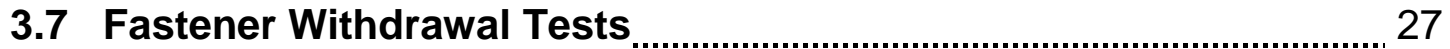

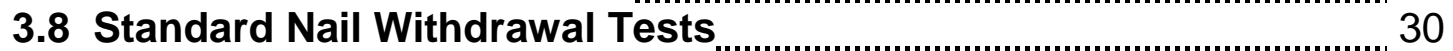

3.9 Sub-floor Thickness Change

3.10 Moisture Meter Calibration …………………………………………. 32

3.11 Statistical Analysis

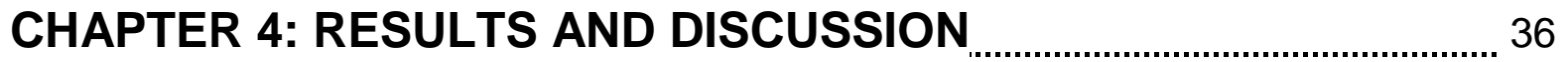

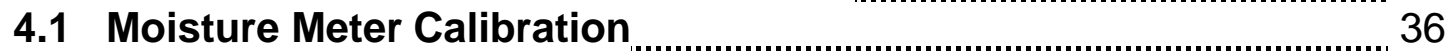

4.2 Horizontal Density Distribution of Panels …………………………….... 36

4.3 Moisture Cycling ............................................................... 47

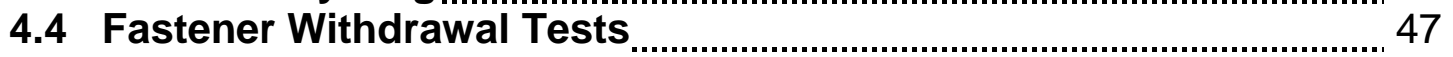

4.5 Standard Nail Withdrawal Tests

4.6 Sub-floor Thickness Change

CHAPTER 5: SUMMARY AND CONCLUSIONS $\ldots$

5.1 Summary

5.2 Conclusions

Recommendations

LITERATURE CITED

APPENDICES

Appendix I: ANOVA Tables $\ldots$

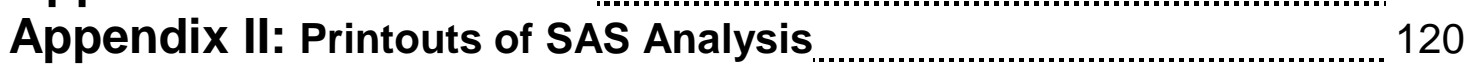




\section{LIST OF TABLES}

$\underline{\text { Table }}$

Page

4.1 Summary of descriptive statistics of horizontal density distribution data

4.2 Summary of descriptive statistics from five series of fastener withdrawal tests

4.3 Summary of descriptive statistics for floors fastened with 2" nails at an angle of $30^{\circ}$

4.4 Summary of descriptive statistics for finished floor combinations

4.5 Percent change in mean fastener holding capacity

4.6 Results of the General Linear Model procedure for panel type versus fastener type.

4.7 Rank of GLM procedure results for panel type versus fastener type in descending order

4.8 Comparison of results from two fastener withdrawal studies done ten years apart

4.9 Summary of descriptive statistics for five series of standard nail withdrawal tests

4.10 Results of Tukey Test for standard nail withdrawal 


\section{LIST OF FIGURES}

Figure

Page

3.1 View of sixty-eight constructed floor systems (a); example of a typical APA OSB panel grade stamp (b).

3.2 Dimensions of test floor systems for O3, P3, and P5.

3.3 Floor joist spacing template for $\mathrm{O} 3$ floor system (a); APA designated nailing pattern for $\mathrm{O} 3$ floor system (b).

3.4 Three fasteners used in floor system construction (a); cutaway profile of floor fastener installed at a $45^{\circ}$ angle (b).

3.5 Environmental chamber midway through construction (a); front view of completed environmental chamber (b).

3.6 Relative humidity and temperature of test floor systems and panels during (a) occupancy simulation phase; (b) mild exposure site simulation.

3.7 Cross-shaped fastener withdrawal test specimens. 28

3.8 MTS Servo-Hydraulic Universal test machine set up for specimen testing (a); special specimen withdrawal testing jig with specimen in place (b).

3.9 ASTM standard nail withdrawal test setup (a); ASTM standard nail withdrawal test specimen (b).

3.10 Delmhorst RDM 2-S handheld moisture meter.

4.1 Regression equation of oven-dry MC vs. moisture meter MC with $95 \%$ confidence and prediction intervals for (a) East Coast plywood; (b) West Coast plywood.

4.2 Regression equation of oven-dry MC vs. moisture meter MC with $95 \%$ confidence and prediction intervals for (a) East Coast OSB: (b) West Coast OSB.

4.3 Histogram of horizontal density distribution with probability density function overlaid for (a) EO3 panels; (b) WO3 panels.

4.4 Histogram of horizontal density distribution with probability density function overlaid for (a) EP3 panels; (b) WP3 panels. 
4.5 Histogram of horizontal density distribution with probability density function overlaid for (a) EP5 panels; (b) WP5 panels.

4.6 Regression analysis of fastener withdrawal strength vs. specific gravity of OSB panels (pre-treatment) for (a) staple fastener; (b) nail fastener.

4.7 Regression analysis of fastener withdrawal strength vs. specific gravity of OSB panels (post-treatment) for (a) staple fastener; (b) nail fastener.

4.8 Regression analysis of fastener withdrawal strength vs. specific gravity of plywood panels (post-treatment for (a) staple fastener; (b) nail fastener.

4.9 Changes in fastener holding capacity by exposure for panel code
(a) EO3N; (b) WO3N.

4.10 Changes in fastener holding capacity by exposure for panel code
(a) EO3S; (b) WO3S

4.11 Changes in fastener holding capacity by exposure for panel code

(a) EP3N; (b) WP3N.

4.12 Changes in fastener holding capacity by exposure for panel code
(a) EP3S; (b) WP3S.

4.13 Changes in fastener holding capacity by exposure for panel code
(a) EP5N; (b) WP5N.

4.14 Changes in fastener holding capacity by exposure for panel code
(a) EP5S; (b) WP5S.

4.15 Changes in fastener holding capacity by exposure for panel code

(a) EP3N2; (b) WP3N2.

4.16 Changes in fastener holding capacity by exposure for panel code
(a) EP5N2f; (b) WP5N2f.

4.17 Changes in fastener holding capacity by exposure for panel code
(a) EP5Sf; (b) WP5Sf.

4.18 Comparison of fastener holding capacity by panel code during coupon phase for (a) nail fastener; (b) staple fastener. 
4.19 Comparison of fastener holding capacity by panel code during

Phase IV for (a) nail fastener; (b) staple fastener.

4.20 Comparison of fastener holding capacity by panel code during

Phase $\mathrm{V}$ for (a) nail fastener; (b) staple fastener.

4.21 Comparison of fastener holding capacity by panel code during

Phase VI for (a) nail fastener; (b) staple fastener.

4.22 Comparison of fastener holding capacity by panel code during

Phase VII for (a) nail fastener; (b) staple fastener.

4.23 Changes in fastener holding capacity by exposure for standard nail withdrawal; (a) panel code EO3, (b) panel code WO3.

4.24 Changes in fastener holding capacity by exposure for standard nail withdrawal; (a) panel code EP3, (b) panel code WP3.

4.25 Changes in fastener holding capacity by exposure for standard nail withdrawal; (a) panel code EP5, (b) panel code WP5.

4.26 Comparison of fastener holding capacity of standard nail withdrawal

by panel code for (a) coupon phase; (b) phase IV.

4.27 Comparison of fastener holding capacity of standard nail withdrawal by panel code for (a) phase V; (b) phase VI.

4.28 Comparison of fastener holding capacity of standard nail withdrawal by panel code for phase VII.

4.29 Moisture content change (a), thickness change (b), and shrinkage and swelling ratios (c) of EO3 panels during exposure cycle.

4.30 Moisture content change (a), thickness change (b), and shrinkage and swelling ratios (c) of EP3 panels during exposure cycle.

4.31 Moisture content change (a), thickness change (b), and shrinkage and swelling ratios (c) of EP5 panels during exposure cycle.

4.32 Moisture content change (a), thickness change (b), and shrinkage and swelling ratios (c) of WO3 panels during exposure cycle.

4.33 Moisture content change (a), thickness change (b), and shrinkage and swelling ratios (c) of WP3 panels during exposure cycle. 
Figure

Page

4.34 Moisture content change (a), thickness change (b), and shrinkage and swelling ratios (c) of WP5 panels during exposure cycle. 


\section{LIST OF SYMBOLS AND ABBREVIATIONS}

\begin{tabular}{|c|c|}
\hline $\mathrm{F}_{\mathrm{w}} \ldots \ldots \ldots \ldots \ldots$ & fastener withdrawal strength (lb) \\
\hline SG & specific gravity \\
\hline TS & thickness swell (\%) \\
\hline$\beta \ldots \ldots \ldots \ldots$ & ...shrinkage/swelling coefficient (\%/\%MC) \\
\hline $\mathrm{MC}$ & ....moisture content (\%) \\
\hline EMC & ...equilibrium moisture content (\%) \\
\hline HDD . & horizontal density distribution \\
\hline IB & internal bond \\
\hline$t \ldots \ldots . .$. & ...panel thickness (in) \\
\hline $\mathrm{h} \ldots \ldots$. & panel height (in) \\
\hline $\mathrm{w}_{\ldots \ldots \ldots \ldots}$ & ...panel width (in) \\
\hline $\mathrm{M}$ & mass $(\mathrm{g})$ \\
\hline$M_{0} \ldots \ldots \ldots \ldots$ & ...oven-dry mass (g) \\
\hline LE ......... & ...linear expansion (\%) \\
\hline $\mathrm{RH} \ldots$. & relative humidity (\%) \\
\hline $\mathrm{T} \ldots \ldots \ldots \ldots$ & temperature $\left({ }^{\circ} \mathrm{F}\right)$ \\
\hline$E$ & East Coast \\
\hline W. & West Coast \\
\hline $\mathrm{P} \ldots \ldots \ldots \ldots \ldots$ & ...plywood \\
\hline O or OSB. & ...oriented strand board \\
\hline 3. & 3 / 4" thick panel \\
\hline $5 \ldots .$. & $5 / 8 "$ thick panel \\
\hline S. & .... $.5 "$ staple fastener \\
\hline $\mathrm{N}$ & 1.5" nail fastener \\
\hline $\mathrm{N} 2 \ldots \ldots \ldots$ & ..." nail fastener \\
\hline 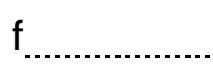 & finished flooring \\
\hline$b_{0}, b_{1}, b_{2}$ & regression coefficients \\
\hline
\end{tabular}




\section{INTRODUCTION}

Hardwood flooring provides an aesthetically pleasing option for the homebuilder in search of a practical yet elegant floor surface. Its simple elegance and intrinsic beauty are unmatched by any other type of finished flooring. Cassens and Feist (1980) stated that the properties of wood make it a highly desirable flooring material in residential and public buildings. Hardwood floors are relatively easy to maintain and will provide years of trouble free service if they are installed and maintained correctly. Installation of these flooring systems must be designed to minimize the some of the negative physical and mechanical properties that are inherent with wood and wood products.

In a typical residential light frame construction, a flooring system is made up of several key components. These components include the floor joists, the sub-floor and/or underlayment, and the finished flooring surface, usually applied over construction felt paper or some other form of vapor barrier. Floor joists may be solid wood or a wood composite product varying in size, shape, and style. Advances in the forest products industry have caused the choice of sub-floor materials change from solid wood to woodbased panel products; specifically plywood and oriented strand-board (OSB).

Due to a steady increase in the population of the United States, there is an ever growing need for building materials, including wood and wood-based products. Therefore, more and more immature and sub-standard trees are being harvested. The harvesting of inferior trees often results in lumber and boards lacking in strength and performance qualities. The best way to utilize this inferior raw material is to break it down into pieces and bond these pieces together, making a finished product with 
properties far surpassing those of the raw material. Also, solid wood is a substance that has very unpredictable properties. By breaking down the raw material and then reconstructing it, the industry can create a building material that is very homogeneous and in turn more predictable based on performance criteria. Youngquist (1999) stated that because wood properties are variable among species, within species and even within the same tree, solid wood cannot match processed wood-based products where mechanical and physical properties are concerned.

Flooring systems in general are fairly simple in design yet may become complex when the system must be based on performance criteria. Wood is a hygroscopic substance; readily gaining or losing moisture depending on the conditions surrounding it. Since the basic components of a flooring system are predominantly wood and woodbased materials, this hygroscopic property will influence the performance of wood products subjected to moisture patterns.

Hardwood flooring is generally installed in the final stages of building construction. This normally occurs after a structure is enclosed and the other floor system components are in place. However, sometimes a situation arises in which the sub-floor material has not yet reached its in service moisture content before flooring installation. As the sub-floor moves toward its in-service equilibrium moisture content and goes through subsequent seasonal environmental changes, the fastener holding capacity between the hardwood flooring and the sub-floor may be decreased. The subflooring and the flooring itself will experience dimensional changes in the form of shrinkage and swelling due to changes in environmental humidity and temperature. The problem arises when these changes do not occur at the same rate or in the same 
magnitude. Over time, this may result in buckling, gaps, squeaks, floor migration or other forms of unacceptable flooring behavior.

With this in mind, it is evident that a process to test the performance of flooring systems is necessary in order to understand the interactions of the various floor system components and the role that these components play in the overall performance of the entire system. By understanding these components and how they interact with one another, we can combine them in a way that preserves the longevity of flooring in service. An accelerated environmental simulation allows us to test the efficacy of a flooring system during the first two and one-half years after installation. By comparing various combinations of fastener style and sub-floor panel type during an accelerated environmental simulation, conclusions may be drawn indicating which combination best supports acceptable in-service floor system performance.

Lang et al (1992) conducted a similar project at Virginia Tech approximately ten years ago. Results of that project aided the National Oak Flooring Manufacturers Association (NOFMA) in recommending fastener and sub-floor combinations that would offer the best performance when used in conjunction with oak strip flooring. The rate at which technological advancements in the composite panel industry have grown spawned a recent interest by NOFMA as to how these advancements may have changed the recommendations established after the previous project. This interest caused NOFMA to provide funding for this project to determine the performance status of currently available composite panel products as possible sub-floor materials under oak strip flooring. 


\section{OBJectives}

The overall objective of this project was to evaluate the performance of currently available wood-based panel products as sub-floor materials under quality oak strip flooring in cyclic equilibrium moisture content (EMC) conditions. In order to accomplish this, evaluation of the interactions between sub-floor panel type, fastener type, and moisture cycling was performed. Implementation of an accelerated environmental simulation provided information as to the performance of various sub-floor/fastener combinations and how they change over time. Specific objectives of this project were:

1. To investigate the in-plane density variations of currently available panel products for use as sub-flooring.

2. To relate the density to the fastener holding capacity of the different panels.

3. To compare the fastener holding capacity of six different wood-based composite panel products (two types of OSB and four types of plywood) during and after a simulated two and one-half year moisture cycle.

4. To investigate the interaction between moisture content cycling, sub-floor materials and fasteners on the performance of floor systems measured by the fastener holding capacity of the system.

5. To compare the experimental results with data obtained by a prior similar project.

This Masters thesis details the work done in order to fulfill these objectives. All relevant procedures and conclusions are contained in the following chapters: 
- Chapter 2 provides a detailed literature review.

- Chapter 3 contains all relevant experimental methods.

- Chapter 4 details the project results and discussion.

- Chapter 5 provides a project summary and conclusions based on the research data along with recommendations for further research. 
CHAPTER 2

\section{Literature Review}

\subsection{Floor System Performance}

Several factors can influence the expected performance of a hardwood flooring system. Among these are the performance of the components that make up the system and the performance of the fasteners that hold the components together. Furthermore, the magnitude of the environmental changes that a flooring system undergoes will have a profound impact on the floor system performance. Wood in service undergoes constant changes in moisture content due to cyclic humidity changes. Due to the hygroscopic nature of wood and wood-based products, their moisture content is directly related to atmospheric conditions; relative humidity $(\mathrm{RH})$ and temperature. Consequently, their performance characteristics are very much dependent on the environmental conditions surrounding them. It would stand to reason then, that in order to accurately gauge the performance of wood and wood based panel products, the products must be tested in cyclic environmental conditions, similar to what they would experience in service.

Mohammad and Smith (1996) stated that environmental changes at the seasonal level might result in variations in single elements of a system, leading to degradation in the constituents and degradation in the ability of the fasteners to hold them together. Testing with the inclusion of the element of moisture cycling is important in establishing the behavior of hardwood flooring when used in conjunction with building materials commonly seen in construction (Lang et al. 1994). New information on the performance of fasteners in new sheathing and siding products is needed, especially when in a 
weathered or aged condition, compared to conventional plywood sheathing (Chow et al. 1985).

\subsection{Wood Moisture Relations}

The performance of a floor system is based primarily on the response of each of three major system components to changes in moisture content $(\mathrm{MC})$ throughout the system. These three major system components include floor joists, sub-flooring, and finished flooring.

\subsubsection{Floor Joists}

Floor joists in light frame residential construction are generally either nominal 2 "x8" or 2"x10" southern yellow pine (syp) or spruce-pine-fir (s-p-f) lumber, or in a growing number of cases, engineered wood l-joists. Floor joists in residential light frame construction are designed to carry the load distributed by the sub-flooring and finished flooring. With this in mind, it may be said that stiffness, or a resistance to deformation, is a very important design parameter in terms of building serviceability (Chou and Polensek 1987).

In service, floor joists are subject to damping stresses and degradation or slip of nailed joints between the joists themselves and the sub-floor material covering them. Attempts were made to clarify these conditions (Atherton et al. 1980; Chou and Polensek 1987; Polensek and Bastendorff 1987; Feldborg 1989; Jang et al.1993; Mohammad and Smith 1996) and how they affect the performance of framing to panel connections. As with all wood and wood based materials, floor joists are subject to seasonal changes in $\mathrm{RH}$ and temperature. These changes have an effect on the 
mechano-sorptive behavior of wood, which is directly linked to the amount of deformation and strength exhibited by a structural member (Lu and Leichester 1997).

Unfortunately, wood is subject to a sorption hysteresis, where the adsorption (gaining moisture) equilibrium moisture content (EMC) of a given piece of wood is lower than the corresponding desorption (losing moisture) EMC. This would seem to complicate matters even more. However, it was determined (Peralta 1995) that due to the fact that the range of RH's experienced by wood in service is relatively narrow, the effect of hysteresis is minimal on the performance properties of wood. One of the best ways to minimize the effect of moisture cycling on the stiffness of nailed joints is to assemble the connection with the constituents as close to the in-service EMC as possible. By doing this it may be possible to eliminate or reduce the deformation due to conditioning which takes place in the material during initial adsorption (Humphries and Schniewind 1982; Mohammad and Smith 1996).

\subsubsection{Sub-flooring}

Either plywood or oriented strand board (OSB) generally represents materials suitable for use as sub-flooring. Performance criteria for plywood and OSB generally include mechanical properties such as modulus of elasticity (MOE) and modulus of rupture (MOR), and hygroscopic properties such as linear expansion (LE) and thickness swelling (TS). Another term important in the understanding of sheathing material performance is the horizontal density distribution (HDD) of a panel, which may be linked to the bearing strength of a panel (Suchsland and Xu 1989). One way to study HDD is to set up a simulation model in order to analyze the density variations that exist in panels. Measurement of HDD on OSB should be done with caution, however, as the 
size of the specimens have an effect on whether density variations are attributed to nonuniformity in the mat, or simply voids in the panel (Xu and Steiner 1995).

These are all important in regards to floor system performance, especially when considering how they are effected by inevitable cyclic changes in $\mathrm{RH}$ and temperature.

When comparing the performance of wood-based panels, it is important to understand that difference may occur, even with panels of a similar type. Some of this variation may be attributed to differences in the species that make up the panels. In other instances, panels manufactured utilizing the same species but at different mills may exhibit mechanical properties which differ as much as 33\%, even though they fall within acceptable American Plywood Association (APA) guidelines (Biblis 1989).

It would be expected that changes in MC would effectively decrease the mechanical properties of plywood. In the case of Douglas-fir plywood, however, it was determined that over the range of MC's expected in service, $6.8-15.2 \%$, this did not prove true (Palka 1977). The hardness of both Douglas-fir and southern yellow pine (syp) plywood did indeed decrease with an increase in MC (Chow 1976). Use of plywood as a sheathing material (as opposed to OSB) should be considered, although lightly, based on the fact that the deflection in plywood during $\mathrm{RH}$ cycling was found to be less than the deflection of OSB during identical cycling (Price 1985).

Results pertaining to the effect that moisture content changes have on the mechanical properties of OSB ranges from minimal to appreciable (Lehmann 1978; Wu and Suchland 1997). Reasons for this could be species difference, variations in testing methods and variations in panel formation. 
Aside from affecting the mechanical properties of OSB, processing parameters, specifically flake distribution and orientation, may have an impact on hygroscopic factors including LE and TS (Wu 1999). Unfortunately for the contractor or homeowner, the greatest LE of OSB panels occurred throughout a range of moisture contents most likely to occur in service (Wu and Suchland 1996). With all the currently available deformation data that exists for OSB, theoretical models, such as the one developed by Lang et al. (1995) can predict the free hygroscopic deformation of wood composite panels with very acceptable accuracy.

In an attempt to discover new ways to improve the performance of OSB, wood scientists are constantly trying new methods of manufacture. One such method is species substitution. A study conducted by Kuklewski et al. (1985) showed that red maple flakeboard either equaled or exceeded the performance of aspen flakeboard with respect to static bending, internal bond (IB), and nail withdrawal.

\subsubsection{Finished Flooring}

As with other components of a flooring system, hardwood flooring is subject to stresses and performance flaws which occur during seasonal moisture cycling. Hardwood flooring is generally installed at an MC that is correct for a particular season. As the wood dries, shrinkage occurs and cracks tend to develop in the joints of the flooring. A more serious problem arises when the wood picks up moisture and swells. This results in buckling of the flooring strips. At this point, some of the wood cells are crushed and this results in a "compression set" situation from which the wood never fully recovers (Cassens and Feist 1980). In order to combat this, hardwood flooring must be 
properly assembled and finished as quickly as possible. The finish may act to retard or inhibit the gaining of atmospheric moisture, at least to some degree.

\subsection{Fasteners}

The factor in a flooring system, which may well be the weakest link, is the fastener that holds the major components together. Sub-flooring is fastened to the floor joists, usually with nails or screws. Furthermore, the finished flooring itself is in turn nailed to the sub-floor by some means; usually nails or staples.

Nail and staple connections generally experience two types of loading scenarios in service: axial withdrawal and lateral withdrawal. Four factors exist which contribute to the degradation of nailed joints in a lateral direction. These are nail bending strength (nail ductility), bearing strength of sheathing and framing material and the friction which exists between the framing and the sheathing material (Jang et al. 1993).

Fastener performance tests generally involve testing fasteners, whether they be nails, screws, staples, etc., in either axial withdrawal or lateral resistance. Axial withdrawal describes a nail or fastener that is removed directly perpendicular to the face of the substrate to which it is attached. Lateral resistance, important in determining the stiffness of a connection, indicates a fastener's ability to minimize the movement or slip of two fastened substrates in a parallel direction.

Nails and staples used to fasten hardwood flooring to sub-flooring are generally driven through the tongue of the flooring at an angle of $45^{\circ}$. Therefore they are subjected to withdrawal forces which are neither exclusively axial nor exclusively lateral, 
but a combination of both. A good deal of work has been done studying the lateral and axial nail resistance of both solid wood and wood-based panel products.

The lateral nail resistance is especially important in flooring systems, as it has direct impact on floor joist-to-sub-floor connections. Gromala (1985) tested the lateral nail resistance for ten common sheathing materials that could possibly serve as subfloor materials. These included plywood, flakeboard, hardboard and gypsum board. Several equations exist (McLain 1997) which predict the withdrawal strength of plainshank common wire nails by relating it to ultimate shank withdrawal, wood specific gravity, and nominal fastener diameter.

6d common nails were tested in direct withdrawal by Elias (1982) in both 3/8" and $1 / 2$ " plywood in an attempt to establish minimum acceptable values. Information from such a test can be used to predict the performance expected by composite panels in relation to flooring fastener retention.

Finite-element models may be very useful for predicting load-withdrawal relationships (Groom and Leichti 1993). A setup with which to test different loading scenarios would prove very beneficial to the wood scientist. Not only does such a setup and method exist for testing axial and lateral loads, it may even test wood joints under a combination of both axial withdrawal and lateral resistance (DeBonis and Bodig 1975). Parameters of the tests varied by wood species, nail penetration depth, and load application angle.

It seems as though no matter what is discussed with respect to flooring systems, $\mathrm{RH}$ and moisture seem to be factors. The performance of nails and fasteners is no exception. A fair amount of work has been done in an attempt to relate changes in $\mathrm{MC}$ 
to the performance of mechanical fasteners. In the majority of instances, it could be concluded that an increase in MC significantly deteriorated the performance of fasteners due to degradation in the materials which were fastened together (Barnes and Lyon 1978; Chow et al. 1985,1988; Feldborg 1989, Rammer and Winistorfer 2001).

It is apparent based on the literature that the status of the wood-based composite products industry has changed over the past decade. Due to the fact that the need for raw materials is increasing and the quality of the constituents in plywood and OSB seems to be decreasing, an attempt to re-evaluate the fastener holding capacity of currently available panel products in relation to hardwood flooring systems seems to be in order. By following certain procedures done at Virginia Tech by Lang et al. (1994) in which the fastener holding capacity of sub-floor materials under cyclic environmental condions was investigated, conclusions may be drawn as to the type of panel which will give the best performance in service. 
Chapter 3

\section{Experimental Methods}

\subsection{Introduction}

In order to fulfill the previously stated project objectives, plywood and OSB products were received from four plants covering two geographic regions of the United States. East Coast panel products were procured from Hickory, NC and Richmond, VA. West Coast panel products originated in San Francisco, CA and Seattle, WA. These panels were used for all project tests: as sub-floor materials for fastener withdrawal tests, in standard ASTM nail withdrawal tests, in the horizontal density distribution investigation, and in a moisture meter calibration investigation. A code was developed describing the various panel type/fastener/floor combinations:

"E" or "W" - designates panel origin; East Coast or West Coast

"O" or "P" - designates panel type; OSB or plywood

"5" or " 3 " - designates panel thickness; $5 / 8$ " or 3/4"

"N", "N2", or "S" - designates fastener type; 1.5" nail, 2" nail, or 1.5" staple

"f" - denotes finished flooring;

Therefore, a test floor coded EP5Sf would indicate finished flooring installed on East Coast, 5/8" thick plywood fastened with a staple.

East Coast plywood was comprised exclusively of southern yellow pine while West Coast plywood was found to be either Douglas-fir or ponderosa pine. East Coast OSB was a mixture of hardwoods and softwoods, with the principle hardwoods being yellow-poplar and maple along with smaller amounts of various other hardwoods such 
as walnut and cherry. The primary softwood found in the East Coast OSB was southern yellow pine. West Coast OSB was comprised of a mixture of soft hardwoods, with aspen as the predominant species.

Unfinished hardwood flooring was shipped from a manufacturer in Memphis, Tennessee and the pre-finished flooring was purchased at a local home improvement warehouse. All flooring fasteners and tools necessary for their installation were provided by NOFMA. NOFMA personnel were responsible for laying out the nailing patterns of the hardwood floor systems and for performing the actual floor installation.

\subsection{Horizontal Density Distribution}

The horizontal density distribution was investigated for each of the six panel types by calculating panel specific gravity on a dry volume basis. This was performed in an attempt to gain an understanding as to the density variations among panel types and between geographic locations. These included 3/4" OSB, 3/4" plywood, and 5/8" plywood from both East Coast and West Coast points of origin. Originally, 35 2" by 2" specimens were cut from each panel type. In order to obtain a better distribution of data, additional panel specimens (taken from fastener withdrawal tests during the coupon phase) were added. All measurements were done before any treatment cycling took place. Horizontal density distribution measurements were found following ASTM Standard D 2395-93, Standard Test Methods for Specific Gravity of Wood and Wood-Base Materials, Method A-Volume by Measurement. Probability/density functions of the various distributions were found using ExperFit computer software. 


\subsection{Floor Construction}

A total of 68 floor systems were built using nominal $2 \times 4$ No. 2 KD19 s-p-f as floor joists (Figure 3.1a). The joists were spaced according to the span rating of the various sub-floor sheathing. All sheathing was APA Rated and was designated Exposure 1 (Figure 3.1b). Three panel types, P3, O3, and P5 were used from the two geographic locations, East Coast and West Coast, for a total of six panel combinations. All P3 panels consisted of five or seven plies, while the P5 panels were either four or five ply. All O3 was 3-layer with the face strands parallel to the length of the panel. The use of panels from two separate geographic locations allowed us to determine whether or not panels comprised of a certain species had an effect on the overall results of the treatment cycle.

All test floors were 24.75 " in width with the joists running perpendicular to the length of the flooring system (Figure 3.2). Rimboards, joists, and panels were precut and stacked prior to system assembly. Templates were fabricated prior to the assembly of the sub-floor systems according to the span rating of each panel (Figure 3.3a). Cardboard nailing patterns were constructed for P3, O3, and P5. The patterns were simply laid on top of the panels and the nailing points were marked (Figure 3b). All panels were attached to the joists with $8 \mathrm{~d}$ common nails using a pneumatic nail gun, spaced according to APA specifications (APA 1998). Edge joists required five evenly spaced nails and all internal joists were connected using three nails. The number of floor joists were dependent on the span rating of a particular panel. Accordingly, P5 required a span of 16 " and had a finished length of 49.5". P3 sub-floors had a span of 24 " OC and the length of a finished system was also 49.5". O3 sub-floors required a 
a.

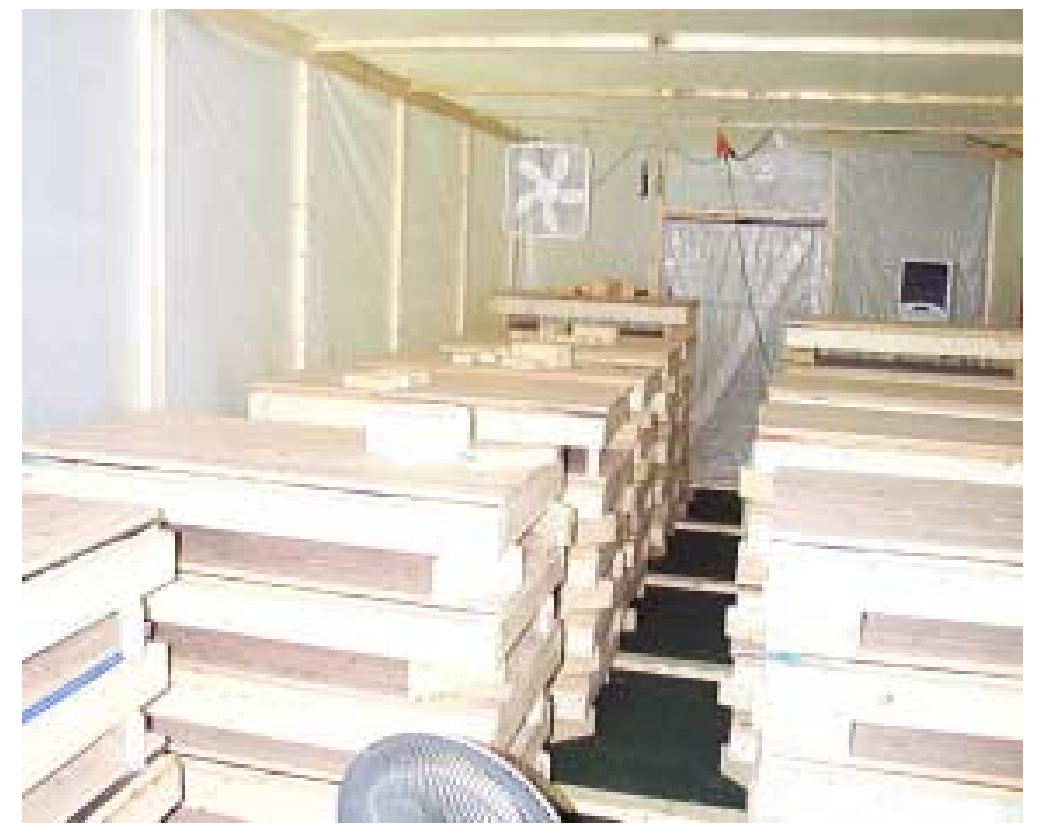

b.

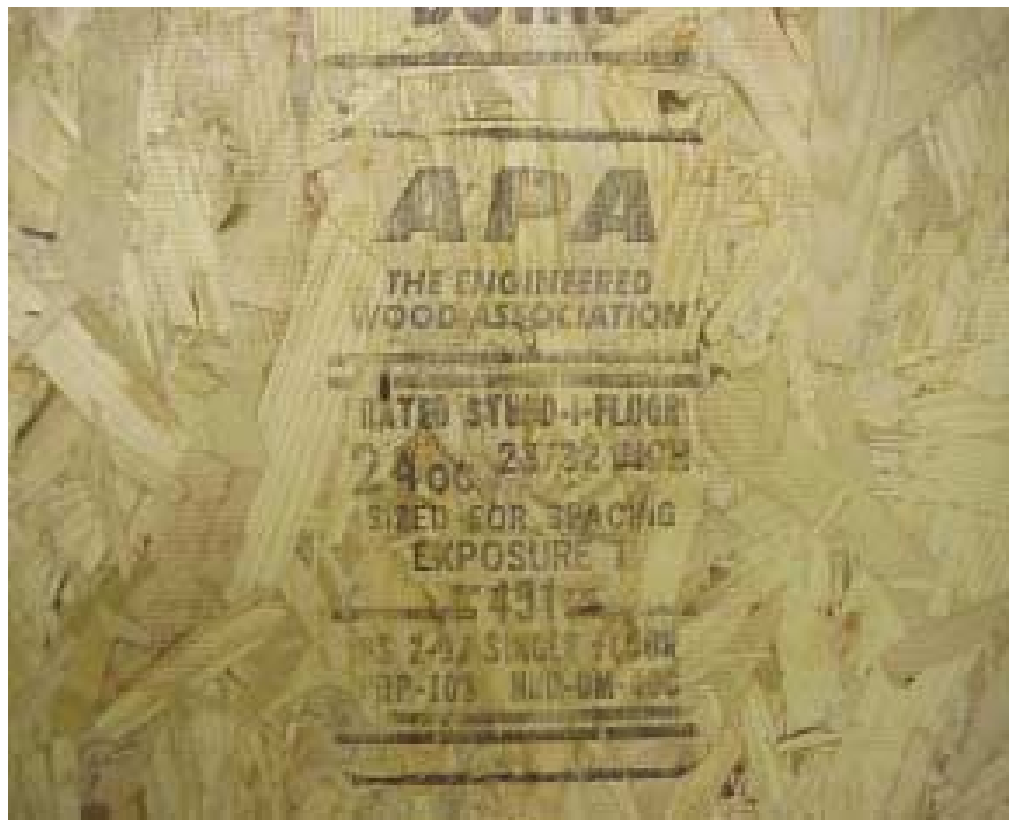

Figure 3.1 Sixty-eight constructed floor systems (a); example of a typical APA grade stamp (b). 


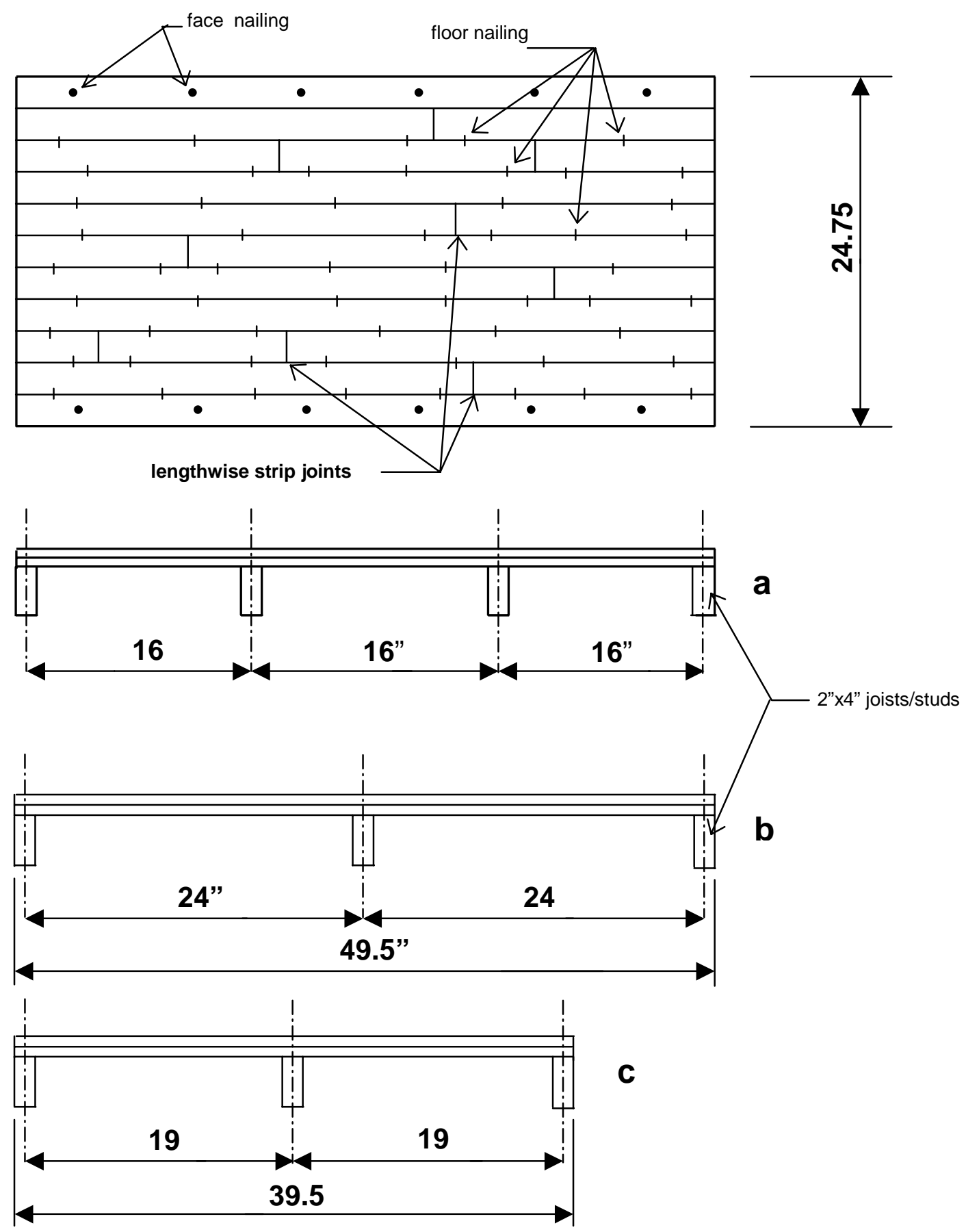

Figure 3.2 Test floor assemblies. a. 5/8" plywood, span rating 16" OC; b. $3 / 4$ " plywood, span rating 24 " OC; c. $3 / 4$ " OSB, span rating 19" OC. 
a.

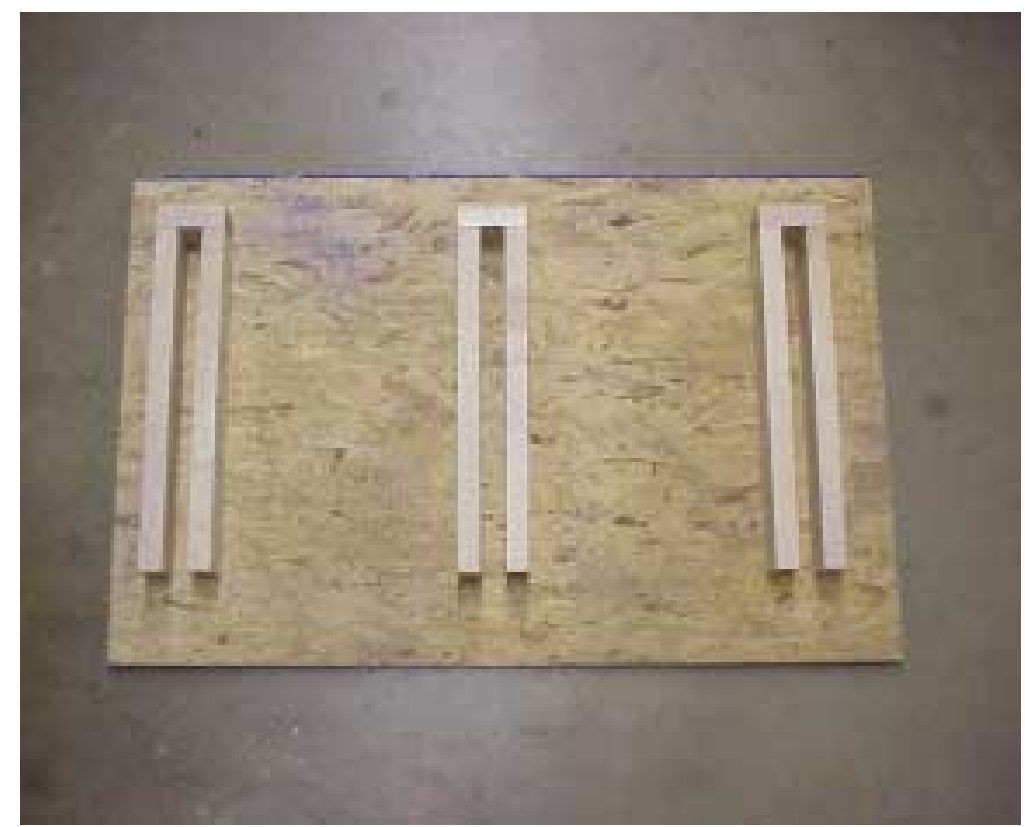

b.

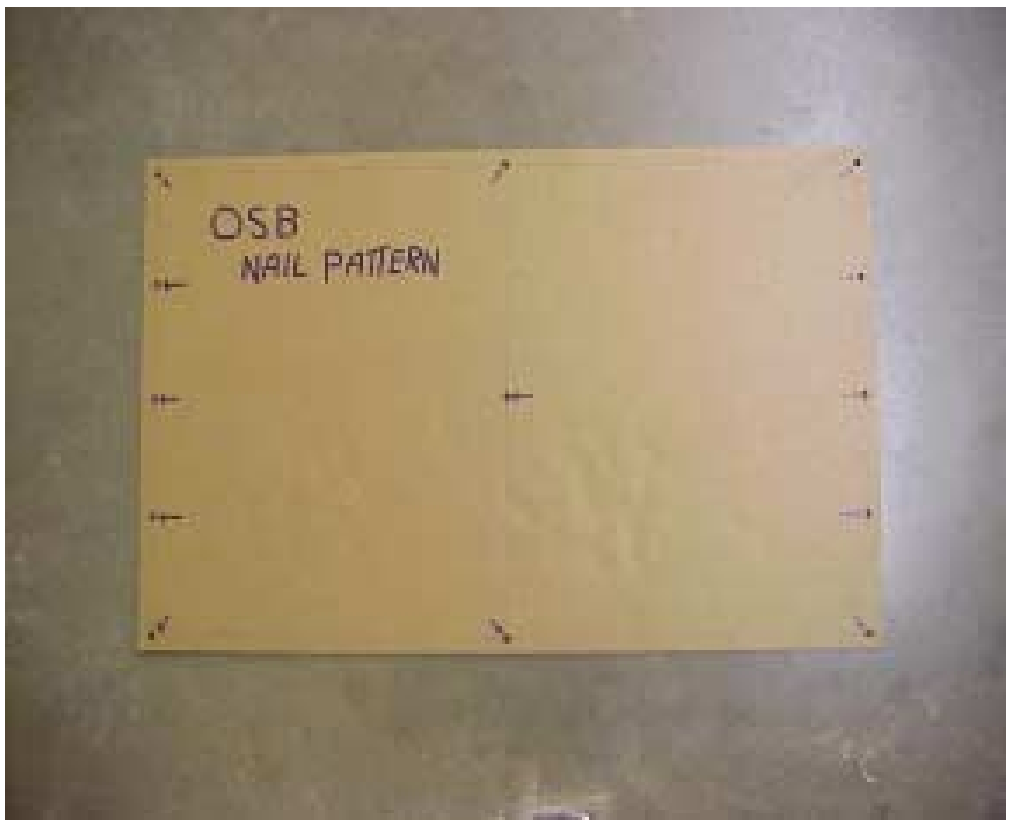

Figure 3.3 Floor joist template for OSB floor system (a); APA specified nailing pattern for OSB (b). 
span of 19 " OC and was 39.5 " in length. Nominal 2"x4" sills or rimboards were fastened to the ends of the joists along the length of each system to prevent any distortion or buckling of the panels during treatment.

After the assembly of the sub-floors was complete, but before any flooring was installed, the sub-floor systems were placed into the environmental chamber and conditioned until they reached a $16 \%$ MC. The purpose of this treatment was to simulate a mild construction site exposure that may exist after the sub-flooring is installed but before the building is enclosed. When the panels reached the targeted $16 \%$ MC, the drying process began and the oak strip flooring was installed when the subfloor panels reached an MC of $10 \%$.

The oak floor shipment consisted of unfinished, non-sanded, tongue and groove, oak strip flooring, 3/4" thick and 2 1/4" wide in random lengths. Pre-finished flooring manufactured by Bruce Hardwoods and purchased locally was used as a means for comparison. This product was tested during the final phase of the project. NOFMA professionals performed the installation of the flooring according to NOFMA standards. Each floor system was comprised of eleven strips of flooring with 15-lb felt construction paper between the sub-floor and the flooring itself. The felt provided a vapor barrier between the two components of the floor as would be done in a real life situation. The first strip in the sequence was face using a pneumatic nail gun. Each subsequent strip was then fastened with either 1.5 " barbed cleats, using a mechanically driven nail gun, or 15 gauge 1.5 " staples with a $1 / 2$ " crown using a pneumatically driven staple gun (Figure 3.4a). The approximate angle of penetration for both the cleats and the staples was $45^{\circ}$ (Figure 3.4b). Both cleats and nails were used for 


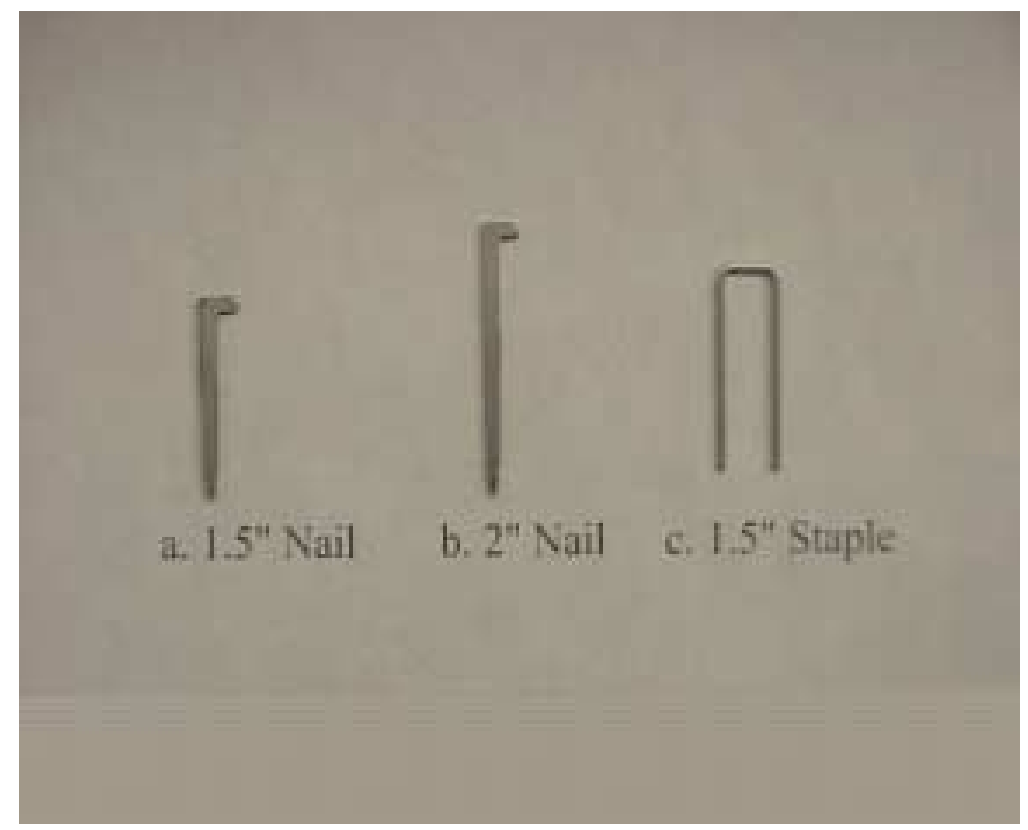

a.

b.

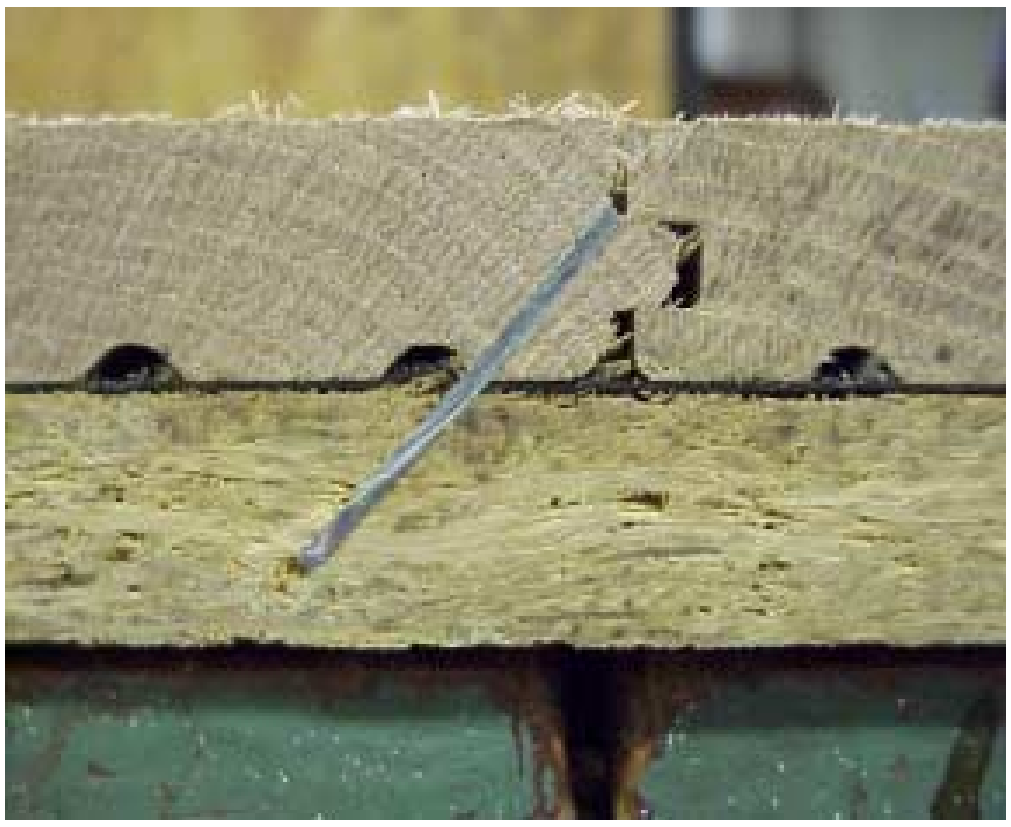

Figure 3.4 Various fasteners used in floor system construction (a); cross-section of a typical flooring assembly (b). 
each of the six panel combinations for a total of twelve system combinations utilizing unfinished flooring. For comparison purposes, four systems were constructed, two on EP3 and two on WP3, using 2" cleats applied at an angle of $30^{\circ}$. One EP3N2 system and one WP3N2 system were tested at both the beginning of the accelerated environmental simulation and again at the end. Four systems were constructed using the factory finished flooring. The variables included EP5 and WP5 with both 2" cleats and 1.5" staples. These were tested in the final phase of the treatment.

The fastener withdrawal testing schedule, by treatment phase, is as follows:

1) Coupon - Combination of Phases II and III. MC of the systems was kept at constant $12 \%$ and the strip flooring was installed. Installations were followed by a series of fastener withdrawal tests (coupon tests) including 6 panel types by two fastener types (1.5" cleats, 1.5" staples) plus 2 panel types with 2" cleats for a total of 14 systems.

2) Phase IV - Described the first "summer" period simulation with a target MC of $10 \%$. Six days after the target MC was achieved, fastener withdrawal test were performed including 6 panel types by two fastener types (1.5" cleats, 1.5" staples) for a total of 12 systems.

3) Phase V - Described the "second" winter period simulation. Target MC was $6 \%$ and after being held for six days, a series of fastener withdrawal tests was performed including 6 panel types by two fastener types (1.5" cleats, 1.5" staples) for a total of 12 systems.

4) Phase VI - Simulation of the second "summer" period where a target MC of $12 \%$ was reached and then held for a period of six days. This was followed by a series of fastener withdrawal tests including 6 panel types by two fastener types (1.5" cleats, 1.5 " staples)for a total of 12 systems.

5) Phase VII - Simulation of the third "winter" period with a target MC of $6 \%$. Target MC was held for six days followed by a series of fastener withdrawal tests including 6 panel types by two fastener types (1.5" cleats, 1.5" staples) plus 2 panel types with 2 " cleats and 4 finished floors (2 panel types by two fastener types) for a total of 18 systems 


\subsection{Chamber Construction}

In order to simulate the two and a half-year moisture cycle, a temporary walk-in environmental chamber was constructed (Figures 3.5a and b). Dimensions of the chamber were as follows: 28 ' in length by $11^{\prime}$ wide by $7{ }^{\prime} 6$ " in height. The framing of the chamber consisted of 8 frames made of nominal 2"x4" s-p-f lumber fastened using 3" drywall screws. The frame structure was covered with 6 mil thickness polyethylene foil attached with standard 1/2" staples. The entire frame was housed atop a 12 ' by 30 ' piece of green indoor/ outdoor mildew resistant all-weather carpet. An access door was constructed and placed in the front wall of the chamber. Duct tape and silicone caulking were used where necessary in order to make the chamber as airtight as possible.

Within the chamber were the climate controls. These included two 40-pint/day Kenmore dehumidifiers elevated by means of constructed stands. Clear plastic tubing was installed between the dehumidifiers and two 30-gallon garbage cans outside the chamber where the water from the dehumidifiers was collected. Two variable speed box fans, suspended from the roof and two variable speed oscillating fans provided ample air circulation.

\subsection{Moisture Cycling}

The treatment for the project involved alternately increasing and decreasing the moisture content of the flooring systems through manipulation of relative humidity. Moisture cycling began at the conclusion of the coupon tests. The $\mathrm{RH}$ within the chamber was increased by periodically spraying the interior walls with water via a 
a.

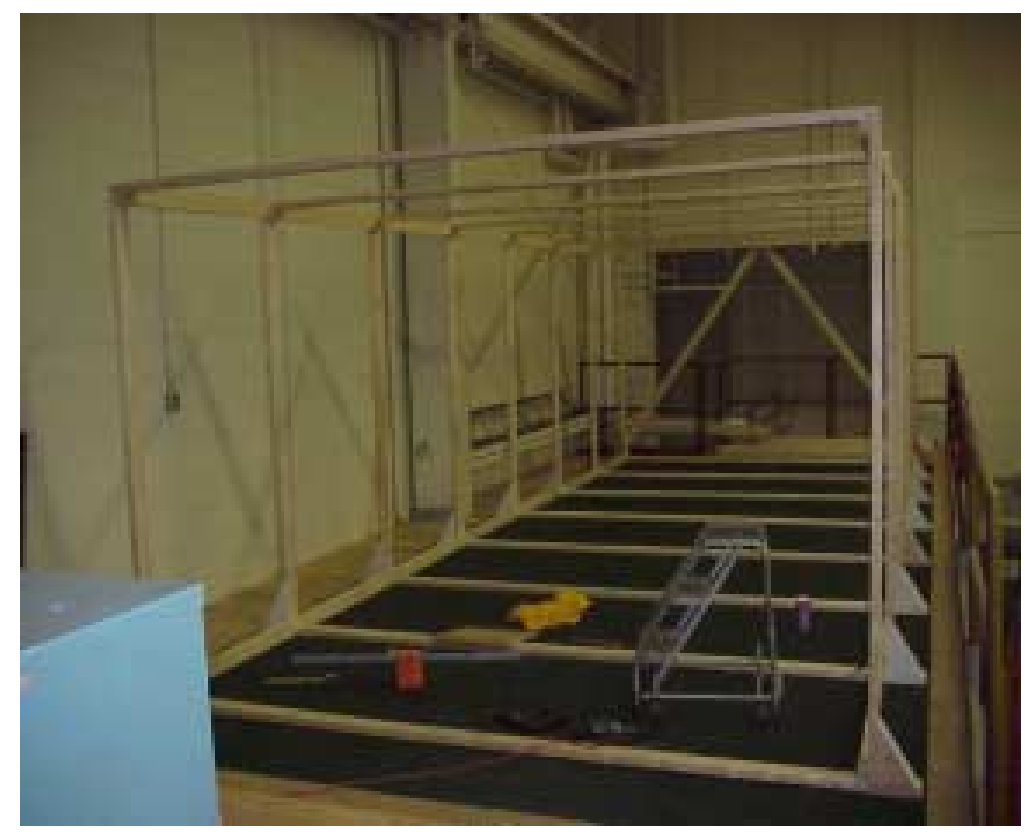

b.

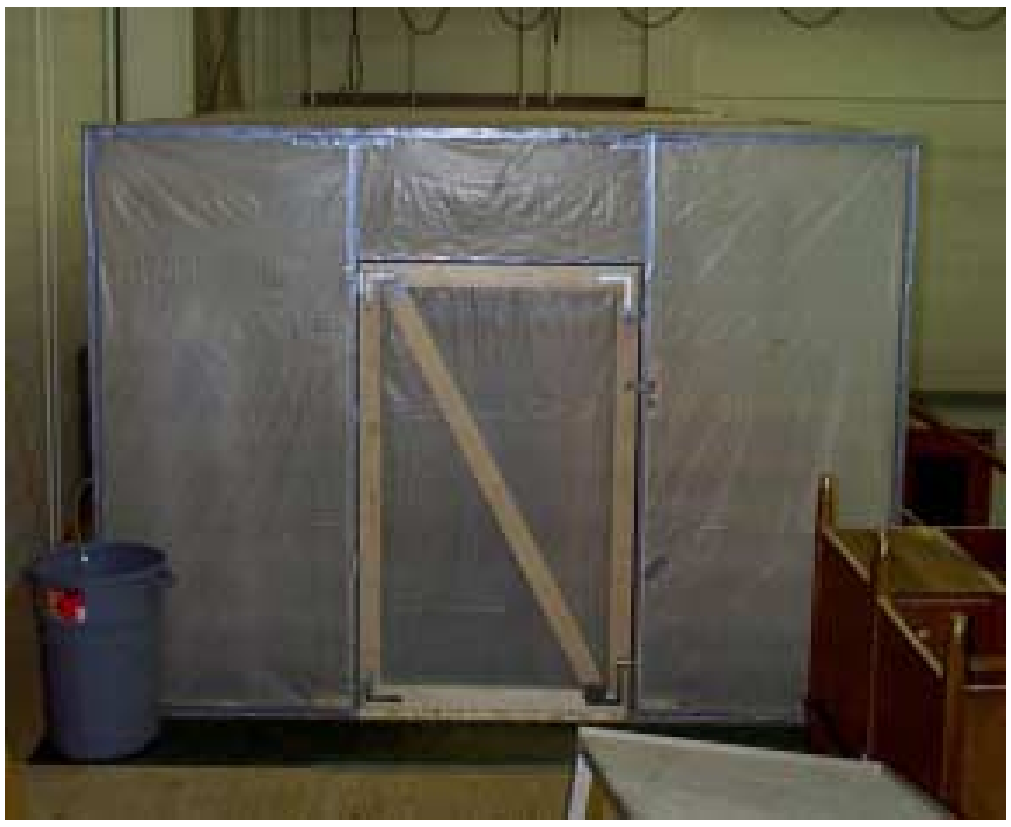

Figure 3.5 Environmental chamber midway through construction (a); front view of completed environmental chamber (b). 
commercial garden sprayer. In order to make sure that the panels did not come in direct contact with the spray, plastic foil was placed over each stack of panels before moisturizing the chamber walls. Phases of the simulated moisture cycle that called for a lower EMC simply required turning on two 40 pint/day dehumidifiers and allowing them to run continually until the target EMC was reached.

Temperature and relative humidity measurements were taken within the chamber with the use of an ERTCO Exact-Temp temperature/humidity datalogger. Windows based software installed on a computer outside the chamber imported the information from the datalogger. Once the data was imported into the computer, the software graphed the readings on a continuous curve. At the conclusion of each treatment phase, data was saved in the computer and the datalogger was cleared and reset. Figure 3.6a shows the actual $\mathrm{RH}$ and temperature values within the chamber during the accelerated moisture cycle simulation. In an attempt to simulate the conditions panels might experience after installation but before a building is enclosed, a mild exposure site simulation was performed. During this phase of the project, all panels were moisturized up to $16 \% \mathrm{MC}$ and then immediately dried back to approximately $7-8 \%$, at which time the flooring was installed. Figure $3.6 \mathrm{~b}$ shows the actual $\mathrm{RH}$ and temperature during this period.

\subsection{Specimen Manufacture}

The manufacturing of flooring fastener withdrawal test specimens took place at the beginning of the project (coupon tests) and at the end of each phase of the accelerated simulation. The coupon tests served as a control for comparison with the 

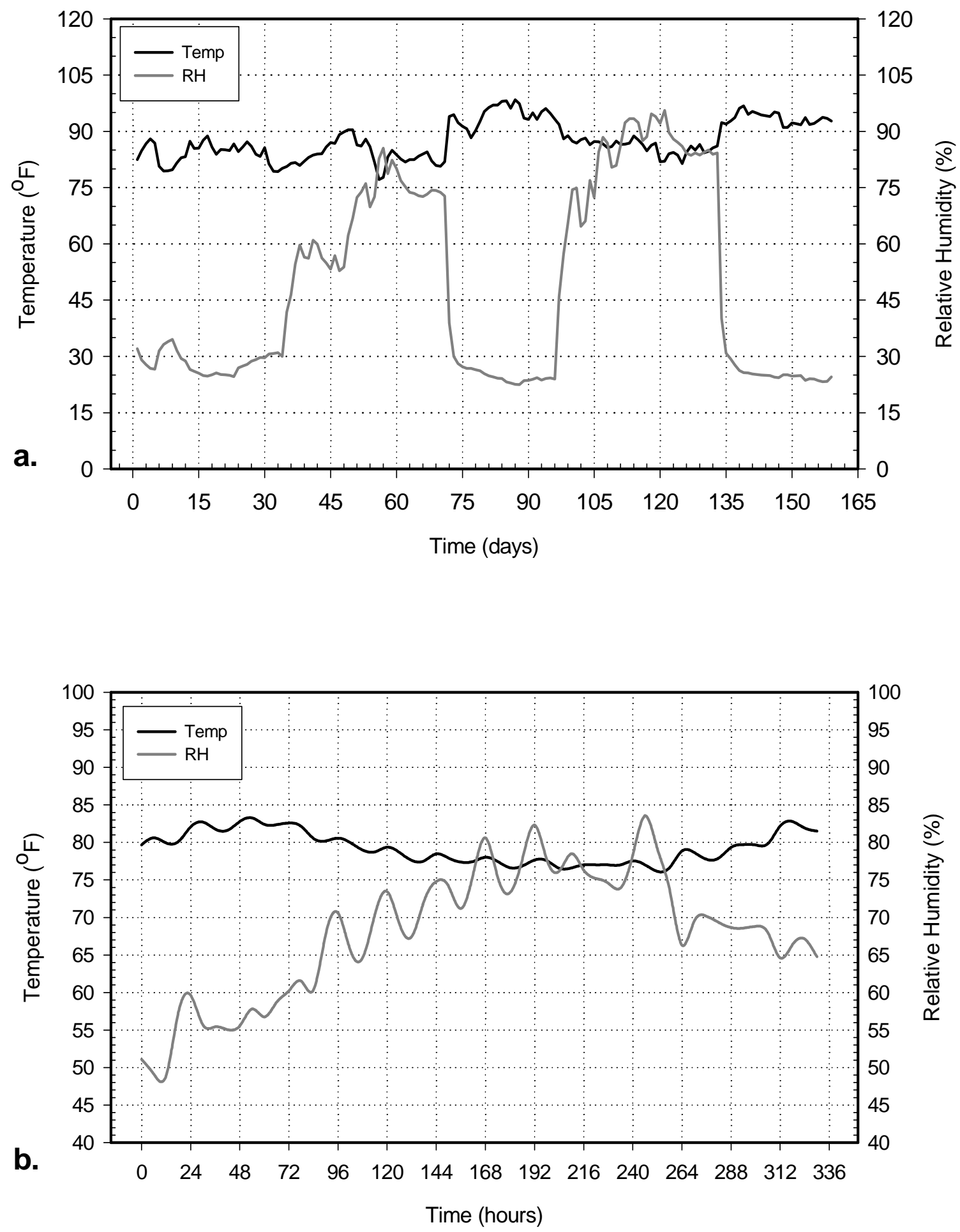

Figure 3.6 Relative humidity and temperature of test floor systems and panels during a.) occupancy simulation phase and b.) mild exposure site simulation. 
data from subsequent tests. These specimens were manufactured in the form of a cross with the hardwood flooring portion oriented above and perpendicular to the sub-floor portion of the specimen. The cross-shaped specimens were cut out from each of the system configurations (Figure 3.7).

The initial step in manufacturing the specimens involved taking a system from the chamber and removing the portion of the panel between the floor joists. At this point, a series of table saw cuts was used to cut strips consisting of both hardwood flooring and sub-floor panels. The next step involved marking each of the fasteners, which were now visible. Another series of cuts on a band saw finished the specimens, which were then placed into airtight plastic bags to await testing. A minimum of 25 specimens was manufactured for each of the panel combinations resulting in approximately 1,800 data observations.

\subsection{Fastener Withdrawal Tests}

Fastener withdrawal tests were performed using an MTS Universal ServoHydraulic testing machine with a specially manufactured testing jig setup (Figures 3.8a and b). The machine was operated under displacement control. The load cell of the

machine had a 20,000-lb capacity with a $0.5-\mathrm{lb}$ sensitivity. Speed of testing was 0.10 in/min, according to ASTM Standard D 1761-88, Standard Test Methods for Mechanical Fasteners in Wood.

The maximum load value for each of the sample specimens was recorded. Immediately following each withdrawal test, moisture content measurements were taken using a handheld Delmhorst electronic, conductance moisture meter using $17 / 16$ " non- 


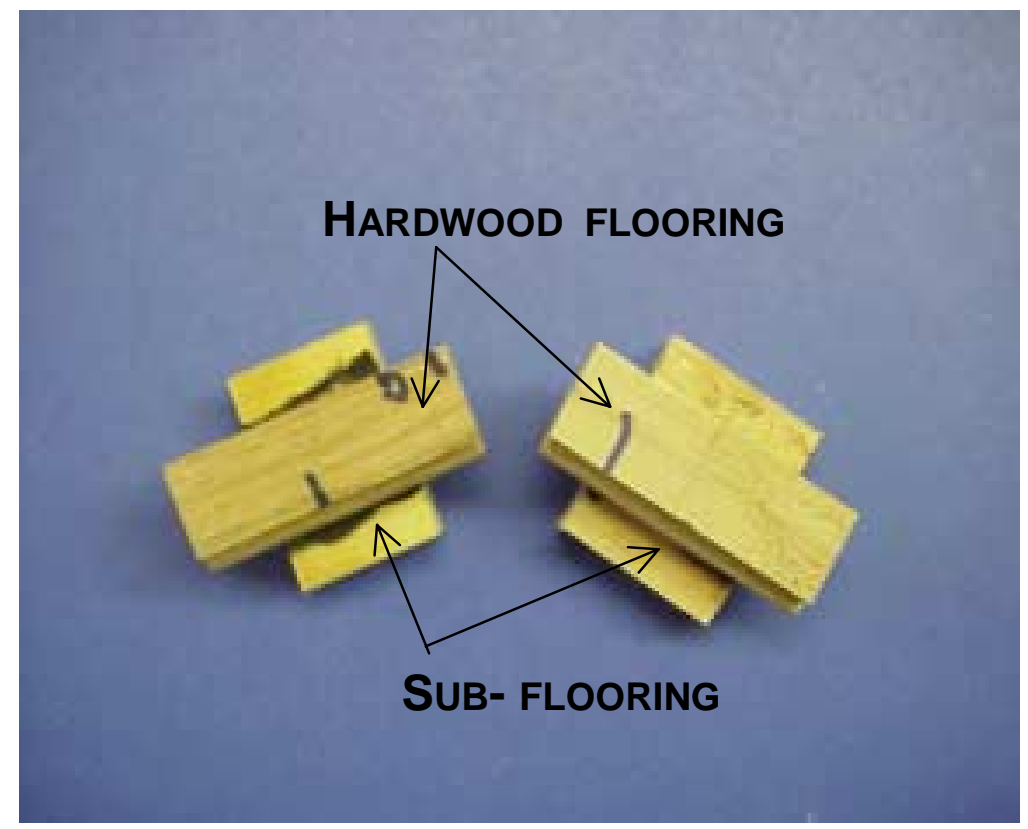

Figure 3.7 Cross-shaped fastener withdrawal test specimens. 

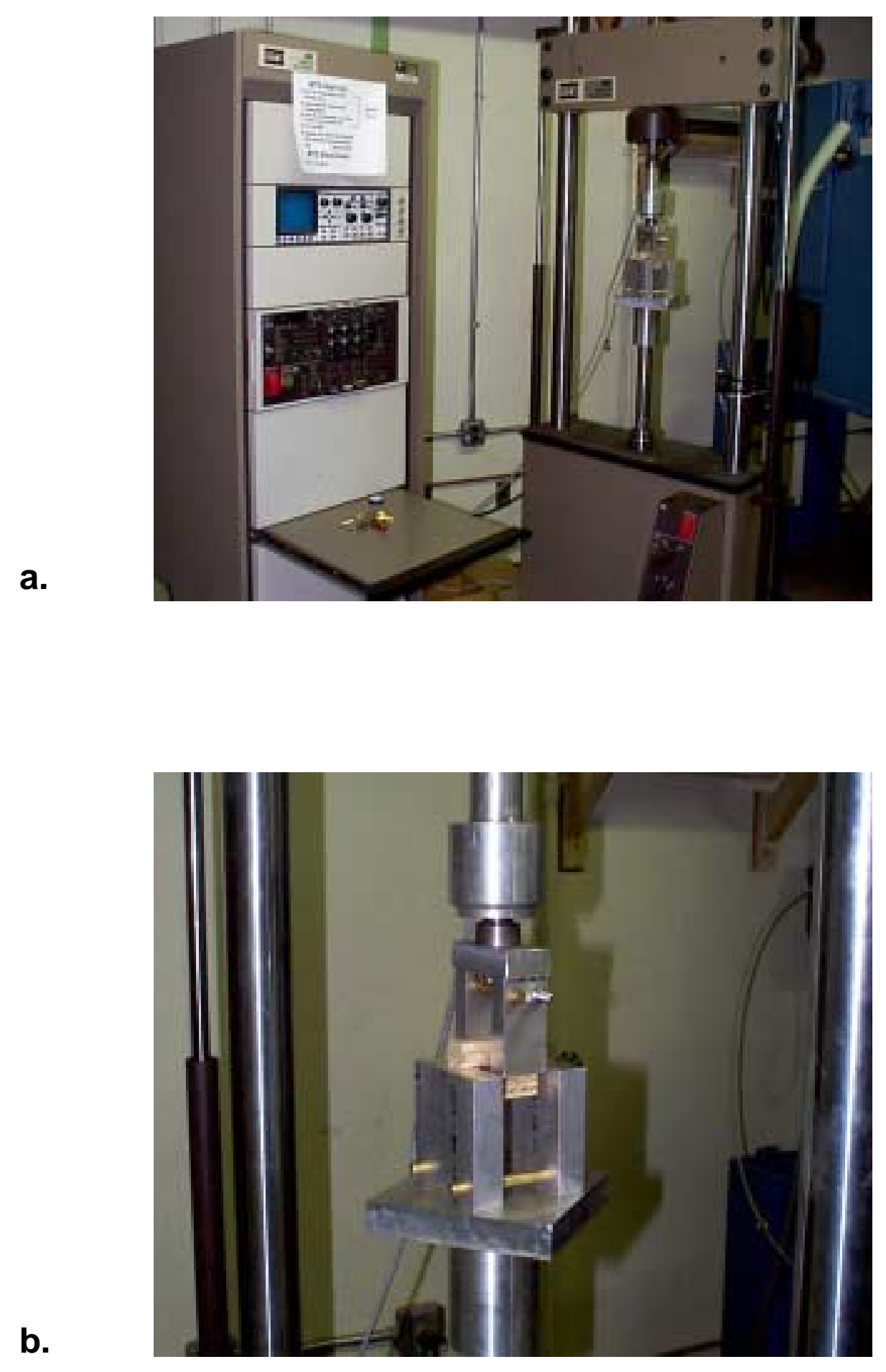

Figure 3.8 MTS unit set up for specimen testing (a); special withdrawal testing jig with specimen in place (b). 
insulated pins. To further validate the readings from the moisture meter, the moisture contents of the sub-floor specimens in the coupon and final phase were found gravimetrically, according to ASTM D 2395-93, Standard Test Methods for Specific Gravity of Wood and Wood-Base Materials.

To further investigate the fastener withdrawal behavior of the flooring specimens, load-displacement data was collected for one sample of each of the system combinations using GPA brand data acquisition software. This data acquisition took place during both the coupon and final phases. When plotted, this data created a visualization of the failure based on a load-displacement curve.

\subsection{Standard Nail Withdrawal Tests}

Standard nail withdrawal tests were performed according to ASTM Standard D 1761-88, Standard Test Methods for Mechanical Fasteners in Wood (Figure 3.9a). This allowed for comparison with the fastener withdrawal resistance tests. Ten 6" by 6" specimens were manufactured creating six panel types: EO3, EP3, EP5, WO3, WP3, and WP5. This provided sixty total specimens. Five $6 \mathrm{~d}$ common wire nails were driven into each of the sixty panels. These five nails represented each of the test phases (Figure 3.9b). Coupon tests were performed immediately and then one nail was pulled from each of the specimens at the end of each treatment cycle. In addition, a moisture content reading was taken from each panel with a Delmhorst handheld moisture meter. 


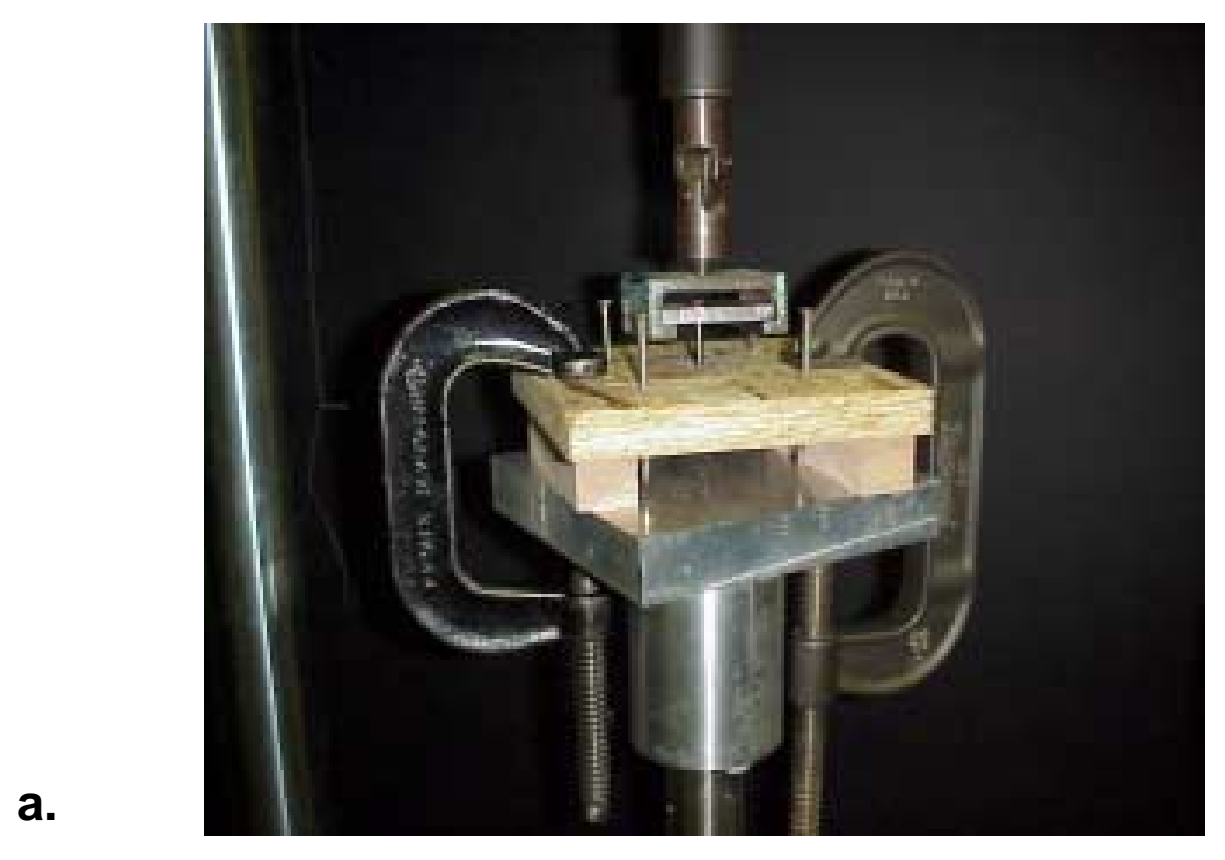

b.

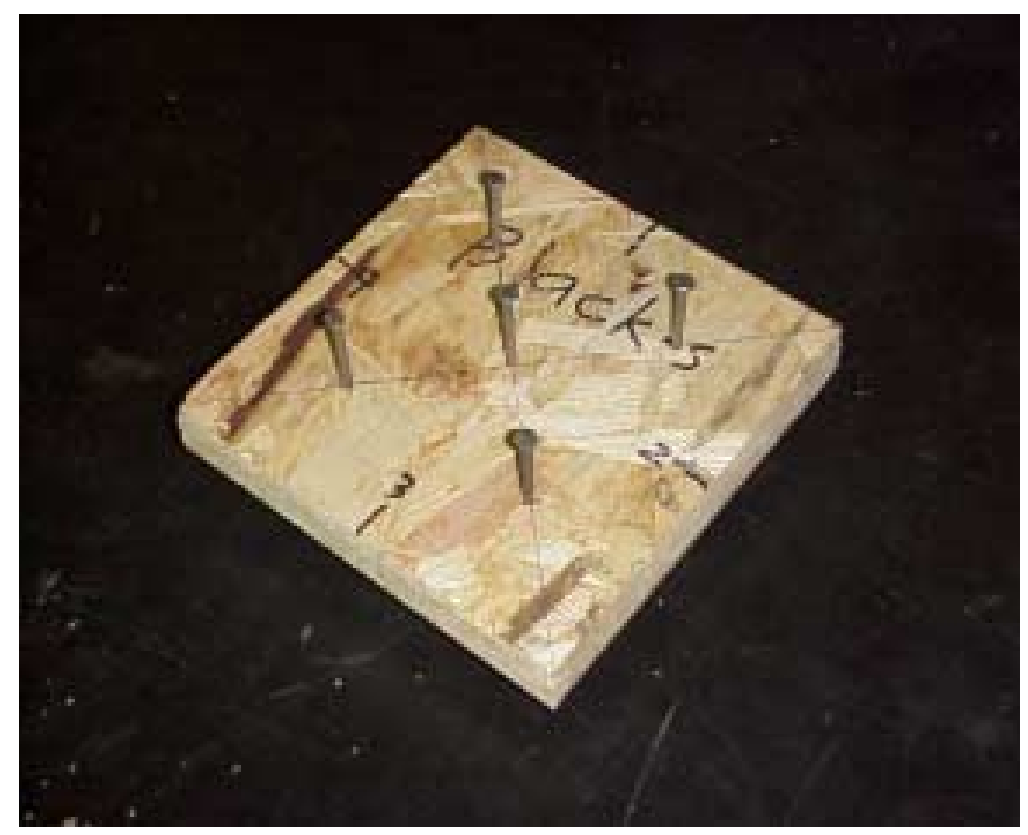

Figure 3.9 Standard nail withdrawal test setup (a); standard nail withdrawal test specimen (b). 


\subsection{Sub-floor Thickness Change}

The standard nail withdrawal specimens also served as specimens for thickness change measurements. This test was performed in order to understand the degree to which the panels shrank and swelled during cycling. The center point of each of the four edges for each specimen was identified and numbered 1 to 4 . Initial thickness measurements were taken at the time the coupon tests were performed and thereafter measurements were taken coinciding with the removal of each nail. This was performed for each of the phases in the moisture cycle.

\subsection{Moisture Meter Calibration}

For the duration of this project, it was necessary to constantly measure and record the moisture content of both the hardwood flooring and the subfloor panels in a non-destructive manner. For this purpose, a Delmhorst RDM 2-S hand-held conductance moisture meter was utilized (Figure 3.10). This unit allows for direct species and temperature alterations. Non-insulated pins measuring $17 / 16$ " were used throughout the project. In order to obtain accurate readings of composite panel products, calibration of the moisture meter was performed. Forty 3" by 3 " specimens were cut randomly from each of the six panel types. Ten samples of each panel type were placed into four areas of differing environmental conditions ranging from $28 \% \mathrm{RH}$ to $85 \% \mathrm{RH}$. Data for P3 and P5 paneling was combined for each geographic location. Calibration was performed according to ASTM Standard D 4444-92, Standard Test Methods for Use and Calibration of Hand-Held Moisture Meters, Method A, for Conductance Meters. Meter values for each panel type were plotted against the actual 


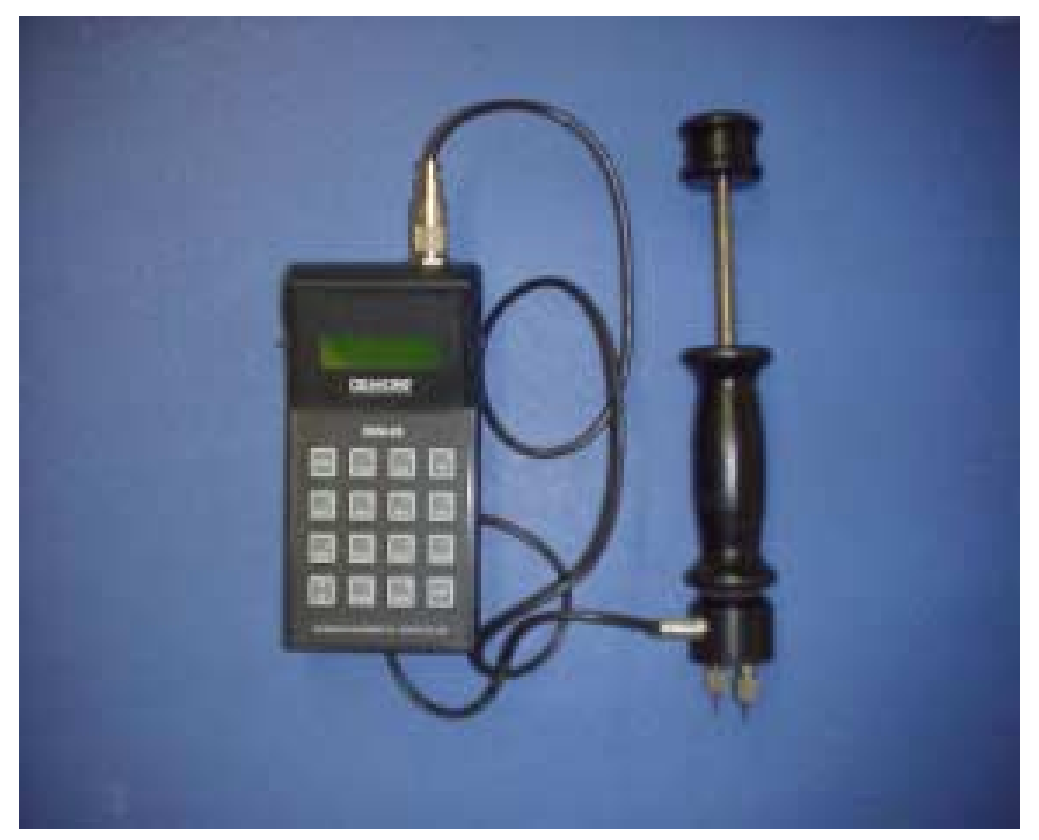

Figure 3.10 Delmhorst RDM 2-S moisture meter. 
moisture content values obtained by gravimetric method. The resulting regression equations $[1,2]$ provided the necessary correction factors. All data fit into first or second order polynomial equations in the following forms:

$$
\begin{aligned}
& \mathrm{Y}=\mathrm{b}_{0}+\mathrm{b}_{1} \mathrm{X} \\
& \mathrm{Y}=\mathrm{b}_{0}+\mathrm{b}_{1} \mathrm{X}+\mathrm{b}_{2} \mathrm{X}^{2}
\end{aligned}
$$

Where: $\quad \mathrm{Y}-\mathrm{MC}$ by gravimetric method $[\%]$;

$\mathrm{X}-\mathrm{MC}$ by handheld meter [\%];

b's - regression coefficients.

\subsection{Statistical Analysis of the Data}

Fastener withdrawal data was analyzed using SAS statistical software with the General Linear Model procedure as well as the Means procedure. Three classes were involved in the GLM model: 1). Moisture cycle, which had five levels including coupon, phase IV, phase V, phase VI, and phase VII; 2). Panel type, which had six levels including EO3, EP3, EP5, WO3, WP3, and WP5; and 3). Fastener type, which had two levels and included 1.5" long nails and 1.5" long staples. The dependent variable for the model was the maximum fastener withdrawal value. The Means procedure drew pairwise comparisons based on mean values for different combinations of levels.

One-Way Analysis of Variance was performed using SigmaStat software for each panel/fastener combination in order to screen out the moisture cycling effect. If both the normality and the equal variance tests passed, Dunnett's Method was used. This method draws multiple comparisons versus a control (coupon) group. If either the normality or equal variance tests failed, a Kruskal-Wallis one way ANOVA on ranks was 
performed using Dunn's Method. This too draws multiple comparisons versus a control group following rank-based ANOVA. SigmaStat generated paired t-tests were performed for EP3N2 and WP3N2 in order to determine if there was a significant difference in the means between the coupon and the final $\left(3^{\text {rd }} 6 \% \mathrm{MC}\right)$ group. Likewise, paired t-tests were performed for finished flooring comparing both 2" nails and 1.5" staples. Because no coupon tests were set up utilizing the finished flooring, coupon values for EP5N, EP5S, WP5N, and WP5S were used as a control. All pair-wise comparisons for nail coupon and staple coupon were performed with a Tukey test. This method is less conservative than a test such as Duncan's New Multiple Range test, which may fail to detect a Type I error, but more conservative than a Student-NewmanKeul's test, which may fail to detect a Type II error.

Data analysis of standard nail withdrawal tests fell into two parts. As was done in the flooring fastener withdrawal tests, One-way ANOVA was performed to screen out the moisture cycling effects on the standard nail withdrawal force of each panel type. Multiple comparisons versus a control (coupon) group were done using either Dunnett's Method or Dunn's Method. A follow up comparison of all pair-wise values was performed using a Tukey Test. This test could identify any significant difference in the initial mean fastener withdrawal values of the six panel types. 
Chapter 4

\section{Results and Discussion}

\subsection{Moisture Meter Calibration}

Moisture meter calibration for composite panels included 240 samples; sixty each for EO3, EP, WO3, and WP. A Delmhorst RDM 2-S was calibrated for East Coast and West Coast plywood and OSB. Both EP3 and WP3 followed a linear regression (Figures $4.1 \mathrm{a}$ and $\mathrm{b}$ ) with $\mathrm{r}^{2}$ values of 0.960 and 0.928 respectively. The regression for EO3 was linear (Figure 4.2a) while WO3 fit a second order polynomial (Figure 4.2b). Their $r^{2}$ values were 0.985 and 0.995 respectively. Percentage of error between moisture meter values and gravimetric values was calculated for each panel type resulting in the following: East Coast OSB, 14.7\%; East Coast plywood, 39.0\%; West Coast OSB, 20.7\%; West Coast plywood, 43.6\%. Moisture meter values were then corrected based on the regression equations and the percentage of error was again computed. East Coast OSB showed an error percentage of $6.5 \%$ while the remaining three panel types showed errors of less than $1 \%$. This proved that the regression equations may be used to correct moisture content meter readings on the four panel types with acceptable accuracy.

\subsection{Horizontal Density Distribution of Panels}

Horizontal density distribution measurements were taken from each of six panel types resulting in 688 observations. Density measurements taken from panels with East Coast origin were higher than density measurements of panels originating on the West Coast. For example, EO3 exhibited higher density values than did WO3. Similar results 
Panel Code: EP(3\&5)

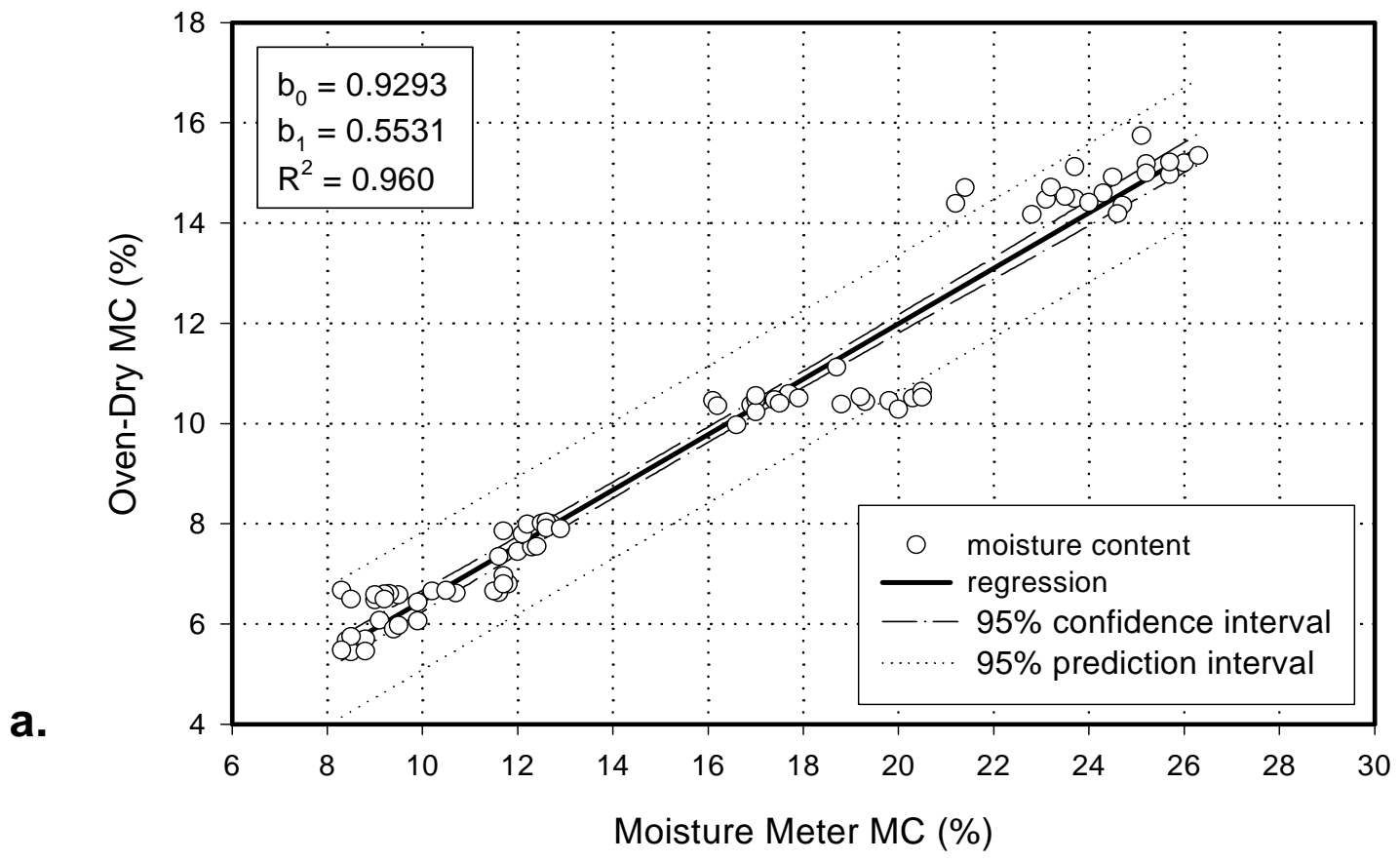

Panel Code: WP(3\&5)

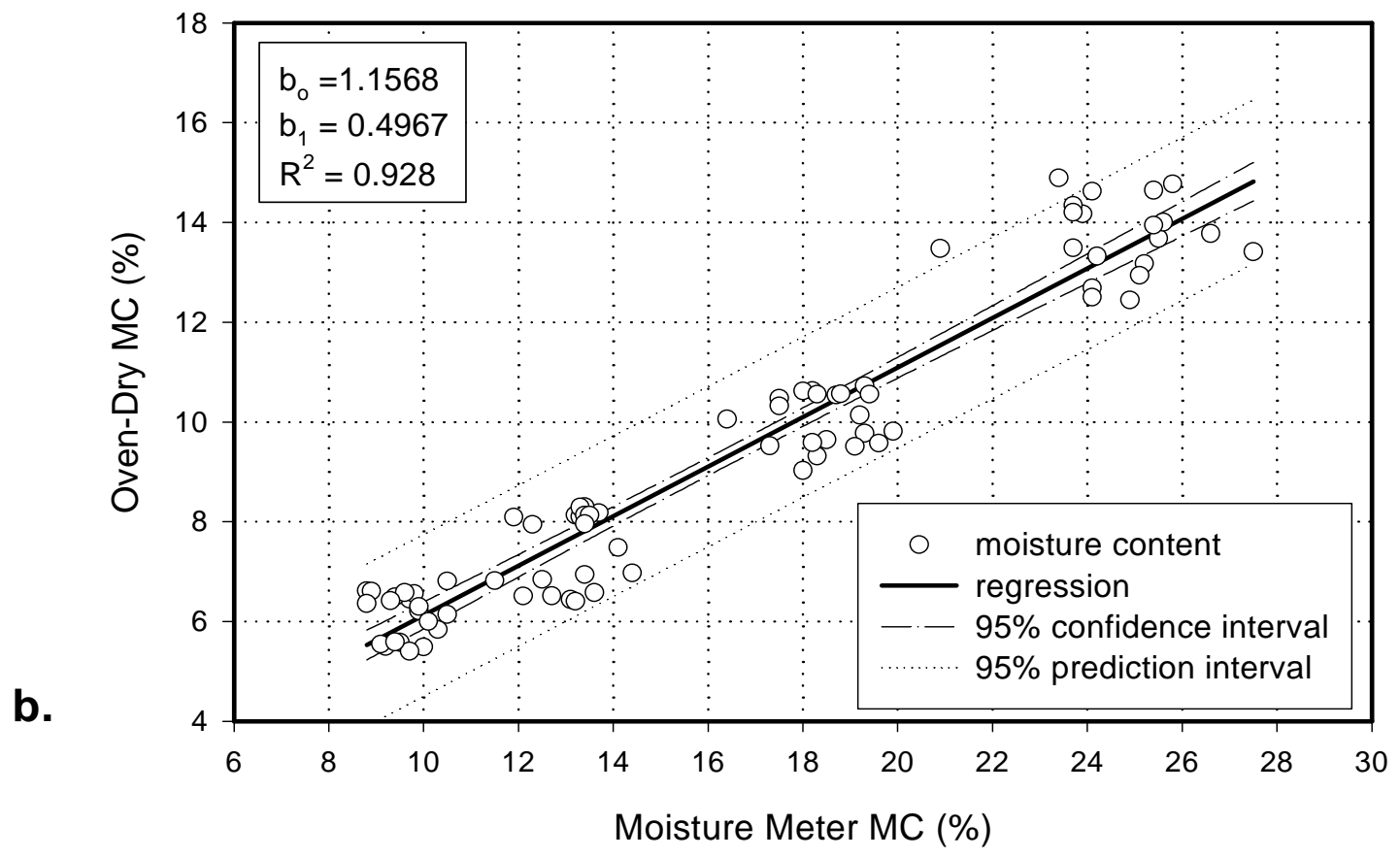

Figure 4.1 Regression equation for oven-dry MC vs. moisture meter MC with $95 \%$ confidence and prediction intervals; a. East Coast plywood, b. West Coast plywood 

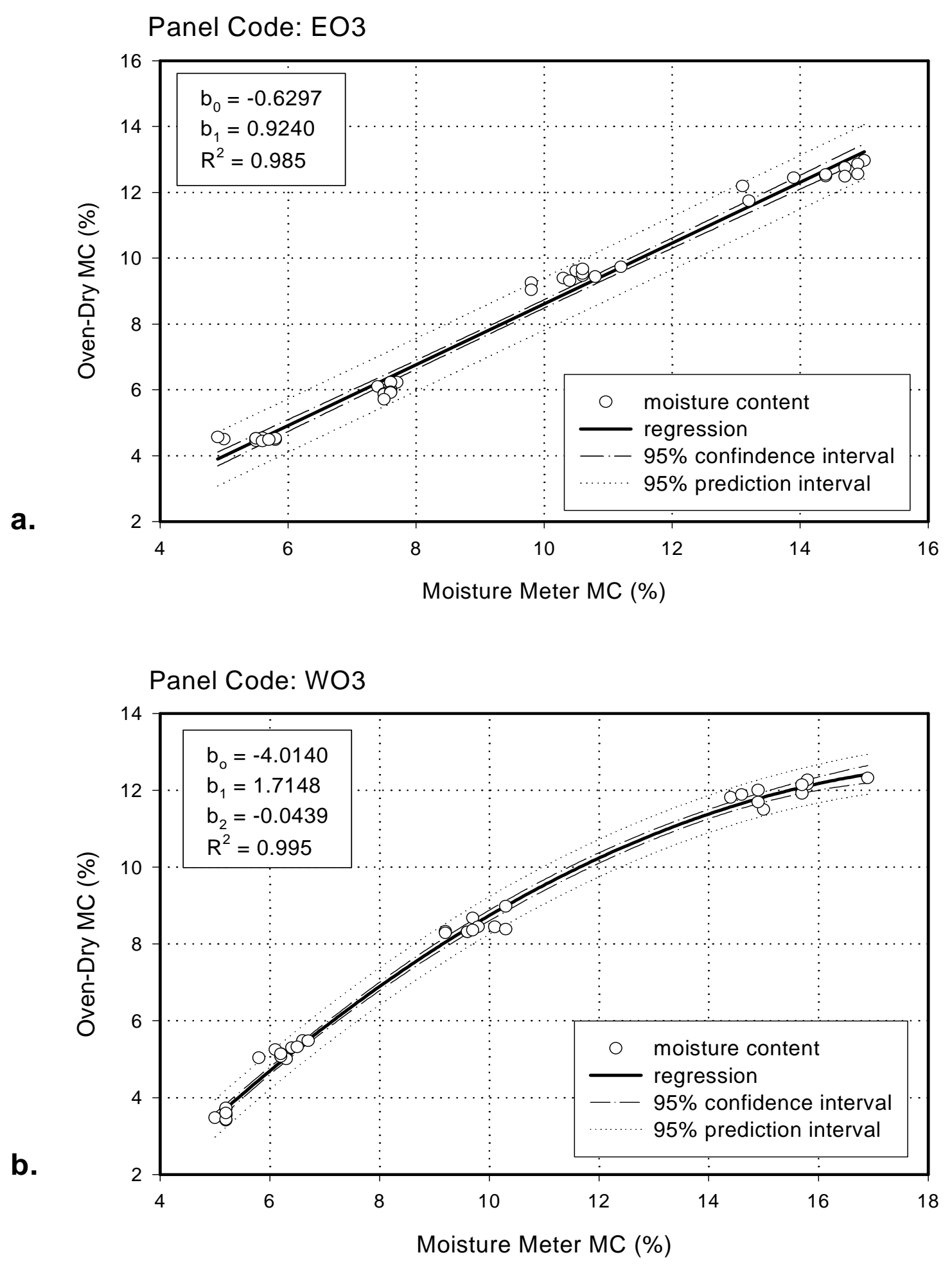

Figure 4.2 Regression equation for oven-dry MC vs. moisture meter MC with $95 \%$ confindence and prediction intervals; a. East Coast OSB, b. West Coast OSB 
were noted with P3 as well as P5. A summary of descriptive statistics for horizontal density distribution data is found in Table 4.1. Average SG values for EO (0.62) and WO (0.54) agreed well with those values, 0.64 and 0.55 respectively, discovered by Wu and Suchsland (1997). The average SG value that was found for WP3 (0.49) was similar to the literature value of 0.50 (Chow 1976). Whereas the average SG value for EP3 (0.56) was higher than the literature value (0.47). Histograms with the appropriate probability density functions were compiled using ExpertFit software describing the horizontal density distribution of the six panel types (Figures 4.3-4.5). EO3, EP3 and WP3 all fit a 2-parameter Lognormal function while a 3-parameter Weibull function best described the distribution of WO3, WP5 and EP5.

In order to determine whether or not there is a relationship between fastener holding capacity and panel density, regressions were plotted for fastener withdrawal strength versus panel specific gravity for both O3S and O3N before cycling (Figures 4.6a and b) and again after cycling (Figures $4.7 \mathrm{a}$ and b). The fastener holding capacity values for the plywood panels were normalized to a one-inch thickness by dividing the fastener withdrawal strength values by the panel thickness. Regression lines for P3S and P3N were found after cycling (Figures $4.8 \mathrm{a}$ and $b$ ). Low $r^{2}$ values indicated that there was insignificant correlation between the two factors for plywood while moderate $r^{2}$ values for OSB indicated that a positive correlation may indeed exist between panel density and fastener holding capacity. 
Table 4.1 Summary of descriptive statistics for horizontal density distribution data.

\begin{tabular}{cccccc}
\hline & & \multicolumn{4}{c}{ SPECIFIC GRAVITY } \\
PANEL Code & SAMPLE SIZE & MeAN & StD. DeV. & MIN & MAX \\
\hline \hline EO3 & 148 & 0.620 & 0.041 & 0.52 & 0.75 \\
EP3 & 110 & 0.563 & 0.035 & 0.47 & 0.64 \\
EP5 & 135 & 0.557 & 0.043 & 0.49 & 0.69 \\
WO3 & 149 & 0.543 & 0.042 & 0.46 & 0.68 \\
WP3 & 111 & 0.491 & 0.071 & 0.37 & 0.70 \\
WP5 & 135 & 0.469 & 0.069 & 0.37 & 0.67 \\
\hline \hline
\end{tabular}



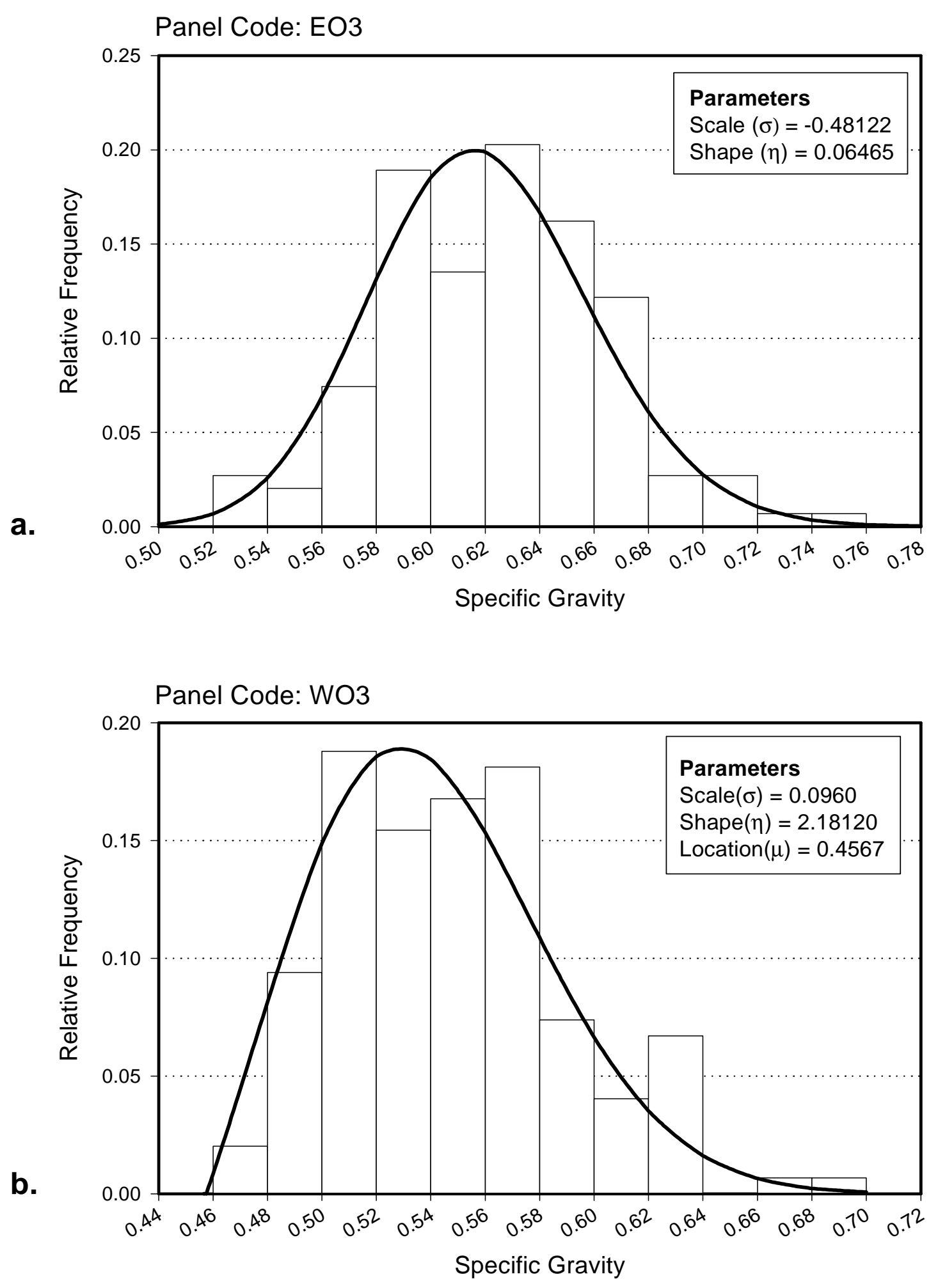

Figure 4.3 Histogram of horizontal density distribution with probability density function overlaid; a. panel code EO3, b. panel code WO3 

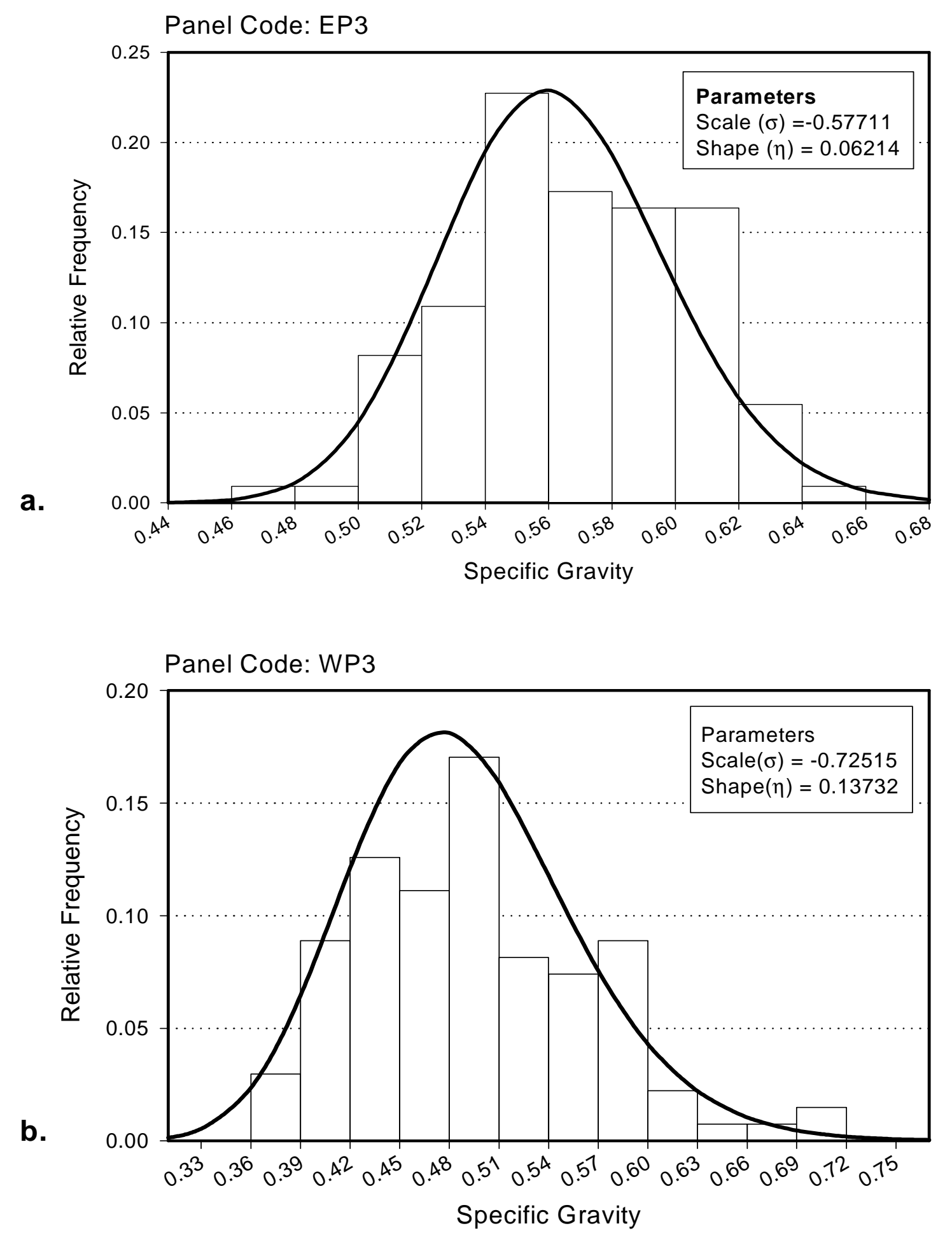

Figure 4.4 Histogram of horizontal density distribution with probability density function overlaid; a. panel code EP3, b. panel code WP3 

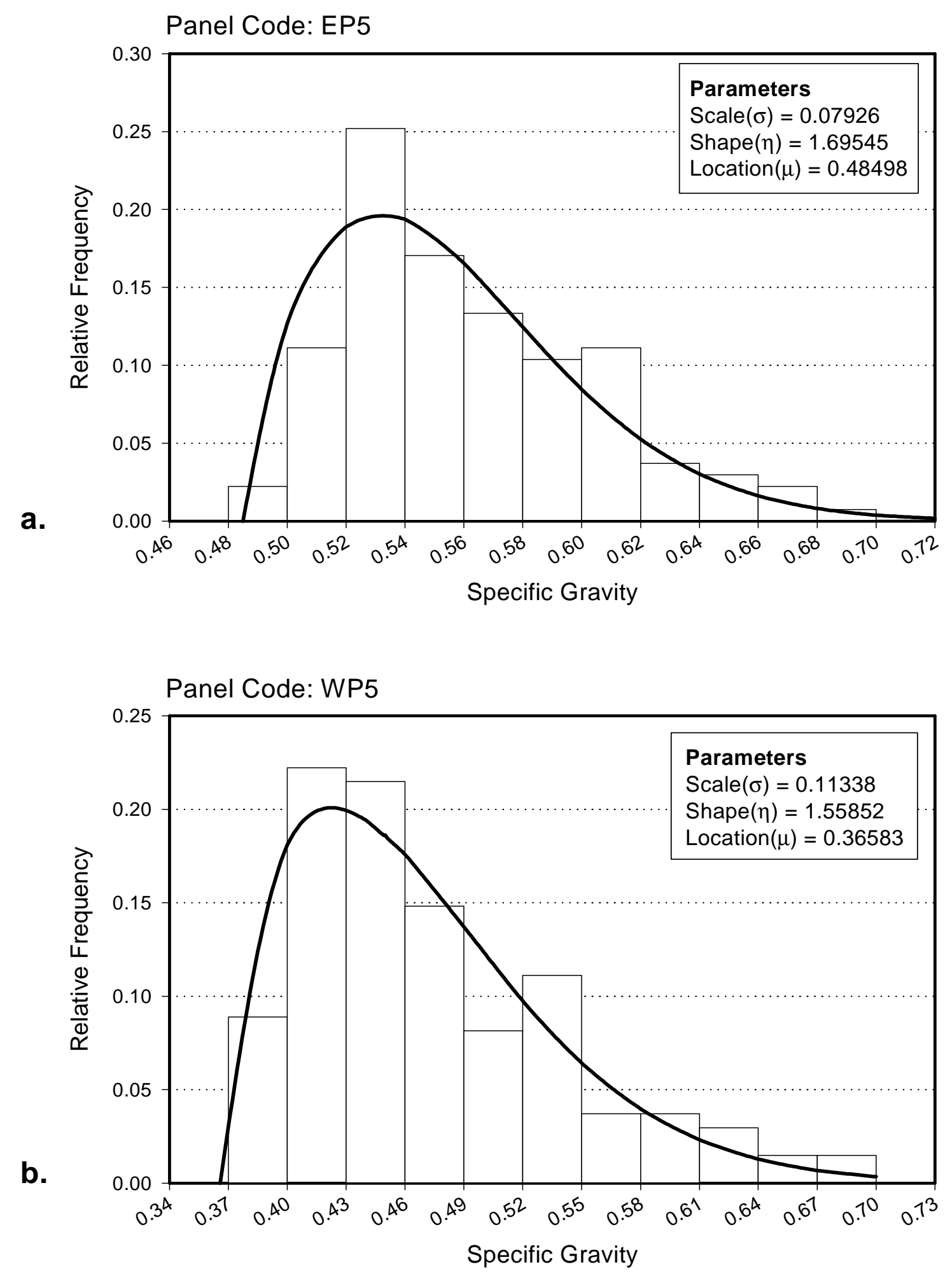

Figure 4.5 Histogram of horizontal density distribution with probability density function overlaid; a. panel code EP5, b. panel code WP5 

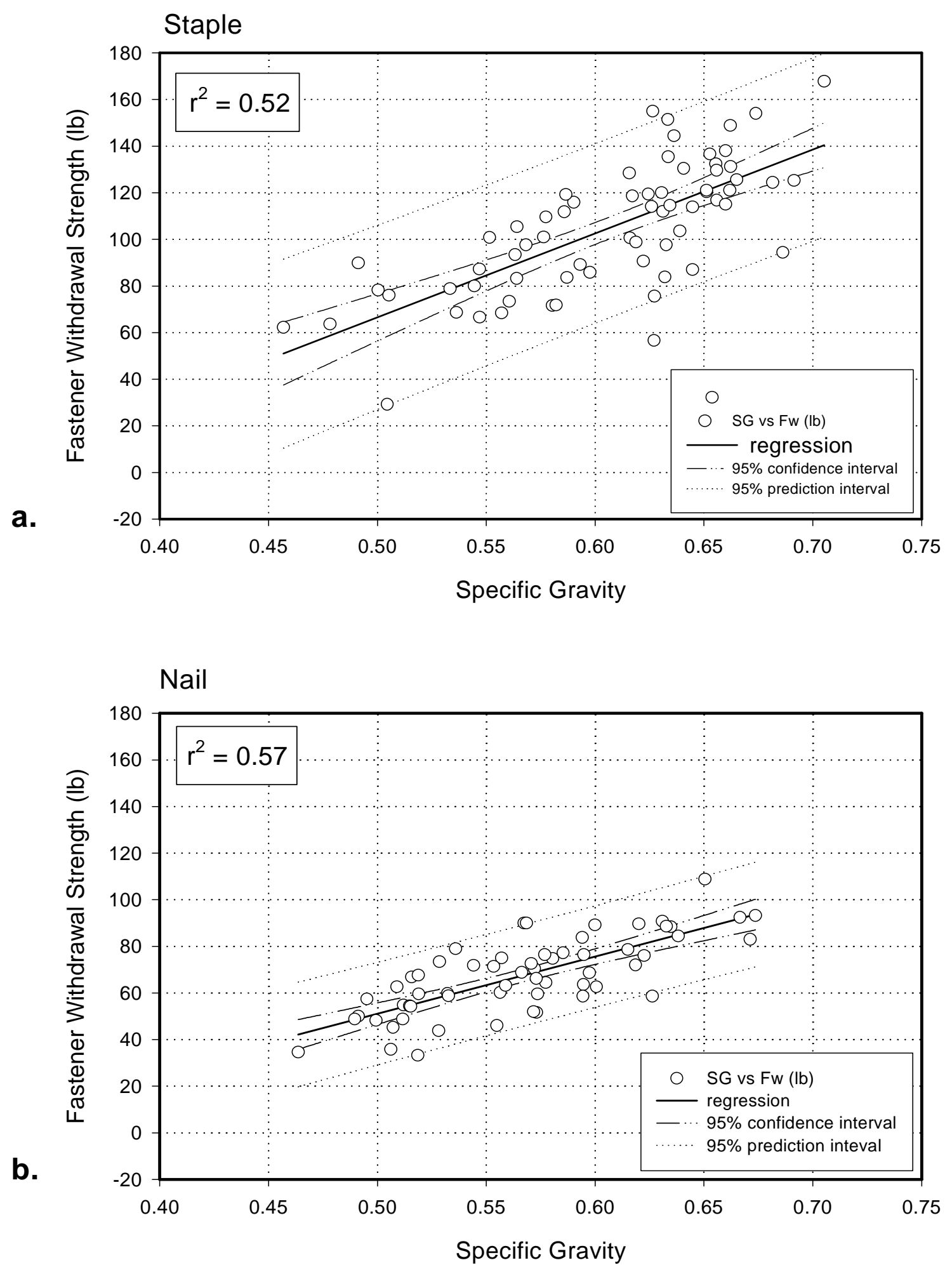

Figure 4.6 Regression analysis of fastener withdrawal strength versus specific gravity for OSB (coupon); a. staple fastener, b. nail fastener 

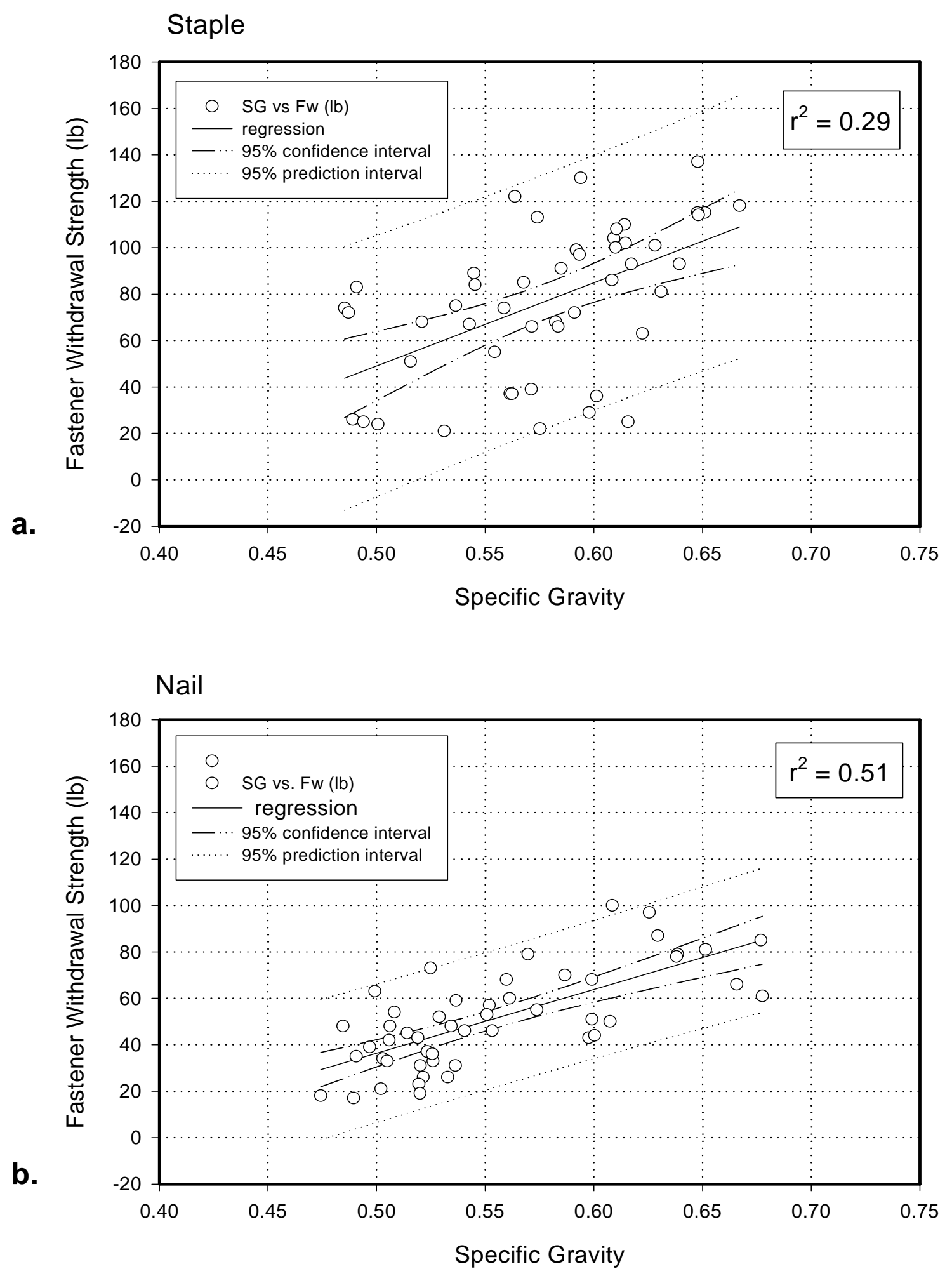

Figure 4.7 Regression analysis of fastener withdrawal strength versus specific gravity for OSB (post treatment); a. nail fastener, b. staple fastener 

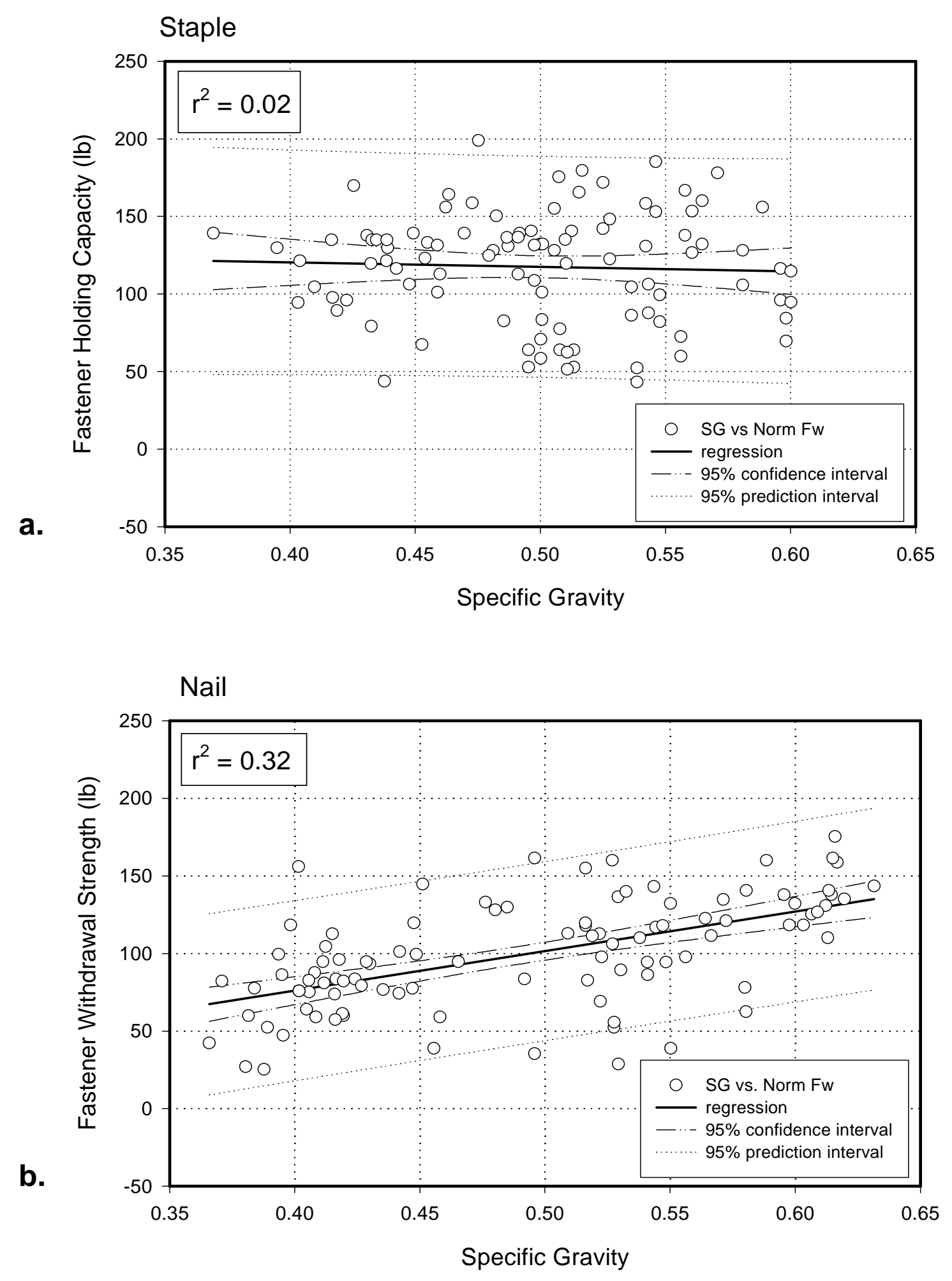

Figure 4.8 Regression analysis of fastener withdrawal strength versus specific gravity for plywood (post treatment); a. staple fastener, b. nail fastener 


\subsection{Moisture Cycling}

Moisture cycling began with a mild exposure site simulation where installed subflooring was moisturized up to an equilibrium moisture content (EMC) of approximately $16 \%$. This lasted fourteen days and attempted to simulate the conditions sub-flooring might be exposed to after installation but before building enclosure. One hundred and fifty nine days were required to complete the accelerated simulation. For the duration of the simulated moisture cycling, relative humidity and temperature were recorded at sixhour intervals through the use of an ERTCO brand datalogger.

\subsection{Fastener Withdrawal Tests}

Fastener withdrawal tests were performed over the course of this project resulting in 1815 data observations. Table 4.2 shows descriptive statistics, including mean and standard deviation, for maximum fastener holding capacity of the five cycle fastener withdrawal tests. Staple fasteners 1.5" long provided higher maximum mean values than did 1.5" nails for all panel types during all phases except for EP3 during the final phase. Table 4.3 provides a summary of descriptive statistics for floors fastened with 2" nails on EP3 and WP3 panels driven at an angle of $30^{\circ}$. Descriptive statistics for finished flooring fastened with both 2" nails and 1.5" staples on EP5 and WP5 panels can be found in Table 4.4. For quick visual evaluation, box plot diagrams were constructed by exposure (Figures 4.9-4.17) and by panel code (Figures 4.18-4.22). Table 4.5 shows the percent change in mean fastener-holding capacity between phases for each sub-floor panel type/fastener combination. 
Table 4.2 Summary of descriptive statistics from five series of fastener withdrawal tests.

\begin{tabular}{|c|c|c|c|c|c|c|c|c|c|c|c|c|c|c|c|c|}
\hline \multirow{4}{*}{ 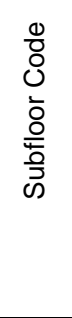 } & \multirow{4}{*}{ 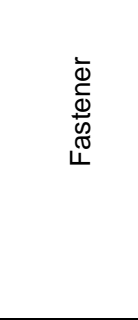 } & \multicolumn{15}{|c|}{ STATUS OF EXPOSURE } \\
\hline & & \multicolumn{3}{|c|}{ Coupon } & \multicolumn{4}{|c|}{$10 \% \mathrm{MC}$} & \multicolumn{2}{|c|}{$2^{\text {nd }} 6 \% \mathrm{MC}$} & \multicolumn{3}{|c|}{$12 \% \mathrm{MC}$} & \multicolumn{3}{|c|}{$3^{\mathrm{rd}} 6 \% \mathrm{MC}$} \\
\hline & & \multicolumn{15}{|c|}{ STATISTICS OF MAXIMUM NAIL WITHDRAWAL FORCE (LBS) } \\
\hline & & $\mathrm{n}^{1}$ & Mean & $\begin{array}{l}\text { Std. } \\
\text { Dev. }\end{array}$ & $\mathrm{n}^{1}$ & Mean & $\begin{array}{l}\text { Std. } \\
\text { Dev. }\end{array}$ & $\mathrm{n}^{1}$ & Mean & $\begin{array}{l}\text { Std. } \\
\text { Dev. }\end{array}$ & $\mathrm{n}^{1}$ & Mean & $\begin{array}{l}\text { Std. } \\
\text { Dev. }\end{array}$ & $\mathrm{n}^{1}$ & Mean & $\begin{array}{l}\text { Std. } \\
\text { Dev. }\end{array}$ \\
\hline \multirow{2}{*}{ EP3 } & NAIL & 34 & 92 & 14.878 & 25 & 111 & 17.634 & 25 & 88 & 11.865 & 25 & 85 & 15.232 & 25 & 93 & 15.866 \\
\hline & STAPLE & 34 & 118 & 14.149 & 25 & 119 & 16.594 & 25 & 89 & 20.469 & 25 & 86 & 20.857 & 25 & 69 & 23.773 \\
\hline \multirow[b]{2}{*}{ EP5 } & NAIL & 29 & 74 & 22.094 & 25 & 85 & 17.482 & 25 & 63 & 16.472 & 25 & 75 & 21.637 & 27 & 61 & 21.243 \\
\hline & STAPLE & 34 & 101 & 14.126 & 27 & 101 & 19.661 & 25 & 95 & 12.449 & 25 & 93 & 16.004 & 25 & 78 & 15.140 \\
\hline \multirow[b]{2}{*}{ EO3 } & NAIL & 29 & 77 & 14.270 & 24 & 78 & 17.756 & 25 & 68 & 13.482 & 25 & 68 & 15.740 & 25 & 65 & 17.614 \\
\hline & STAPLE & 34 & 122 & 23.372 & 25 & 114 & 23.826 & 25 & 98 & 24.042 & 25 & 92 & 22.913 & 25 & 91 & 29.547 \\
\hline \multirow[b]{2}{*}{ WP3 } & NAIL & 35 & 95 & 16.908 & 25 & 105 & 21.545 & 25 & 71 & 15.825 & 25 & 82 & 17.088 & 25 & 70 & 20.229 \\
\hline & STAPLE & 35 & 125 & 16.153 & 25 & 110 & 14.678 & 25 & 119 & 17.049 & 25 & 90 & 22.829 & 26 & 106 & 15.083 \\
\hline \multirow{2}{*}{ WP5 } & NAIL & 31 & 63 & 13.026 & 25 & 57 & 13.723 & 25 & 63 & 13.350 & 25 & 77 & 19.930 & 25 & 42 & 15.878 \\
\hline & STAPLE & 32 & 100 & 14.134 & 25 & 104 & 20.112 & 25 & 79 & 17.261 & 25 & 84 & 17.651 & 25 & 66 & 14.475 \\
\hline \multirow{3}{*}{ WO3 } & NAIL & 31 & 59 & 12.985 & 25 & 52 & 11.427 & 25 & 61 & 13.572 & 25 & 46 & 14.347 & 25 & 37 & 12.514 \\
\hline & - & & & $\cdots$ & $\ldots$ & 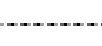 & $\ldots . .$. & ... & $\ldots$ & $\ldots . . .$. & $\cdots$ & ... & $\ldots$ & $\ldots$ & $\cdots$ & ................. \\
\hline & STAPLE & 33 & 87 & 19.904 & 25 & 99 & 21.786 & 25 & 82 & 24.737 & 25 & 68 & 27.274 & 25 & 63 & 28.595 \\
\hline
\end{tabular}

${ }^{1}$ sample size 
Table 4.3. Summary of descriptive statistics for floors fastened with 2" cleats at an angle of $30^{\circ}$.

\begin{tabular}{cccccccc}
\hline \hline & \multicolumn{6}{c}{ STATUS OF EXPOSURE } \\
\cline { 2 - 7 } $\begin{array}{c}\text { SUBFLOOR } \\
\text { CODE }\end{array}$ & \multicolumn{4}{c}{ Coupon } & \multicolumn{4}{c}{ Final $\left(3^{\text {rd }} 6 \%\right.$ MC) } \\
\hline EP3 & 35 & 97 & $\begin{array}{c}\text { Mean } \\
(\text { lbs })\end{array}$ & $\begin{array}{c}\text { Std. Dev } \\
(\text { lbs })\end{array}$ & $n$ & $\begin{array}{c}\text { Mean } \\
(\text { lbs })\end{array}$ & $\begin{array}{c}\text { Std. Dev. } \\
(\text { lbs })\end{array}$ \\
\hline WP3 & 35 & 14.987 & 25 & 92 & 20.081 \\
\hline \hline
\end{tabular}

Table 4.4. Summary of descriptive statistics for finished floor combinations

\begin{tabular}{ccccc}
\hline $\begin{array}{c}\text { SUBFLOOR } \\
\text { CODE }\end{array}$ & FASTENER & $\mathrm{n}$ & $\begin{array}{c}\text { Mean } \\
\text { (lbs) }\end{array}$ & $\begin{array}{c}\text { Std. Dev. } \\
\text { (lbs) }\end{array}$ \\
\hline \multirow{2}{*}{ EP5 } & 2" Nail & 25 & 106 & 17.451 \\
& Staple & 25 & 80 & 16.969 \\
\hline \multirow{2}{*}{ WP5 } & 2" Nail & 25 & 87 & 18.742 \\
& Staple & 25 & 105 & 13.576 \\
\hline \hline
\end{tabular}



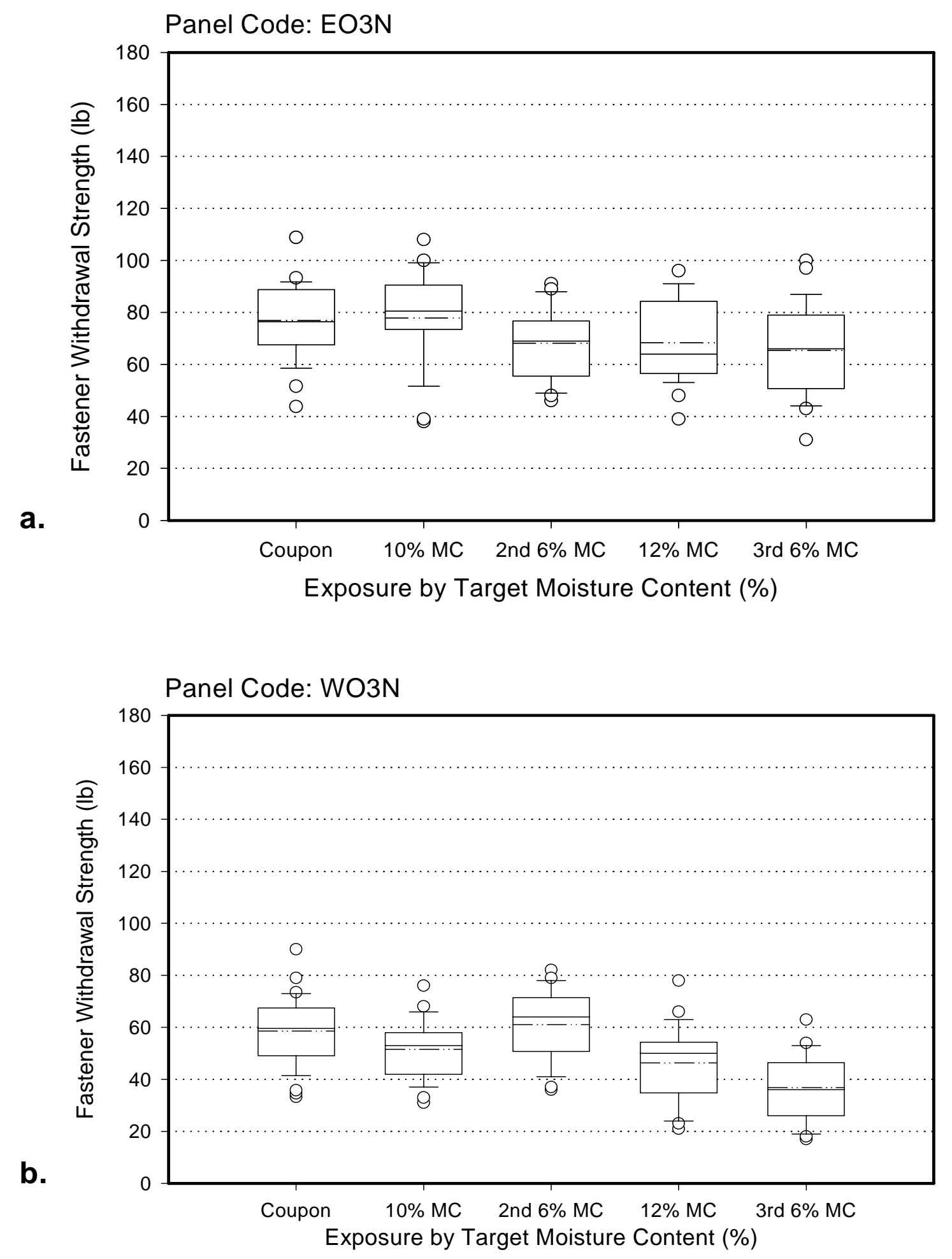

Figure 4.9 Changes in fastener holding capacity by exposure.

a. panel code EO3N; b. panel code WO3N 

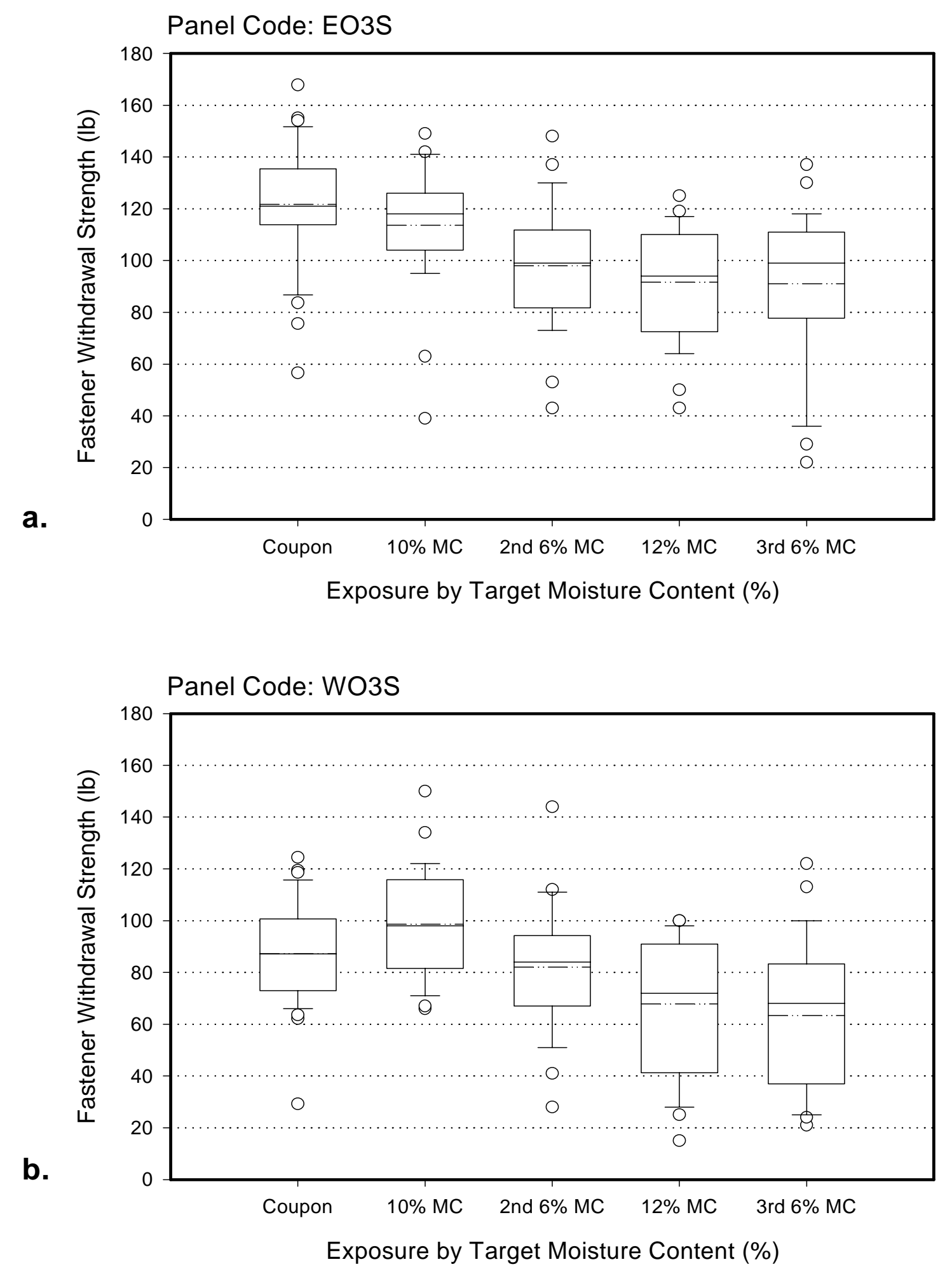

Figure 4.10 Changes in fastener holding capacity by exposure.

a. panel code EO3S; b. panel code WO3S 

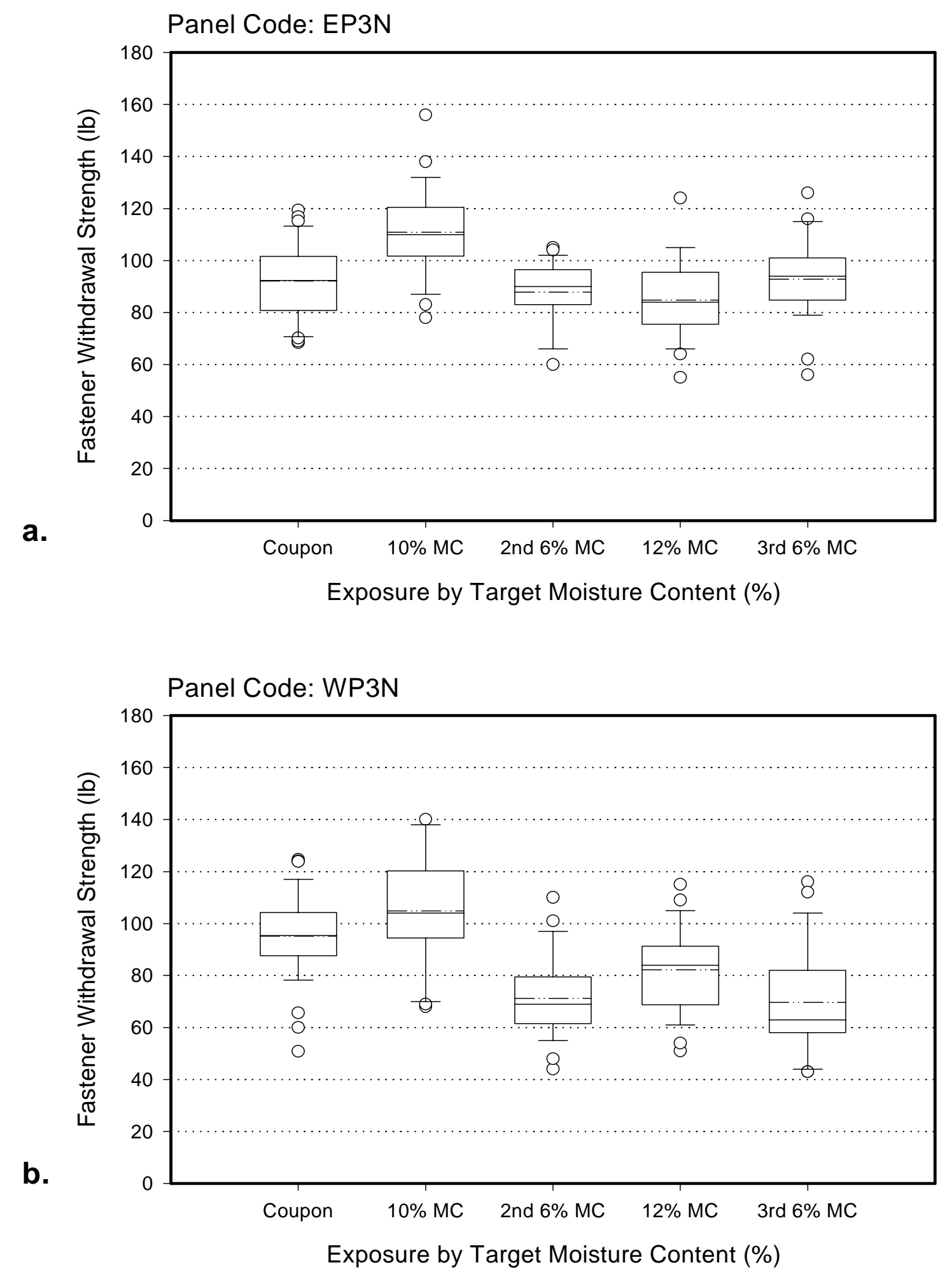

Figure 4.11 Changes in fastener holding capacity by exposure. a. panel code EP3N; b. panel code WP3N 

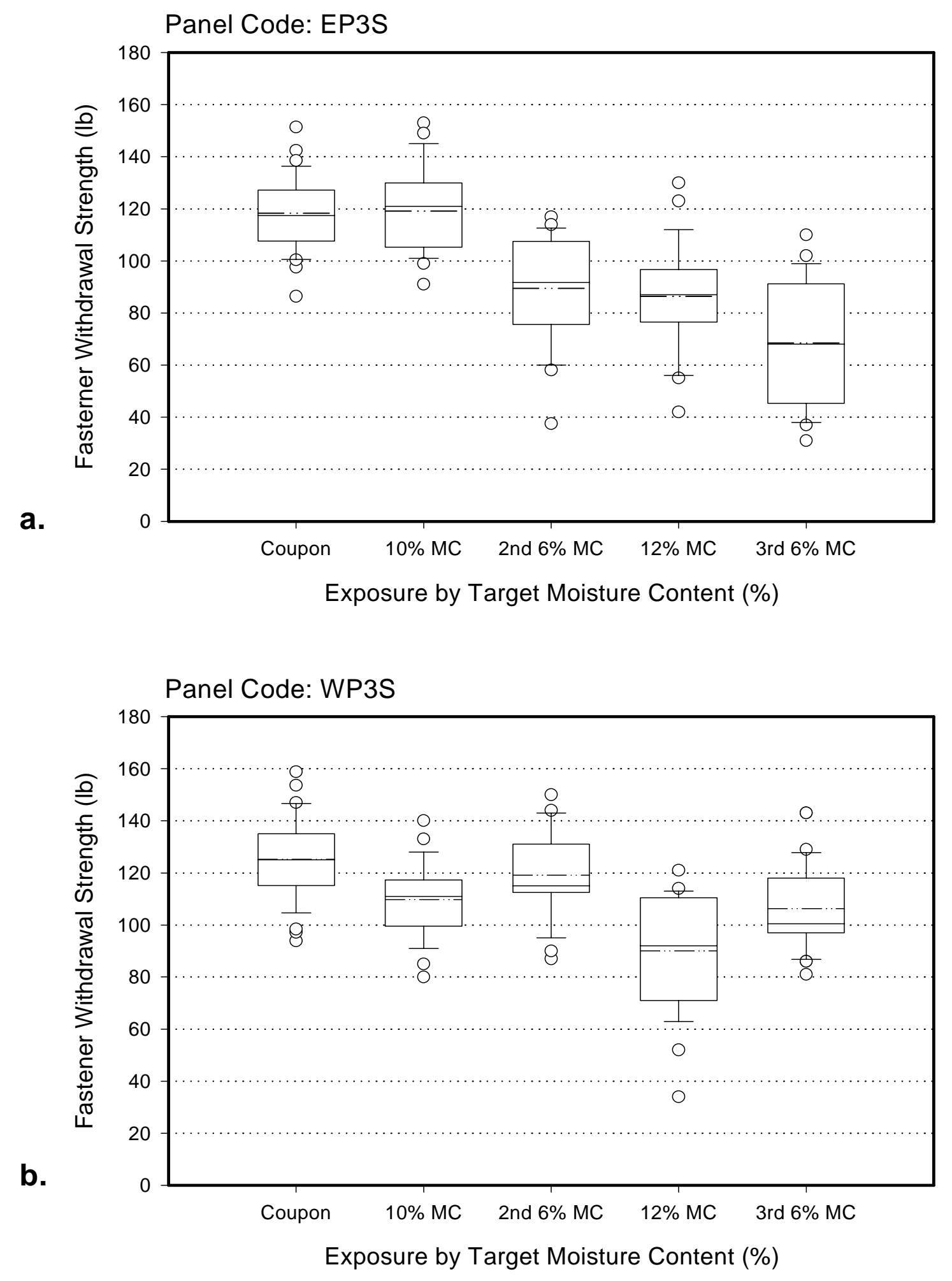

Figure 4.12 Changes in fastener holding capacity by exposure.

a. panel code EP3S; b. panel code WP3S 

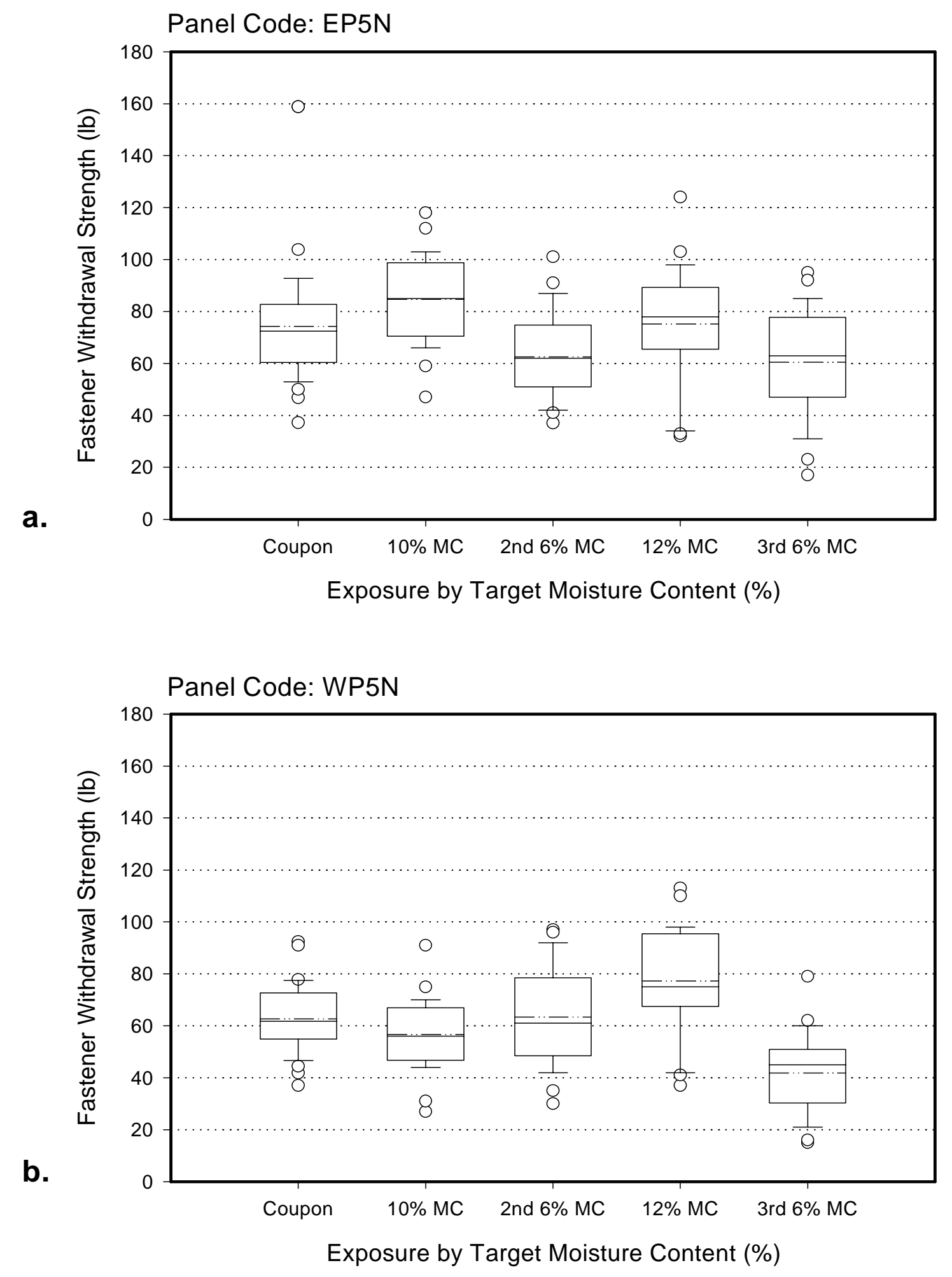

Figure 4.13 Changes in fastener holding capacity by exposure.

a. panel code EP5N; b. panel code WP5N 

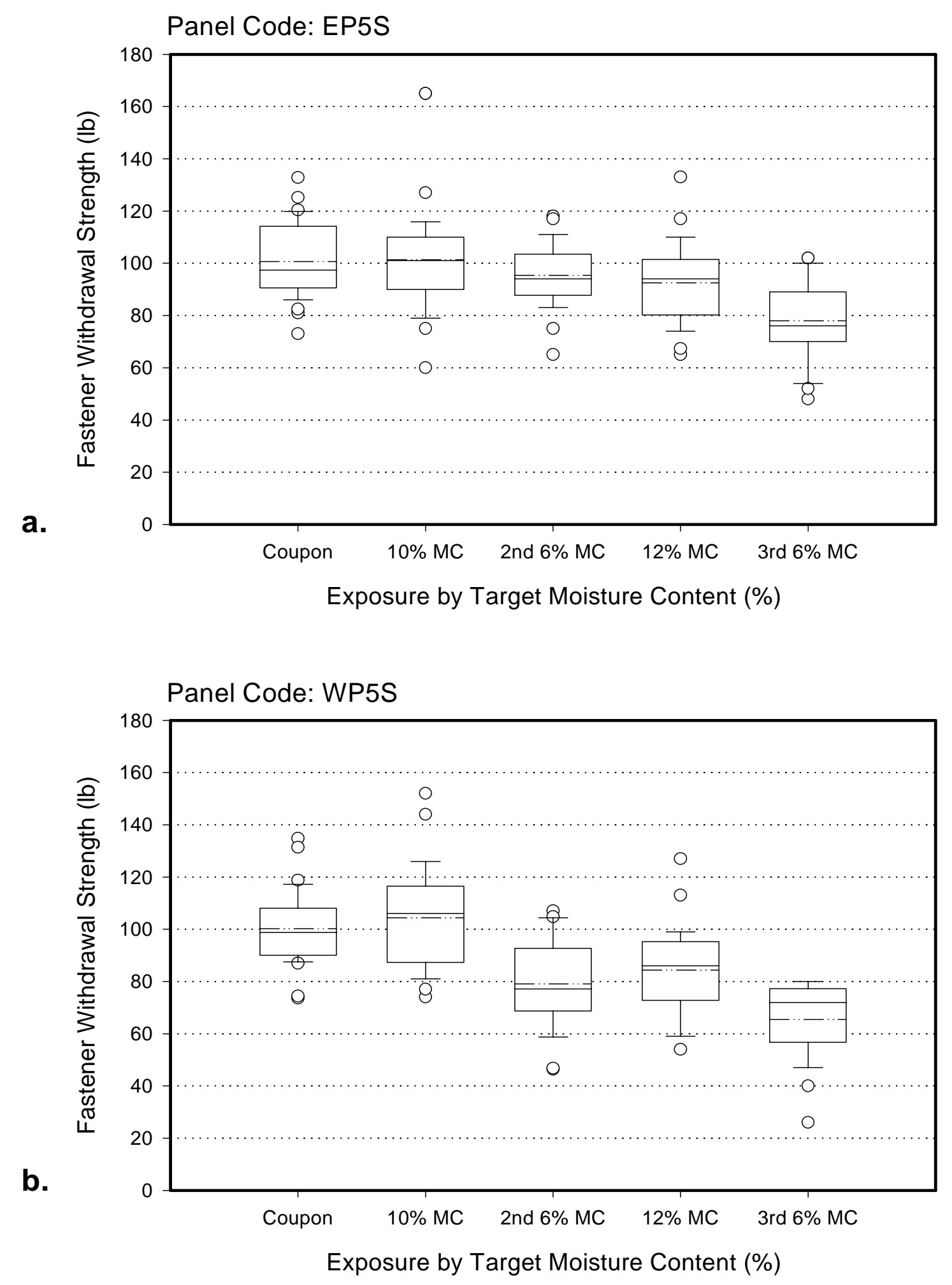

Figure 4.14 Changes in fastener holding capacity by exposure. a. panel code EP5S; b. panel code WP5S 

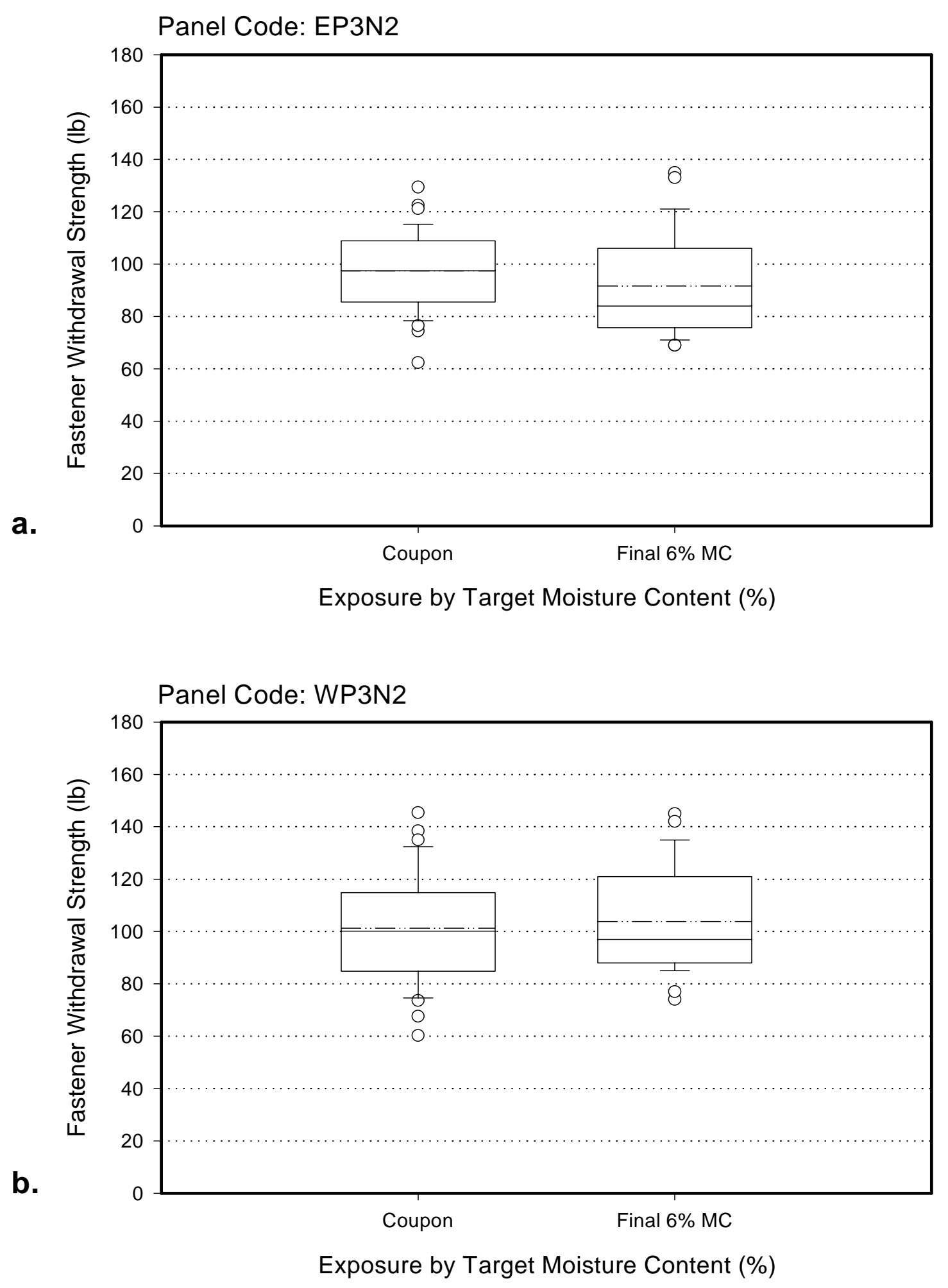

Figure 4.15 Changes in fastener holding capacity by exposure.

a. panel code EP3N2; b. panel code WP3N2 

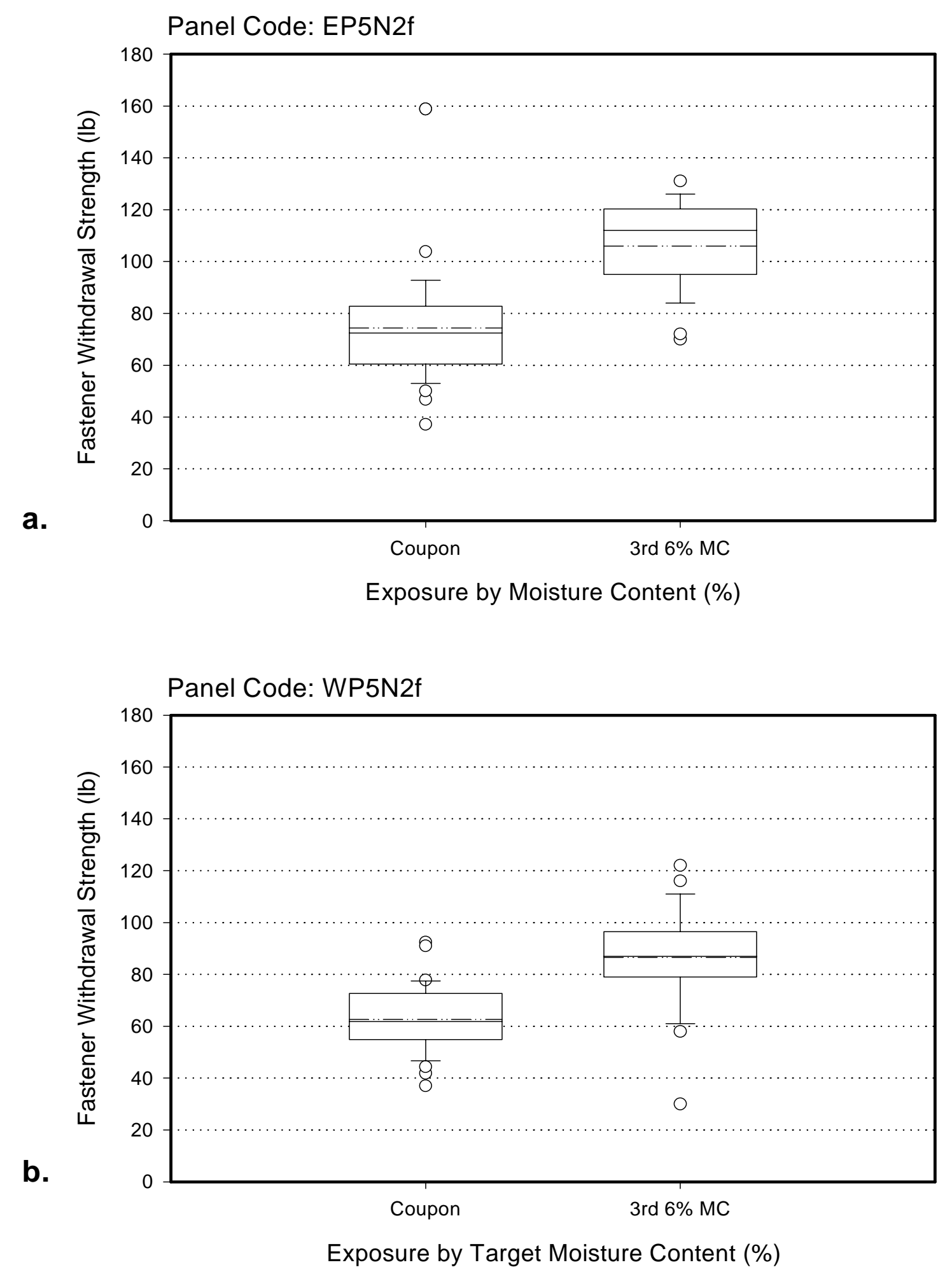

Figure 4.16 Changes in fastener holding capacity by exposure.

a. panel code EP5N2f; b. panel code WP5N2f 

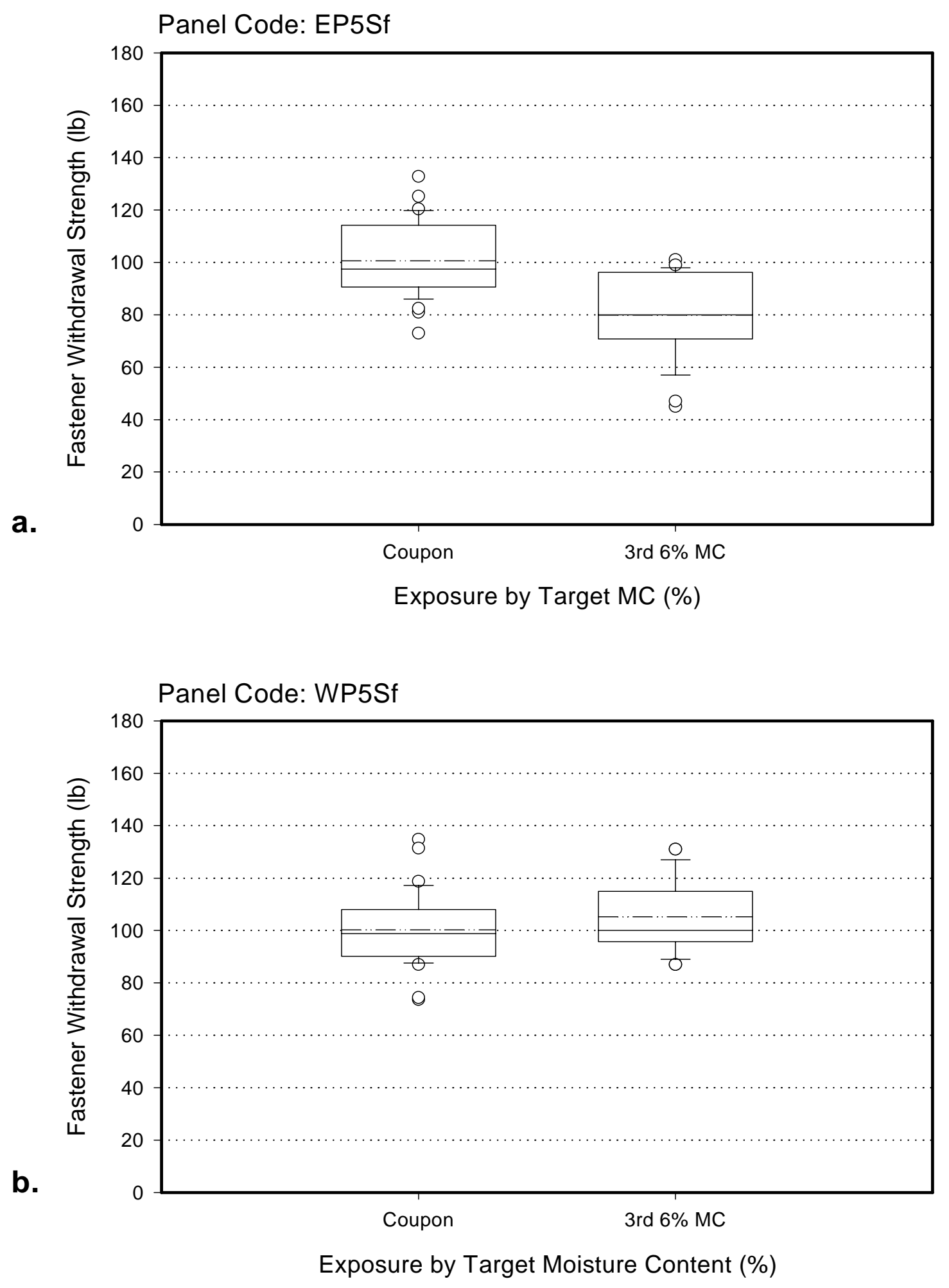

Figure 4.17 Changes in fastener holding capacity by exposure.

a. panel code EP5Sf; b. panel code WP5Sf 
Coupon-Nail
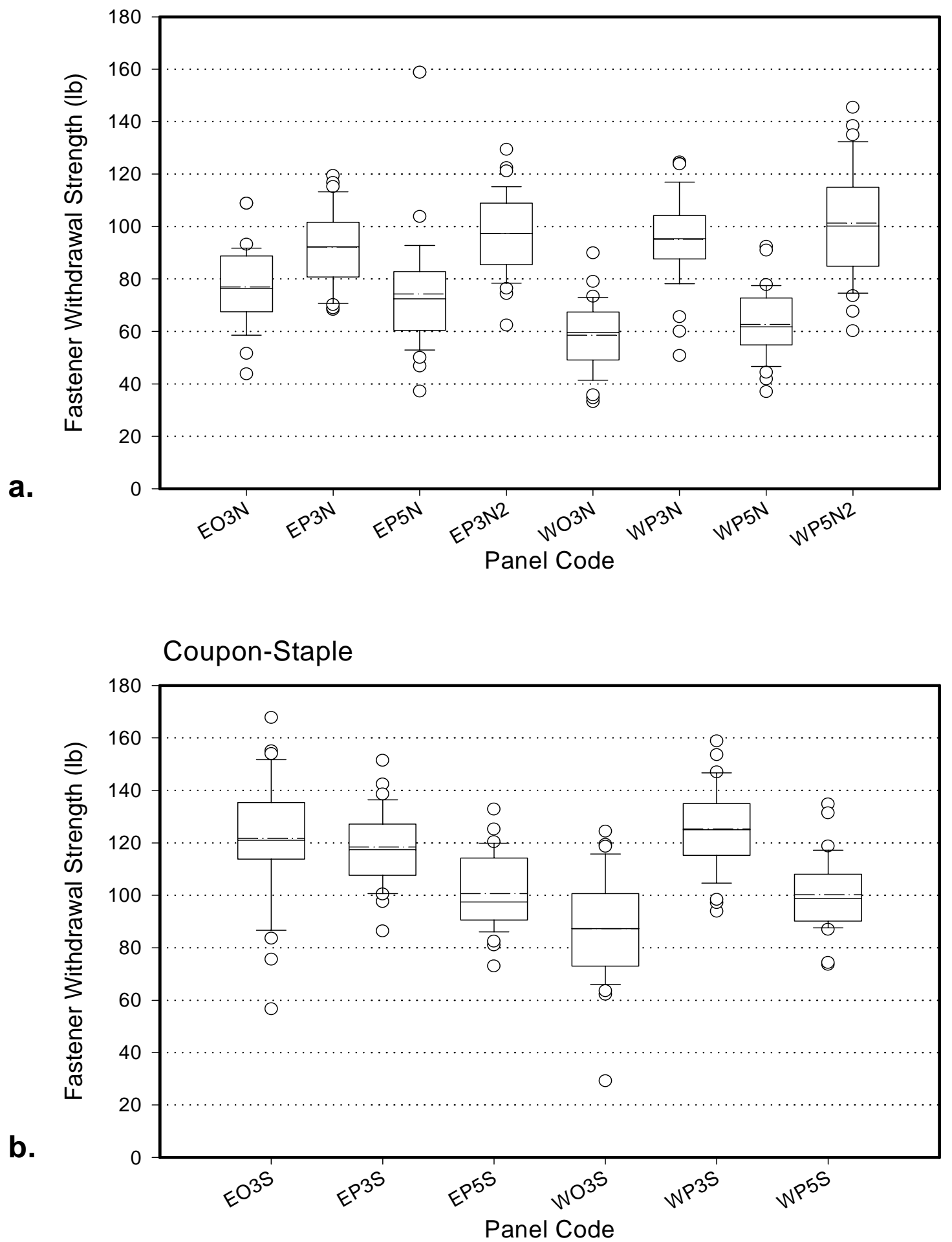

Figure 4.18 Comparison of fastener holding capacity by panel code for coupon phase; a. nail fastener, b. staple fastener 

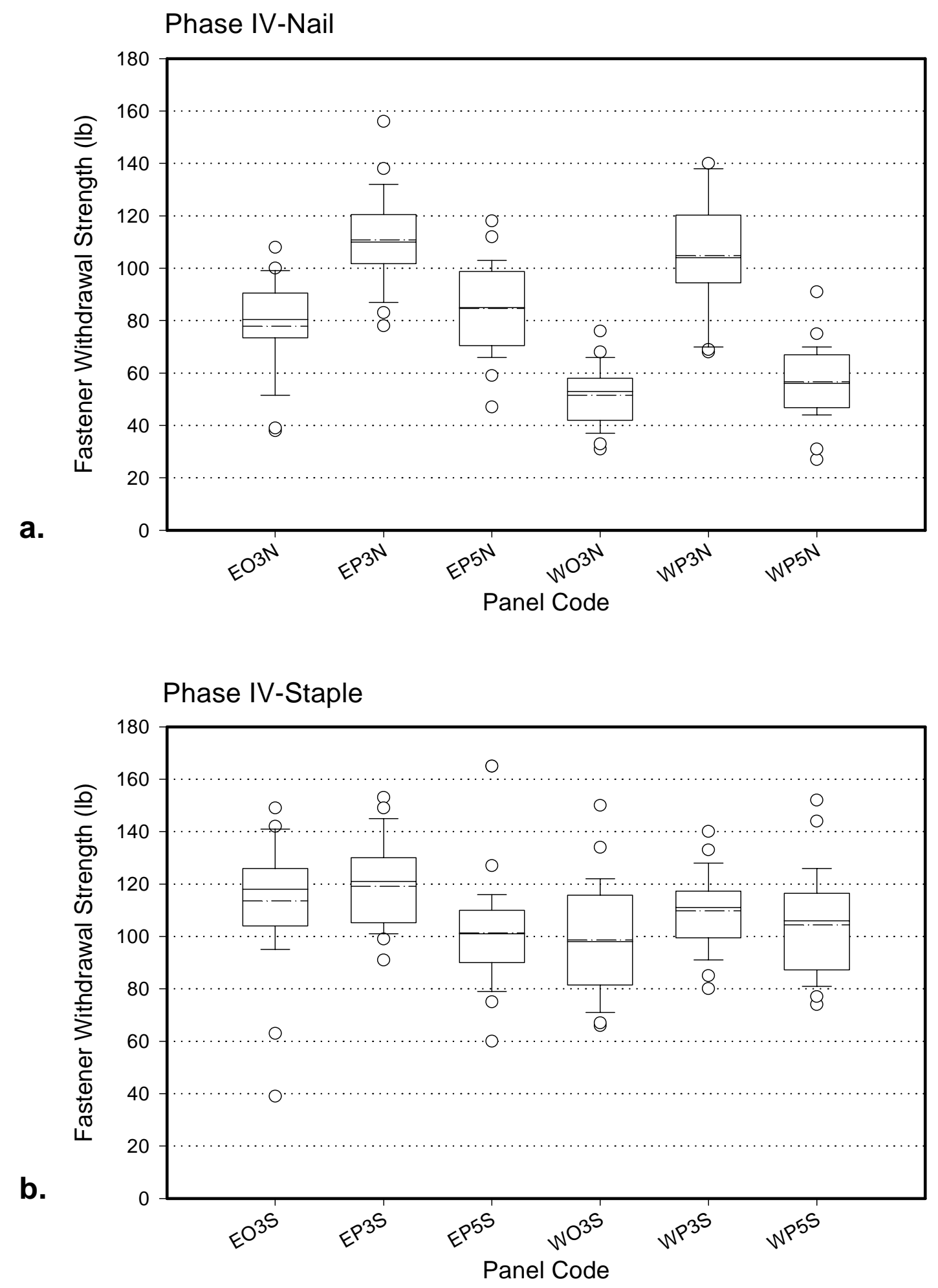

Figure 4.19 Comparison of fastener holding capacity by panel code for phase IV; a. nail fastener, b. staple fastener 

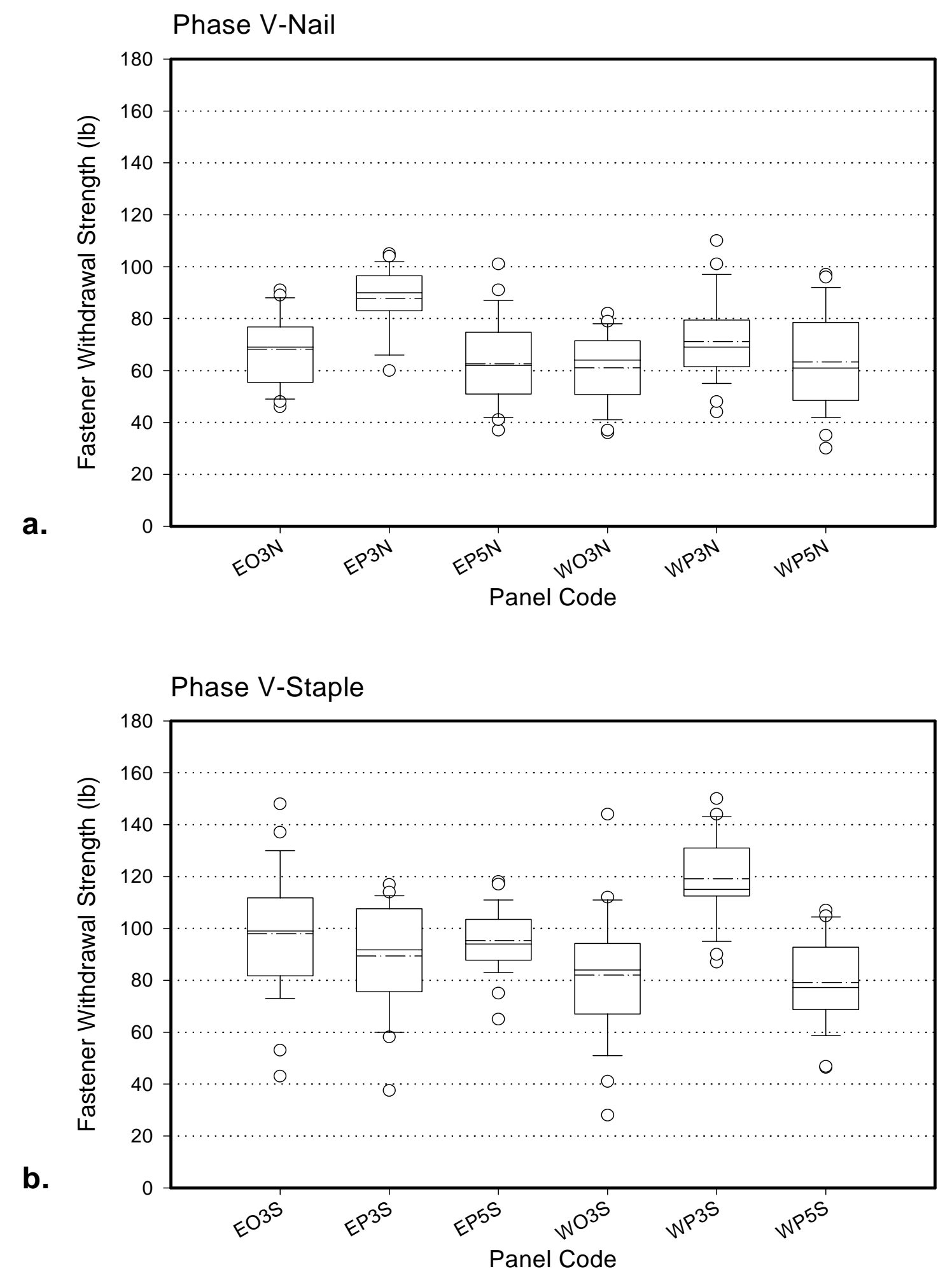

Figure 4.20 Comparison of fastener holding capacity by panel code for phase V; a. nail fastener, b. staple fastener 

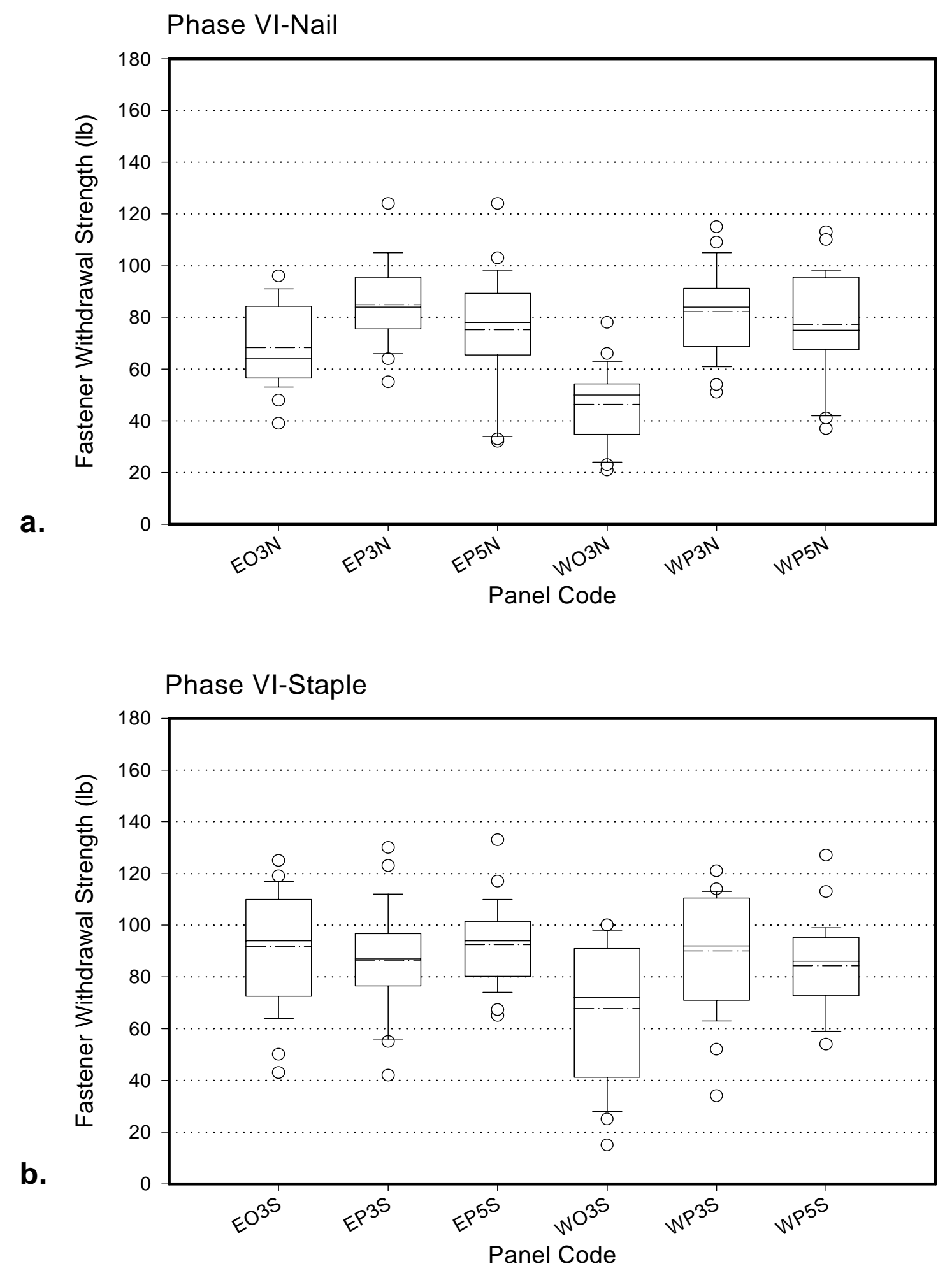

Figure 4.21 Comparison of fastener holding capacity by panel code for phase $\mathrm{VI}$; a. nail fastener, b. staple fastener 

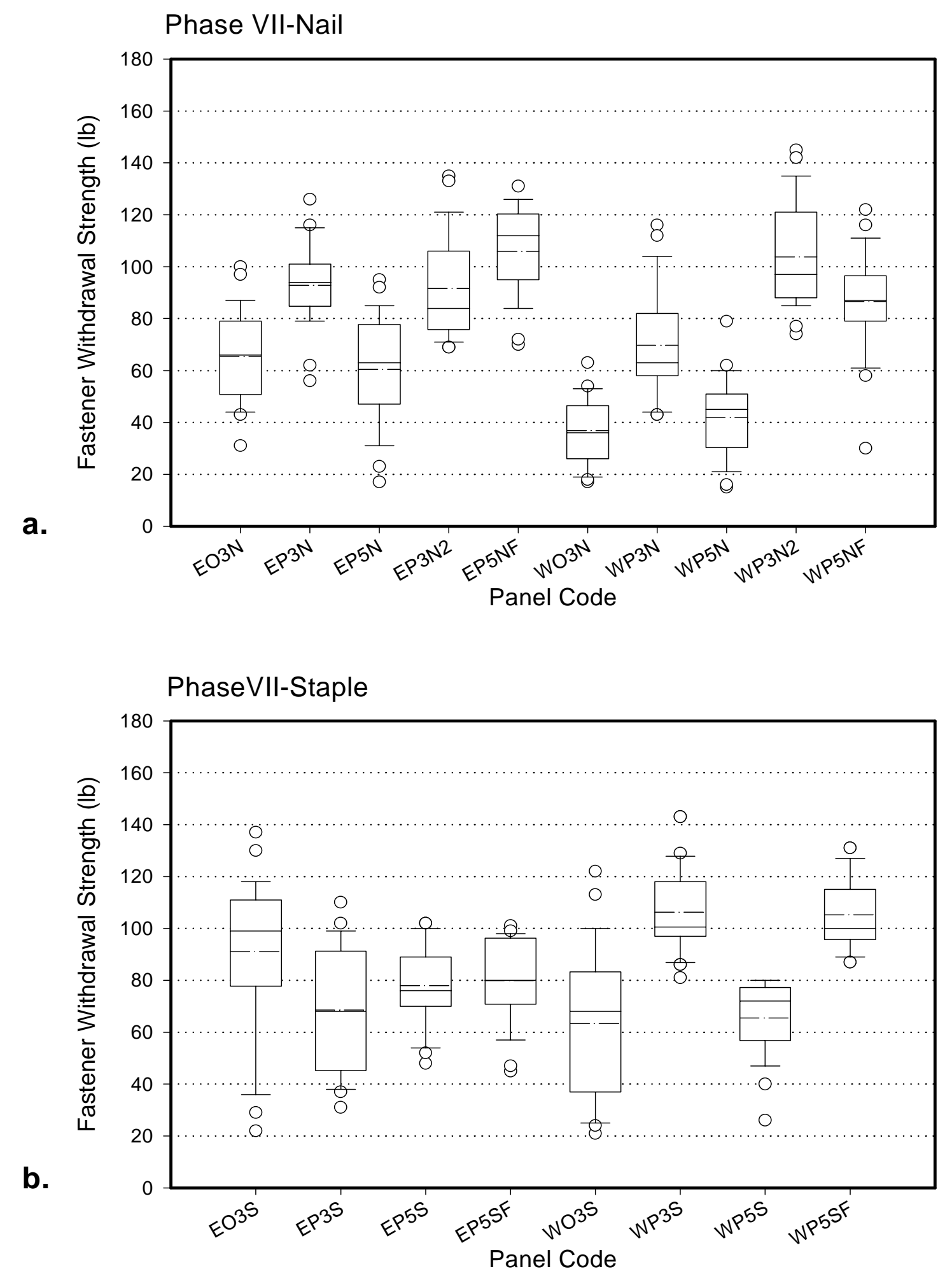

Figure 4.22 Comparison of fastener holding capacity by panel code for phase VII; a. nail fastener, b. staple fastener 
Table 4.5 Percent (\%) change in mean fastener holding capacity.

\begin{tabular}{|c|c|c|c|c|c|}
\hline $\begin{array}{c}\text { SUBFLOOR } \\
\text { CODE }\end{array}$ & FASTENER & $\begin{array}{l}\text { Coupon - } \\
10 \% \mathrm{MC}\end{array}$ & $\begin{array}{l}\text { Coupon- } \\
2^{\text {No }} 6 \% \mathrm{MC}\end{array}$ & $\begin{array}{l}\text { Coupon- } \\
12 \% \text { MC }\end{array}$ & $\begin{array}{l}\text { Coupon - } \\
3^{\text {RD }} 6 \% \mathrm{MC}\end{array}$ \\
\hline \multirow{2}{*}{ EP3 } & NAIL & +20.1 & -4.3 & -7.6 & +1.1 \\
\hline & STAPLE & +0.08 & -24.6 & -27.1 & -41.5 \\
\hline \multirow{2}{*}{ EP5 } & NAIL & +14.9 & -14.9 & +1.4 & -17.6 \\
\hline & STAPLE & 0.0 & -5.9 & -7.9 & -22.8 \\
\hline \multirow{2}{*}{ EO3 } & NAIL & +1.3 & -11.7 & -11.7 & -15.6 \\
\hline & STAPLE & -6.6 & -19.7 & -24.6 & -25.4 \\
\hline \multirow{2}{*}{ WP3 } & NAIL & +10.5 & -25.3 & -13.7 & -26.3 \\
\hline & STAPLE & -12.0 & -4.8 & -28.0 & -15.2 \\
\hline \multirow{2}{*}{ WP5 } & NAIL & -9.5 & 0.0 & +22.2 & -33.3 \\
\hline & STAPLE & +4.0 & -21.0 & -16.0 & -34.0 \\
\hline \multirow{2}{*}{ WO3 } & NAIL & -11.9 & +3.4 & -22.0 & -37.3 \\
\hline & STAPLE & +13.8 & -5.7 & -21.8 & -27.6 \\
\hline EP3 & 2" NAIL & ב---- & ----- & $\begin{array}{l}----- \\
\end{array}$ & -5.1 \\
\hline WP3 & 2" NAIL & ---- & ---- & ---- & +3.0 \\
\hline
\end{tabular}


Raw data was analyzed using SAS statistical software applying a General Linear Model Procedure as well as a Means Procedure. Results of the GLM Procedure by cycle indicate that the mean values of the coupon (93.83 lbs.) and 10\% MC phase (94.53 lbs.) were nearly the same. Mean values of all subsequent phases, Phase $\mathrm{V}$ (81.44 lbs.), Phase VI (78.92 lbs.) and Phase VII (70.11 lbs.) declined fairly uniformly. This indicated that fastener holding capacity does not start to decline until the second 6\% (Phase V) is reached. GLM Procedure for panel type showed similar mean values for EP3 (95.74 lbs.) and WP3 (98.34 lbs.) with EO3 (88.34 lbs.) only slightly lower. EP5 (83.05 lbs.) was next followed by WP5 (73.90 lbs.) and WO3 (66.00 lbs.), which had the lowest value. GLM Procedure by fastener type showed the mean value for 1.5 " staples (95.95 lbs.) was considerably higher than the mean value for 1.5 " nails (72.48 lbs.). GLM Procedure for panel type by fastener type showed WP3S (111.18 lbs.) as the combination which provided the highest fastener withdrawal strength. The combination which provided the lowest mean strength value was WO3N (51.47 lbs.). A complete ranking of panel type by fastener type is listed in Table 4.6 with the results in descending order in Table 4.7.

The Means Procedure took a holistic approach to describing panel performance. It grouped all fastener withdrawal values into categories based on a single factor. For example, it provided mean values for all East Coast products independent of panel type, thickness, or fastener type. Mean values based on geographic origin showed East Coast products (89.08 lbs.) being superior to West Coast products (79.59 lbs.). Mean values based on panel type, either plywood or OSB, showed plywood (87.89 lbs.) as being superior to OSB (77.13 lbs.). P3 (97.04 lbs.) provided substantially 
Table 4.6 GLM results of panel type by fastener type.

\begin{tabular}{cccccc}
\hline \multicolumn{7}{c}{ PANEL TYPE BY FASTENER TYPE } \\
\hline \hline Panel Type & Fastener Type & Sample Size & $\begin{array}{c}\text { Mean } \\
\text { (lbs) }\end{array}$ & $\begin{array}{c}\text { St. Dev. } \\
\text { (lbs) }\end{array}$ & Rank \\
\hline EO3 & $\mathrm{N}$ & 128 & 71.49 & 16.337 & 10 \\
EO3 & $\mathrm{S}$ & 134 & 104.43 & 27.514 & 2 \\
EP3 & $\mathrm{N}$ & 134 & 93.61 & 17.351 & 5 \\
EP3 & $\mathrm{S}$ & 134 & 97.87 & 27.340 & 3 \\
EP5 & $\mathrm{N}$ & 129 & 71.56 & 21.557 & 9 \\
EP5 & $\mathrm{S}$ & 135 & 94.06 & 17.502 & 4 \\
WO3 & $\mathrm{N}$ & 131 & 51.47 & 15.825 & 12 \\
WO3 & $\mathrm{S}$ & 133 & 80.31 & 27.170 & 8 \\
WP3 & $\mathrm{N}$ & 135 & 85.40 & 22.510 & 7 \\
WP3 & $\mathrm{S}$ & 136 & 111.18 & 20.999 & 1 \\
WP5 & $\mathrm{N}$ & 131 & 60.46 & 19.725 & 11 \\
WP5 & $\mathrm{S}$ & 131 & 87.35 & 21.778 & 6 \\
\hline \hline
\end{tabular}

Table 4.7 Rank of panel type by fastener type in descending order.

\begin{tabular}{cc}
\hline Rank Number & Panel Code \\
\hline 1 & WP3S \\
2 & EO3S \\
3 & EP3S \\
4 & EP5S \\
5 & EP3N \\
6 & WP5S \\
7 & WP3N \\
8 & WO3S \\
9 & EP5N \\
10 & EO3N \\
11 & WP5N \\
12 & WO3N \\
\hline \hline
\end{tabular}


higher values than did P5 (78.50 lbs.). Complete SAS data analysis printouts are included in Appendix II.

Mean coupon values of fastener withdrawal tests performed by Lang et al. (1992) were compared with current coupon values for O3, P3 and P5 (Table 4.8). However, the previous project utilized 2" long fasteners while the current project results are based on 1.5" long fasteners. Therefore, any comparisons that may be drawn are done with caution. Based on the time of purchase of the raw materials for the respective projects, these comparisons spanned approximately ten years. The purpose of this comparison was to determine the change, if any, in the maximum fastener holding capacity of the panels over time. All panel type/fastener combinations experienced a decline in maximum fastener holding capacity. The percent loss of maximum fastener holding capacity over time ranged from $15.1 \%$ for P5S to $43.8 \%$ for P3S. All other panel type/fastener combinations fell within this range. This decline may be attributed to the difference in the length of the fasteners, but all indications point toward the growth of the panel products industry and the subsequent use of inferior raw materials as the major cause of this decline. This conclusion is based upon the visual inspection of the panels conducted in this study. It was noted that, upon disassembly of the various panel types, that the quality of the veneers in the plywood panels contained a rather inordinate amount of defects and voids. Furthermore, the core layers of the dismantled OSB panels exhibited high amounts of "fines", or constituents of inferior size and quality. 
Table 4.8 Comparison of results from two different fastener withdrawal studies done ten years apart.

\begin{tabular}{ccccc}
\hline \multicolumn{5}{c}{ Coupon Test Results } \\
\hline \multirow{2}{*}{ Panel Type } & Fastener & $\begin{array}{c}\text { Previous Mean }^{1} \\
\text { Value }^{1} \text { (lbs) }\end{array}$ & $\begin{array}{c}\text { Current Mean } \\
\text { Value }^{2} \text { (lbs) }\end{array}$ & $\begin{array}{c}\text { Fastener Holding } \\
\text { Strength Loss (\%) }\end{array}$ \\
\hline \multirow{2}{*}{ O3 } & Nail & 87.0 & 67.4 & 22.5 \\
& Staple & 155.9 & 104.7 & 32.8 \\
\hline \multirow{2}{*}{ P3 } & Nail & 151.2 & 93.7 & 38.2 \\
& Staple & 217.1 & 121.9 & 43.8 \\
\hline \multirow{2}{*}{ P5 } & Nail & 96.7 & 68.3 & 29.4 \\
\hline \hline
\end{tabular}

${ }^{1} 1990$

${ }^{2} 2000$ 


\subsection{Standard Nail Withdrawal Tests}

Standard nail withdrawal tests were performed throughout this project resulting in 300 data observations. A summary of descriptive statistics for five standard nail withdrawal tests is found in Table 4.9. EO3 had the highest initial maximum withdrawal mean value (81 lbs) while EP3 had the highest final mean value (20 lbs). Available literature data for comparison purposes of plywood panels does exist, but panel thickness' needed to be normalized in order to utilize that data. Ultimate withdrawal data expressed in the literature for $3 / 8$ " and $1 / 2$ " thick plywood was normalized to 1 " by dividing the ultimate withdrawal load by the panel thickness. This resulted in an average ultimate withdrawal value of $98 \mathrm{lbs}$ for a series of 245 tests (Elias 1982). Consequently, normalized coupon data from this project resulted in an average maximum fastener holding capacity of 76 lbs. This represents a loss of approximately $22 \%$ over an eighteen-year period, supporting the theory that the maximum fastener holding capacity of composite panels is on a decline.

Box plot diagrams were constructed by panel code (Figures 4.23-4.25) and by exposure (Figures 4.26-4.28). Results of the One-way ANOVA for both EO3 and WO3 show that there is a significant difference between the coupon values and the values obtained from each of the four remaining moisture phases. All plywood panels showed no significant difference between the coupon, $10 \% \mathrm{MC}$, and $12 \% \mathrm{MC}$ phases while there was a statistically significant difference between the coupon, second $6 \% \mathrm{MC}$, and third $6 \% \mathrm{MC}$ phases. Pair comparisons of the coupon data were drawn using a Tukey test and are shown in Table 4.10. A detailed summary of ANOVA tables is included in the Appendix I. 
Table 4.9 Summary statistics for five standard nail withdrawal tests.

\begin{tabular}{|c|c|c|c|c|c|c|c|c|c|c|c|c|c|c|c|}
\hline \multirow{4}{*}{ 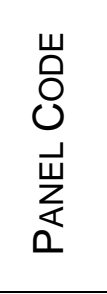 } & \multicolumn{15}{|c|}{ STATUS OF EXPOSURE } \\
\hline & \multicolumn{3}{|c|}{ Coupon } & \multicolumn{3}{|c|}{$10 \% \mathrm{MC}$} & \multicolumn{3}{|c|}{$2^{\text {nd }} 6 \% M C$} & \multicolumn{3}{|c|}{$12 \% \mathrm{MC}$} & \multicolumn{3}{|c|}{$3^{\text {rd }} 6 \% \mathrm{MC}$} \\
\hline & \multicolumn{15}{|c|}{ STATISTICS OF MAXIMUM NAIL WITHDRAWAL FORCE FOR STANDARD NAIL TESTS (LBS) } \\
\hline & $n^{1}$ & MEAN & $\begin{array}{l}\text { STD. } \\
\text { DEV. }\end{array}$ & $n^{1}$ & MEAN & $\begin{array}{l}\text { STD. } \\
\text { DEV. }\end{array}$ & $\mathrm{n}^{1}$ & MEAN & $\begin{array}{l}\text { STD. } \\
\text { DEV. }\end{array}$ & $\mathrm{n}^{1}$ & MEAN & $\begin{array}{l}\text { STD. } \\
\text { DEV. }\end{array}$ & $\mathrm{n}^{1}$ & MEAN & $\begin{array}{l}\text { STD. } \\
\text { DEV. }\end{array}$ \\
\hline EO3 & 10 & 81 & 15.521 & 10 & 55 & 15.000 & 10 & 27 & 16.665 & 10 & 59 & 18.414 & 10 & 15 & 6.896 \\
\hline EP3 & 10 & 76 & 15.702 & 10 & 67 & 9.620 & 10 & 21 & 4.435 & 10 & 73 & 17.928 & 10 & 20 & 13.256 \\
\hline EP5 & 10 & 38 & 11.245 & 10 & 39 & 14.598 & 10 & 17 & 7.625 & 10 & 57 & 17.913 & 10 & 10 & 3.795 \\
\hline WO3 & 10 & 50 & 12.841 & 10 & 32 & 6.099 & 10 & 15 & 6.667 & 10 & 31 & 10.587 & 10 & 9 & 5.116 \\
\hline WP3 & 10 & 57 & 19.535 & 10 & 58 & 16.248 & 10 & 17 & 9.615 & 10 & 60 & 18.403 & 10 & 11 & 4.881 \\
\hline WP5 & 10 & 41 & 17.296 & 10 & 44 & 8.468 & 10 & 15 & 4.059 & 10 & 52 & 13.180 & 10 & 13 & 9.637 \\
\hline
\end{tabular}

${ }^{1}$ sample size 

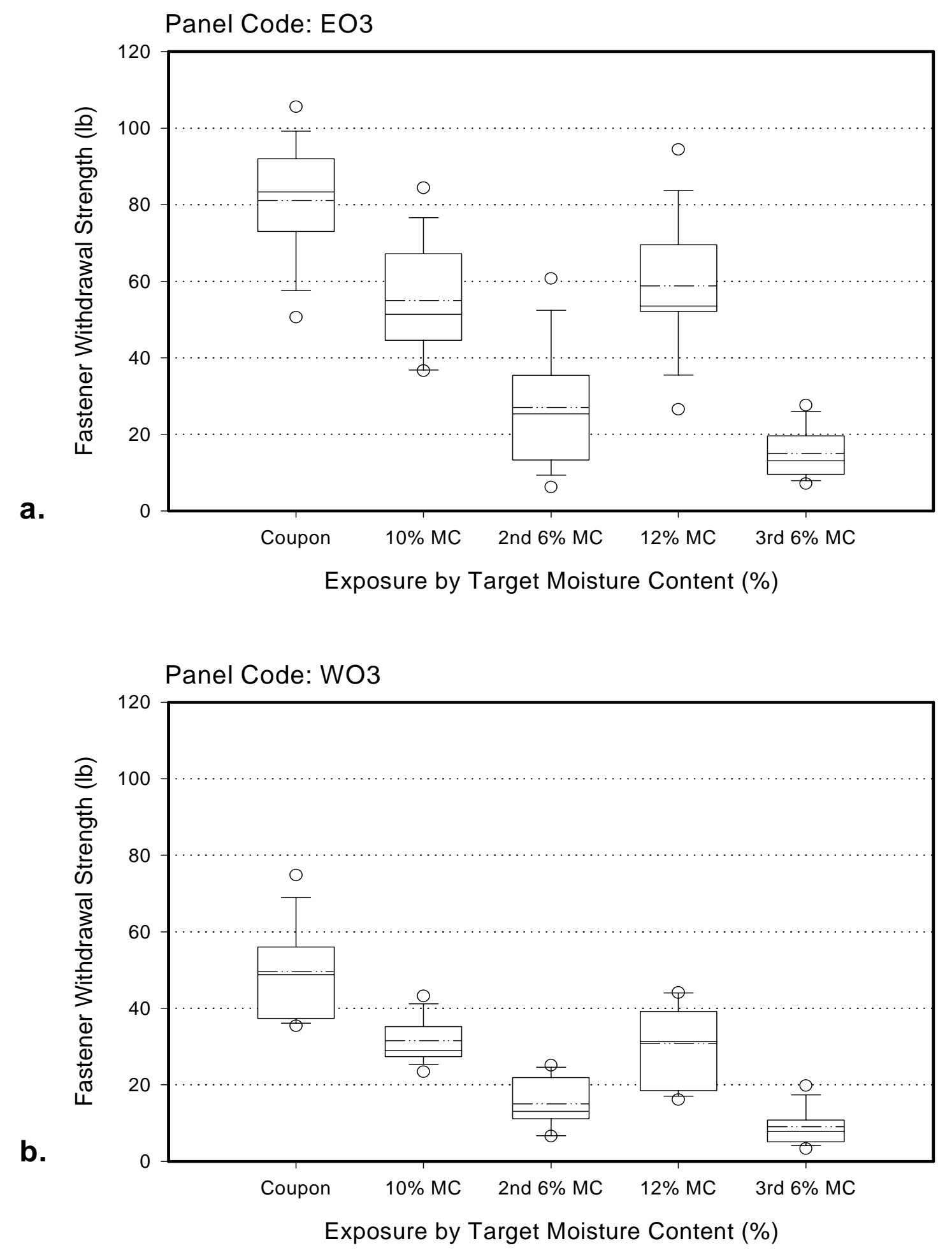

Figure 4.23 Changes in fastener holding capacity by exposure for standard nail withdrawal; a. panel code EO3, b. panel code WO3 

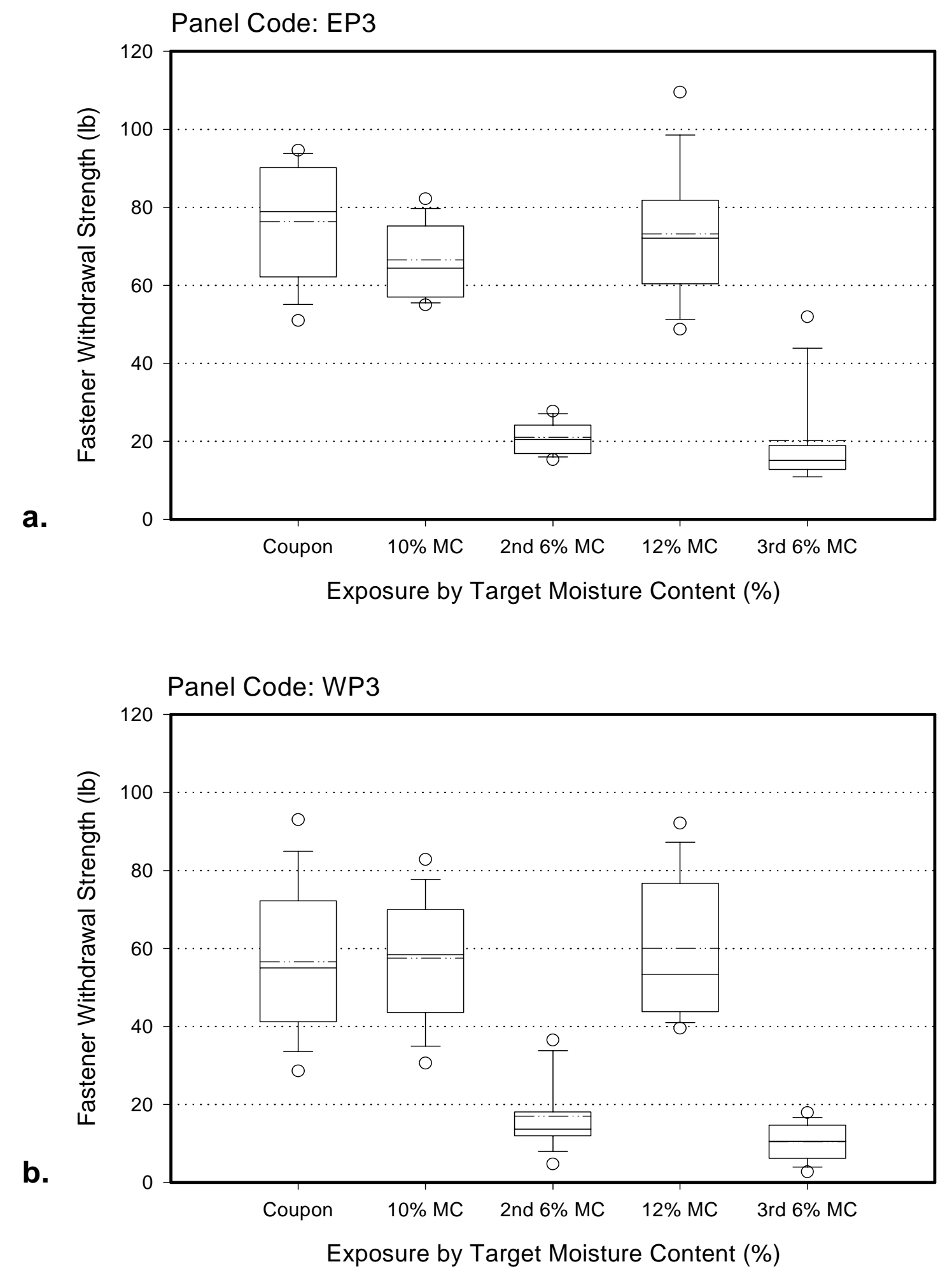

Figure 4.24 Changes in fastener holding capacity by exposure for standard nail withdrawal; a. panel code EP3, b. panel code WP3 

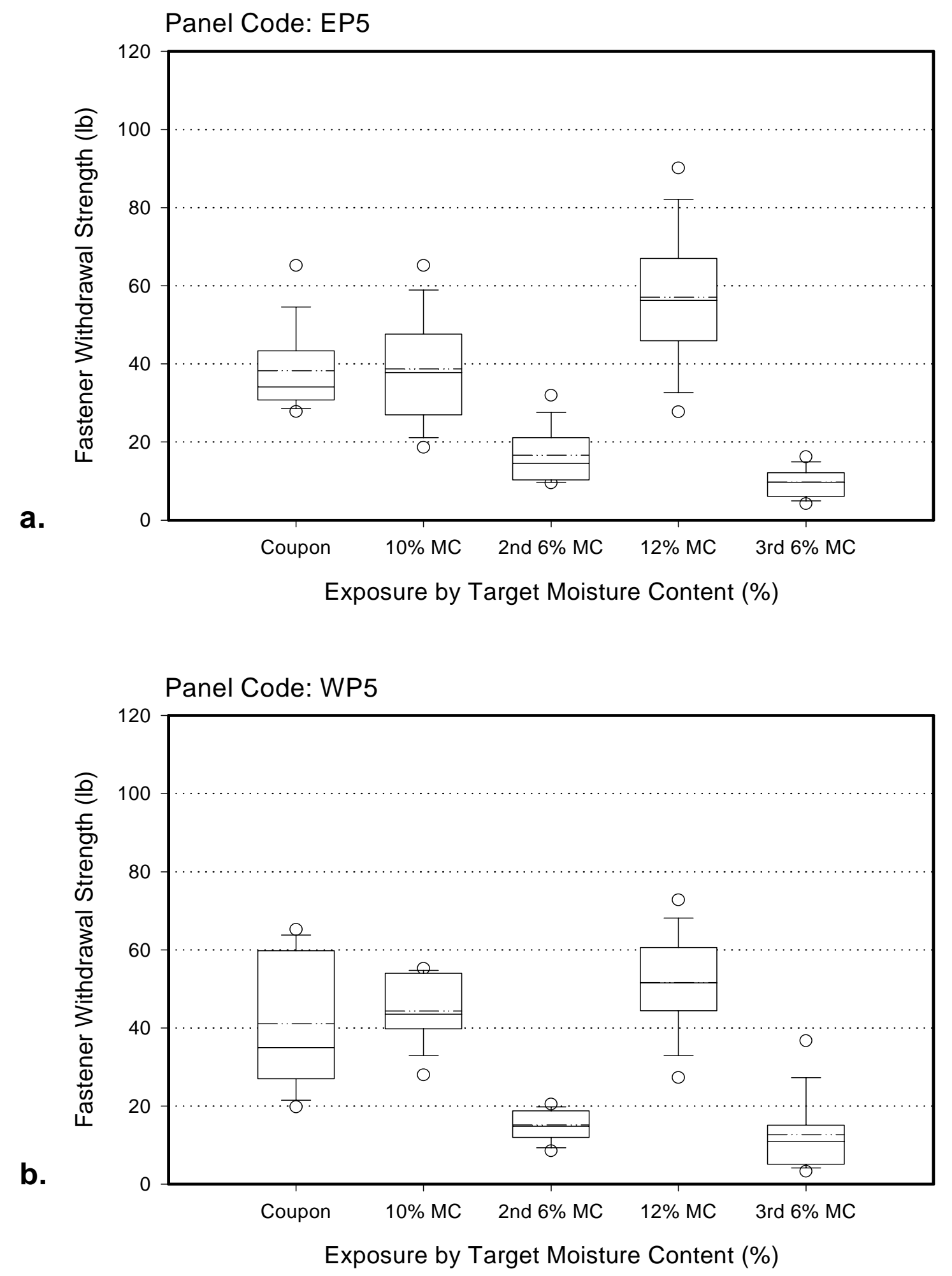

Figure 4.25 Changes in fastener holding capacity by exposure for standard nail withdrawal; a. panel code EP5, b. panel code WP5 

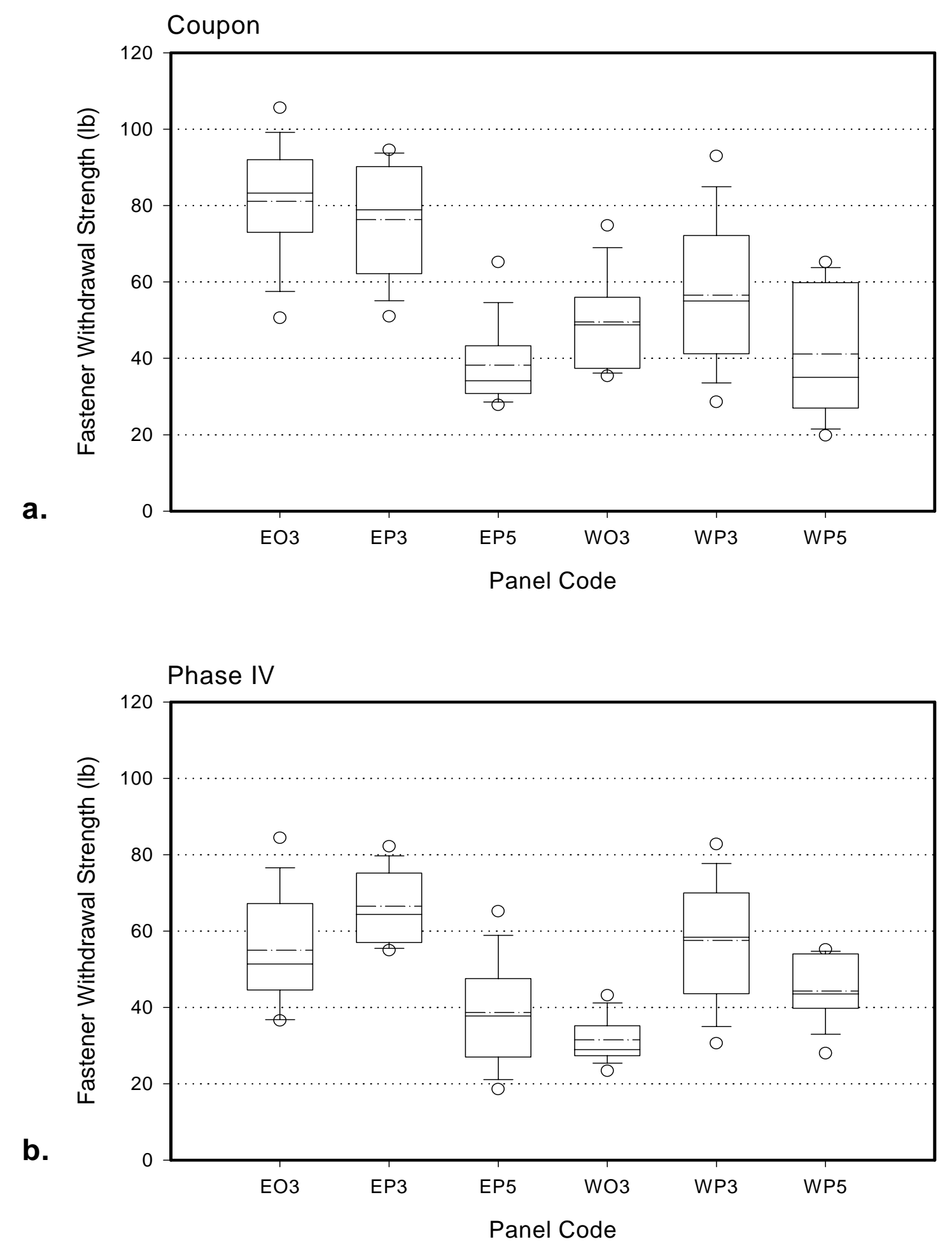

Figure 4.26 Comparison of fastener holding capacity of standard nail withdrawal by panel code; a. coupon phase, b. phase IV 

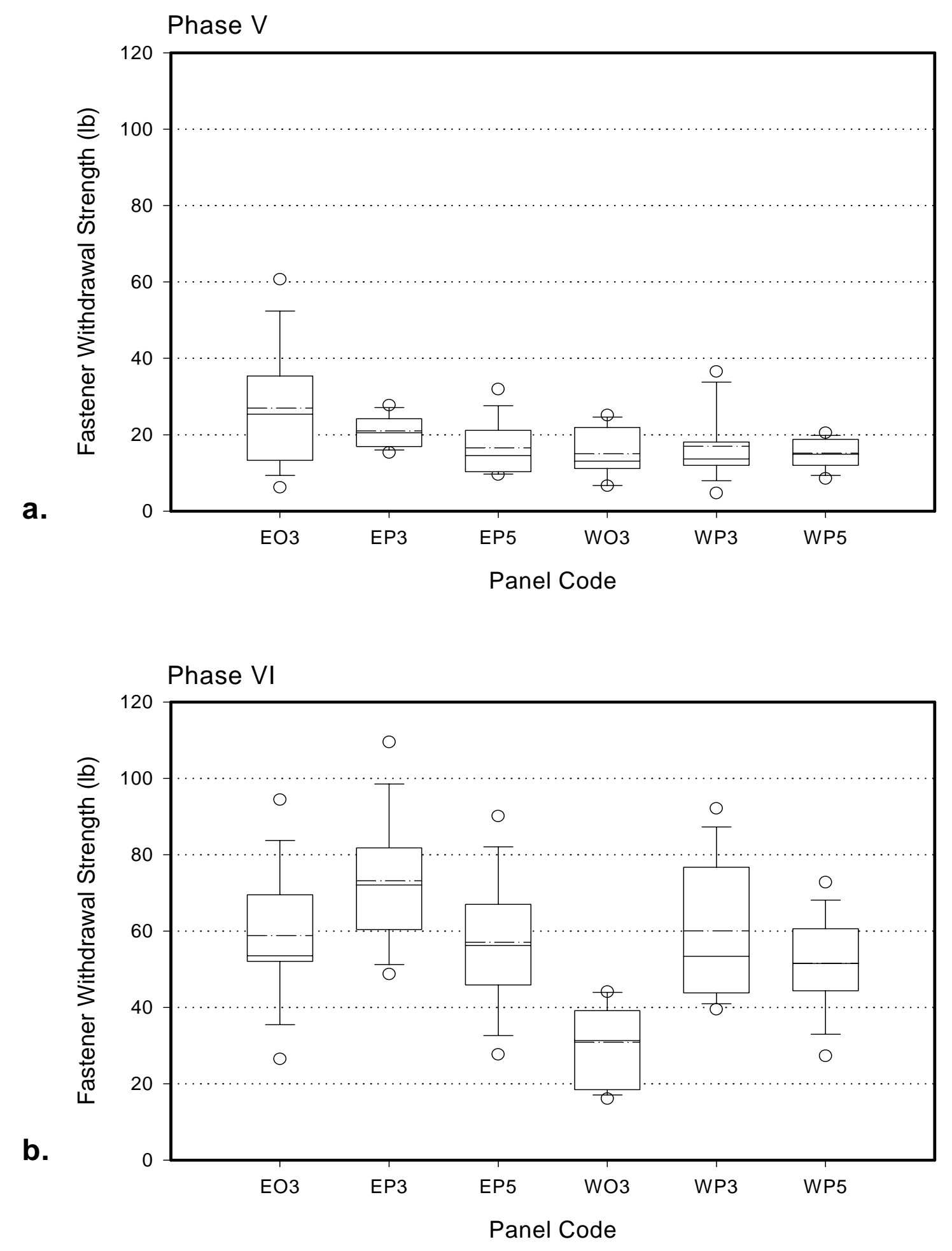

Figure 4.27 Comparison of fastener holding capacity of standard nail withdrawal by panel code; a. phase V, b. phase VI 


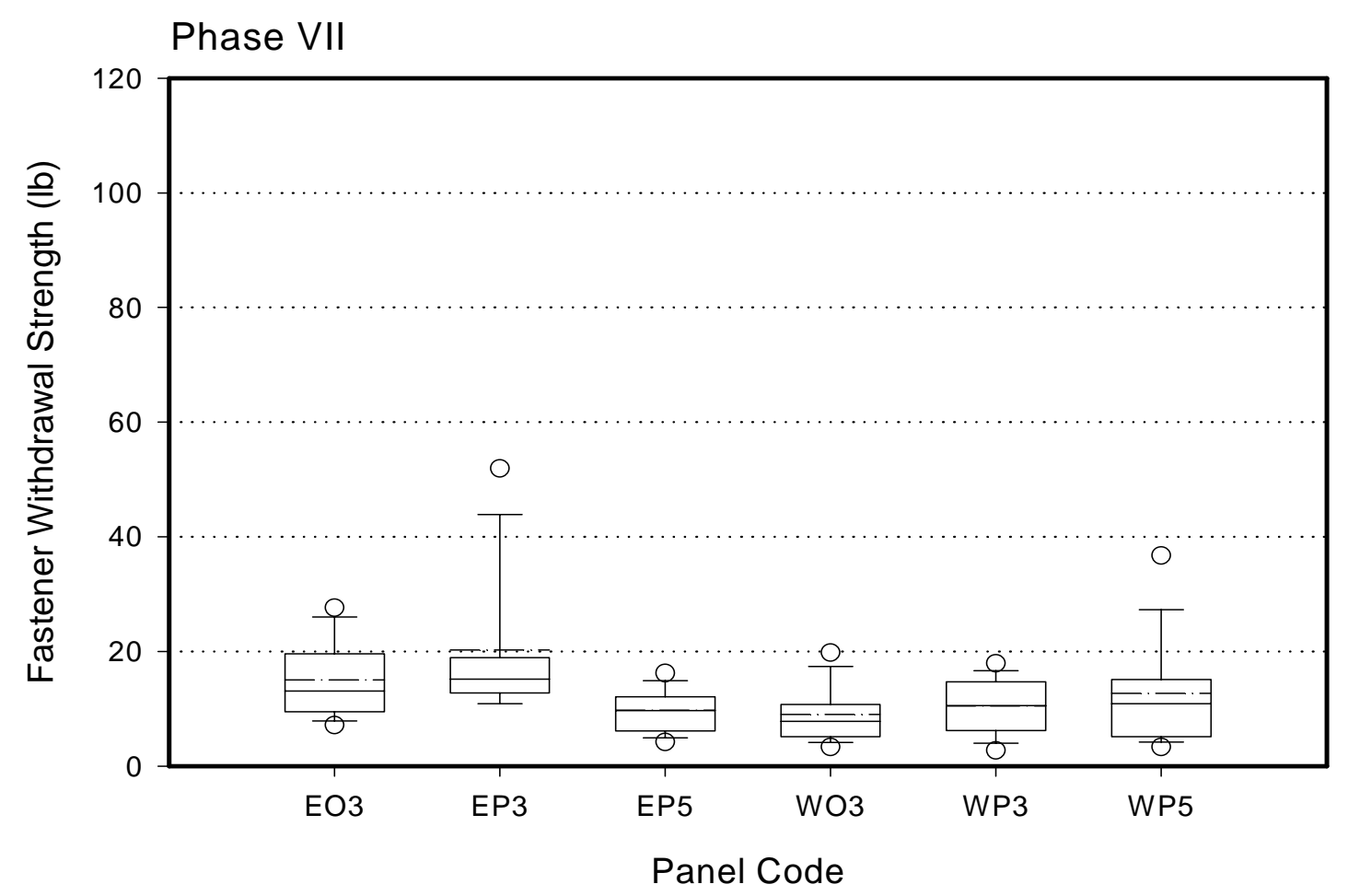

Figure 4.28 Comparison of fastener holding capacity of standard nail withdrawal by panel code for phase VII 
Table 4.10 Results of Tukey Test for standard nail withdrawal.

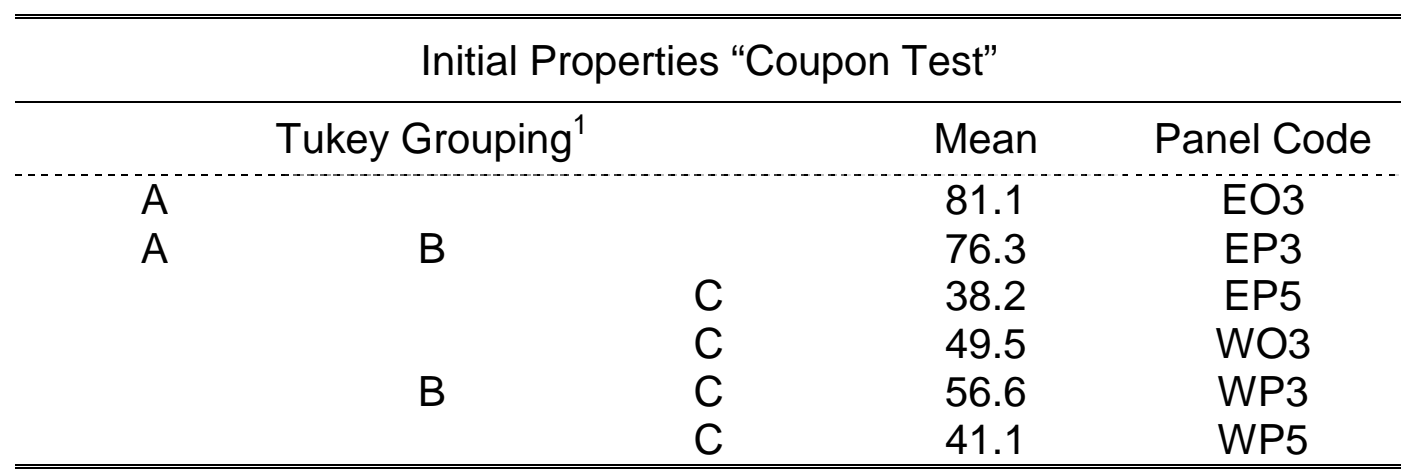

${ }^{1}$ Similar letters indicate panels with means that are not statistically different. 
In a direct comparison with flooring fastener tests, the standard nail withdrawal tests exhibited coupon $f_{\max }$ values that were close to the flooring fastener tests. However, after the first moisture cycle, the $\mathrm{f}_{\max }$ values of the standard nail tests dropped off abruptly and continued to be poor during each subsequent test. This showed that the standard nail withdrawal was more effected by panel degradation due to the simulated moisture cycling. In contrast, the $f_{\max }$ of the flooring fasteners declined at a much more gradual rate and the effect of panel degradation was less pronounced. Furthermore, the flooring fastener $f_{\max }$ values tended to fluctuate up and down in a gradual manner while the standard nail withdrawal values fluctuated up and down in a more exaggerated manner, depending on whether the cycle was experiencing a "summer" or a "winter" phase.

\subsection{Subfloor Thickness Change}

Average moisture content values as well as average thickness values were measured for ten samples of each panel type. This was performed at the beginning of the project (coupon values) as well as at the conclusion of each moisture phase. Calculations, including average percentage moisture content change, thickness change in millimeters, and percentage of shrinkage and swelling compared to percentage of moisture content change were done for the following intervals: coupon to $10 \% \mathrm{MC}, 10 \%$ $\mathrm{MC}$ to second $6 \% \mathrm{MC}$, second $6 \% \mathrm{MC}$ to $12 \% \mathrm{MC}$, and $12 \% \mathrm{MC}$ to third $6 \% \mathrm{MC}$ (Figures 4.29-4.34). Moisture content and thickness change measurements were straightforward and found by subtracting the initial value from the final value. This resulted in positive values during moisturizing intervals and negative values during 
a.

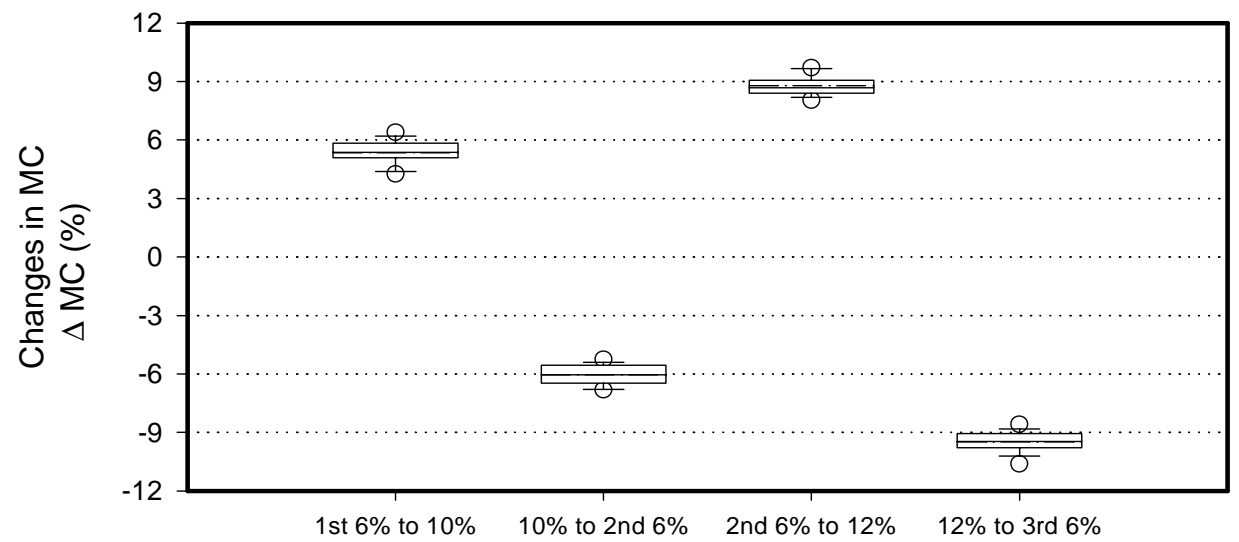

b.
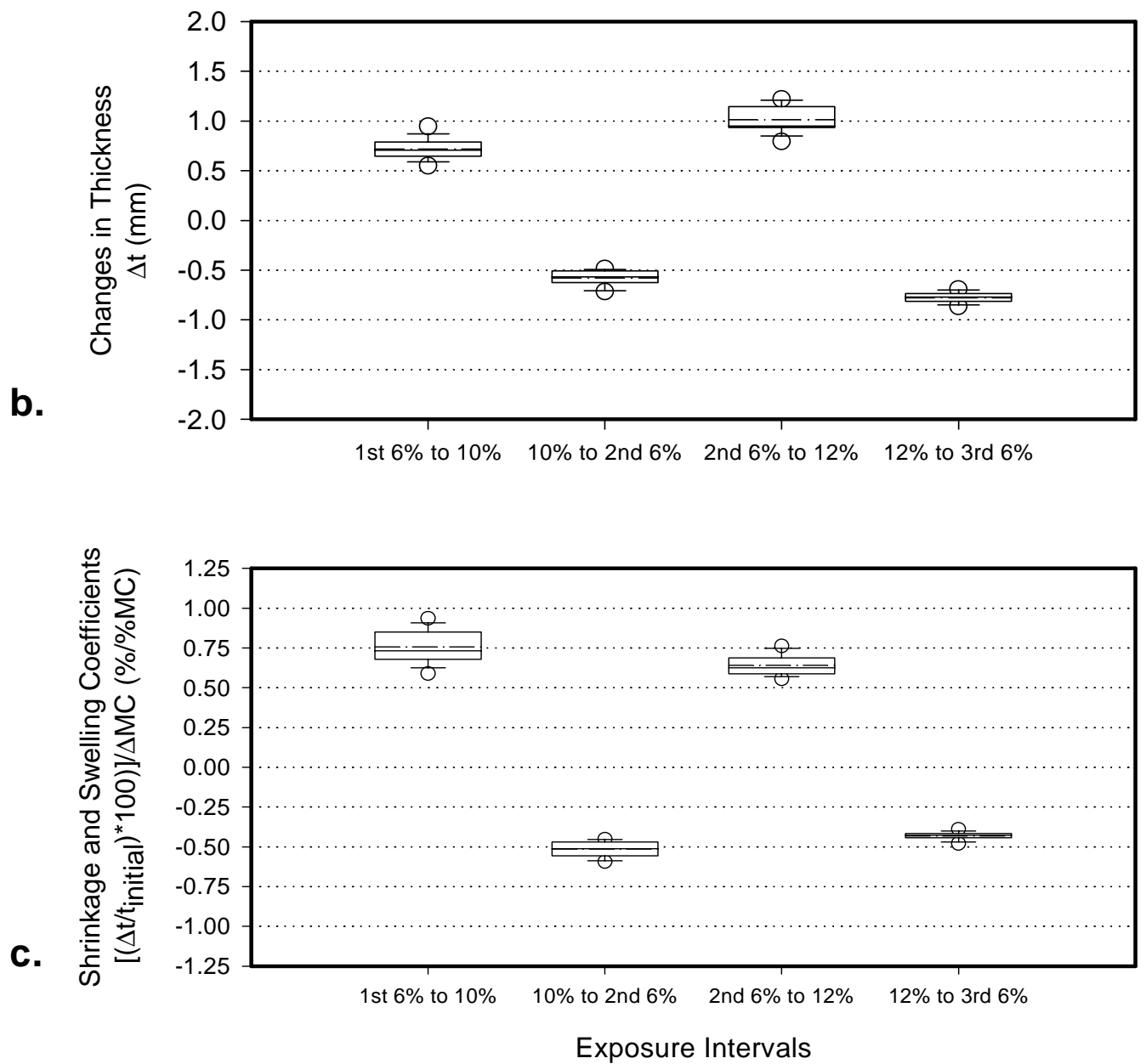

Figure 4.29 Moisture content change (a), thickness change (b), shrinkage and swelling ratios (c) of EO3 panels during exposure cycle. 

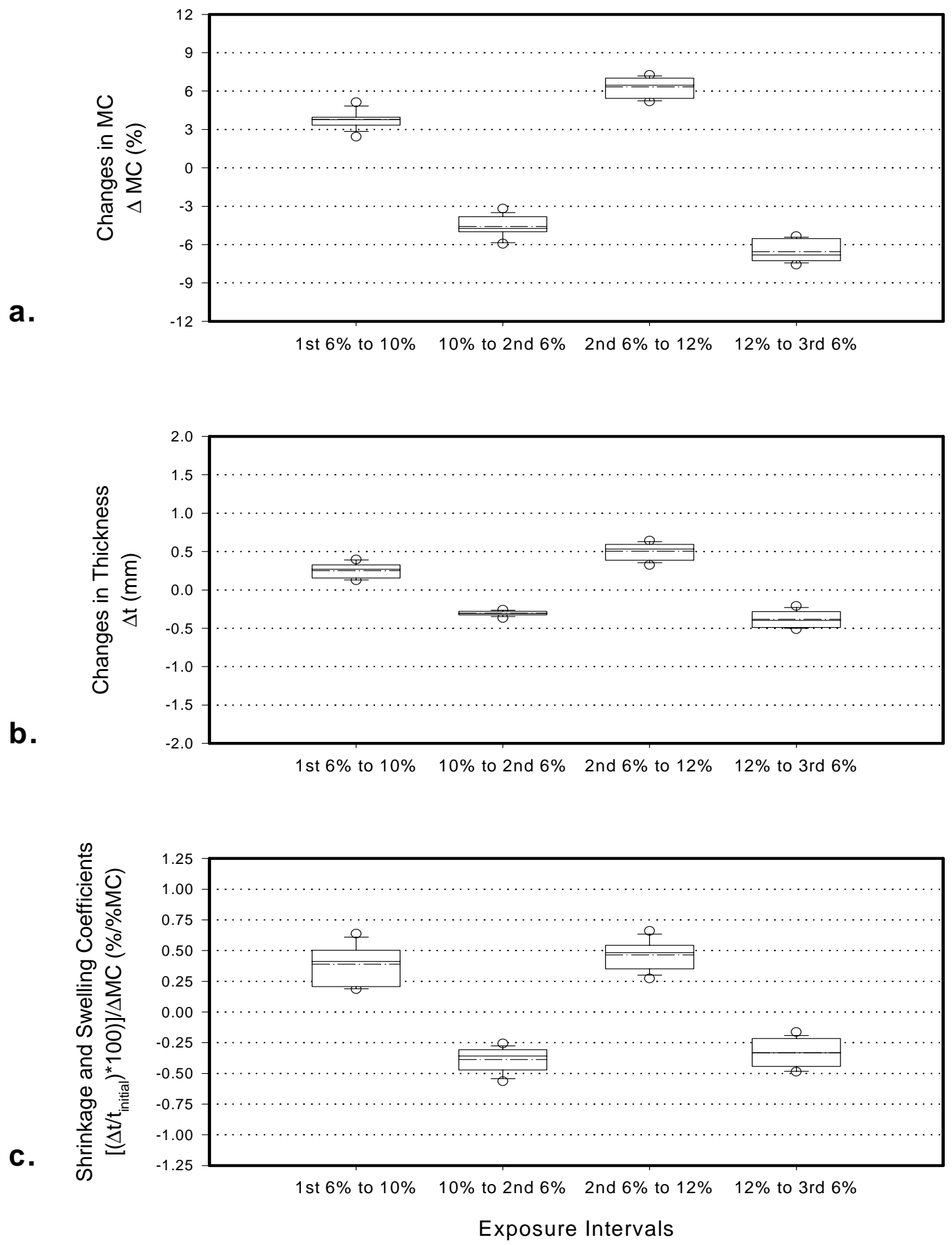

Figure 4.30 Moisture content change (a), thickness change (b), shrinkage and swelling ratios of EP3 panels during exposure cycle. 

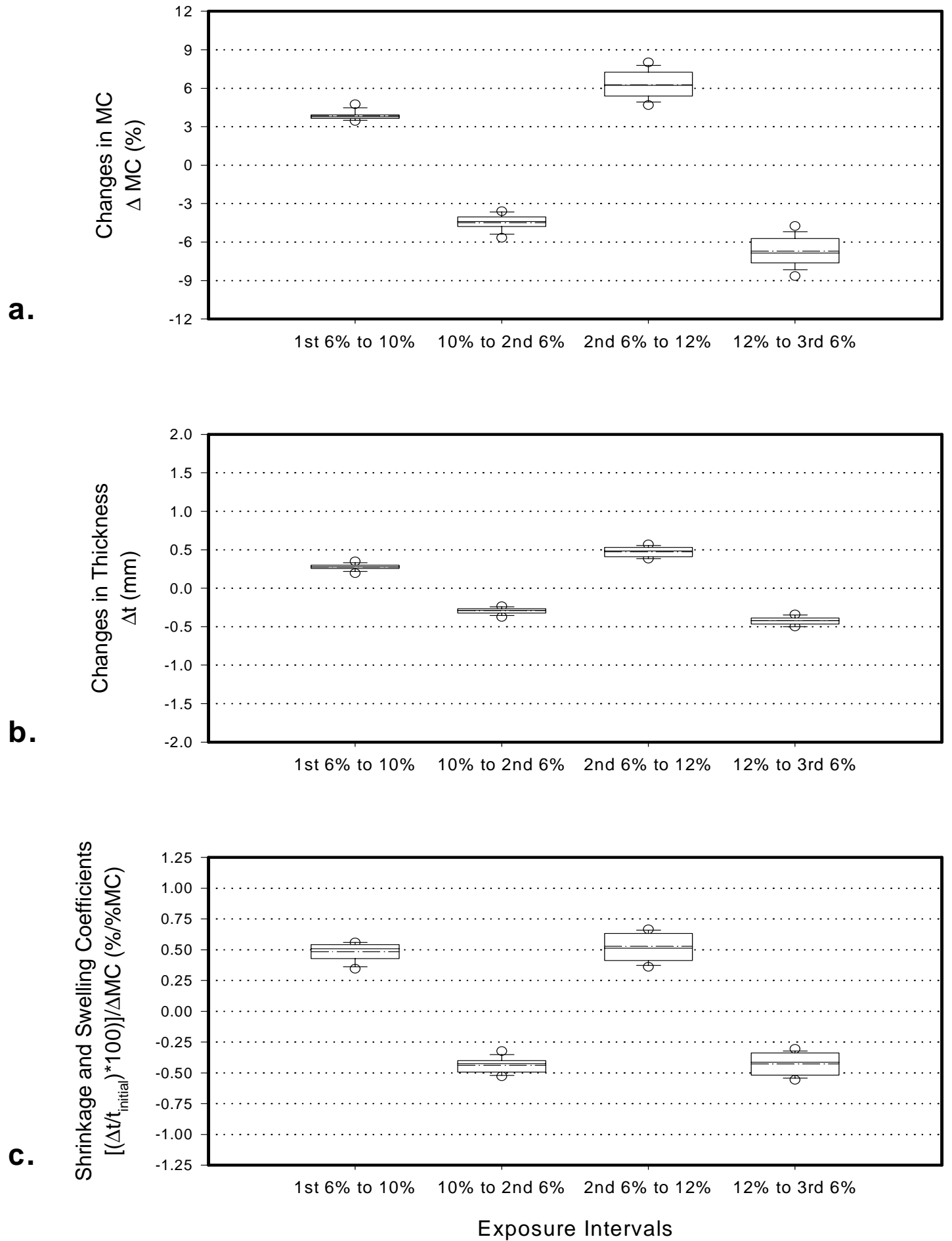

Figure 4.31 Moisture content change (a), thickness change (b), shrinkage and swelling ratios (c) of EP5 panels during exposure cycle. 

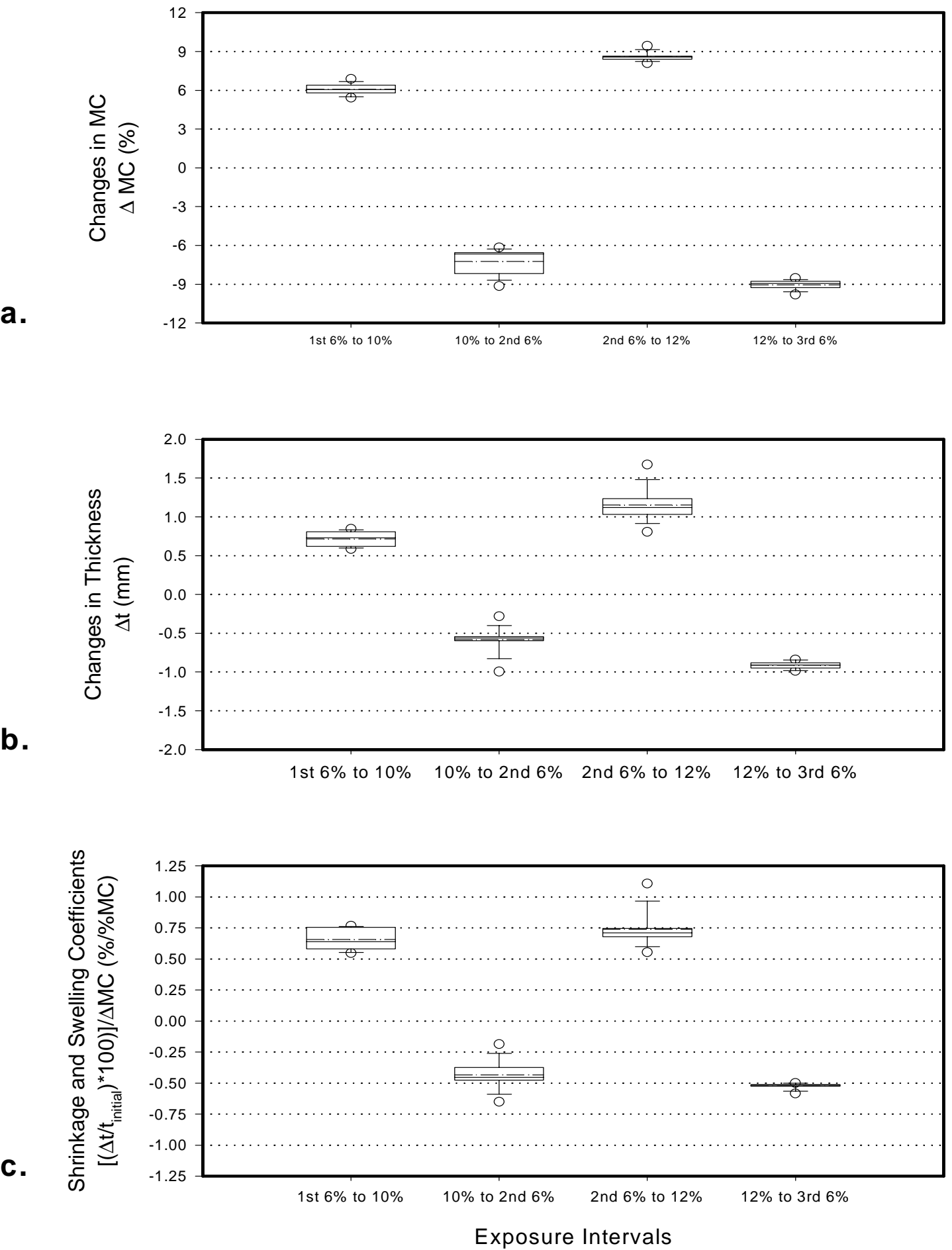

Figure 4.32 Moisture content change (a), thickness change (b), shrinkage and swelling ratios (c) of WO3 panels during exposure cycle. 
a.
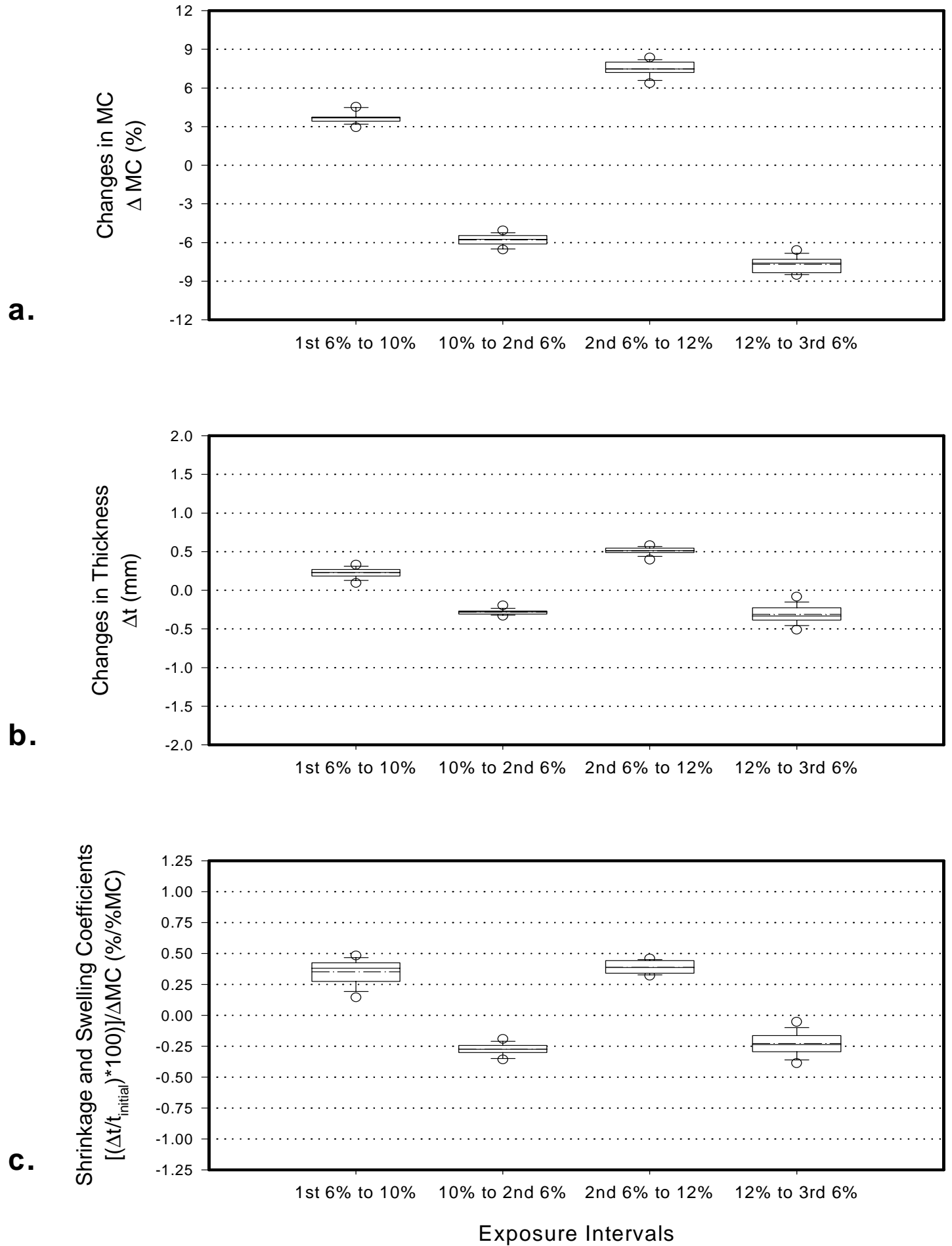

Figure 4.33 Moisture content change (a), thickness change (b), shrinkage and swelling ratios (c) of WP3 panels during exposure cycle. 

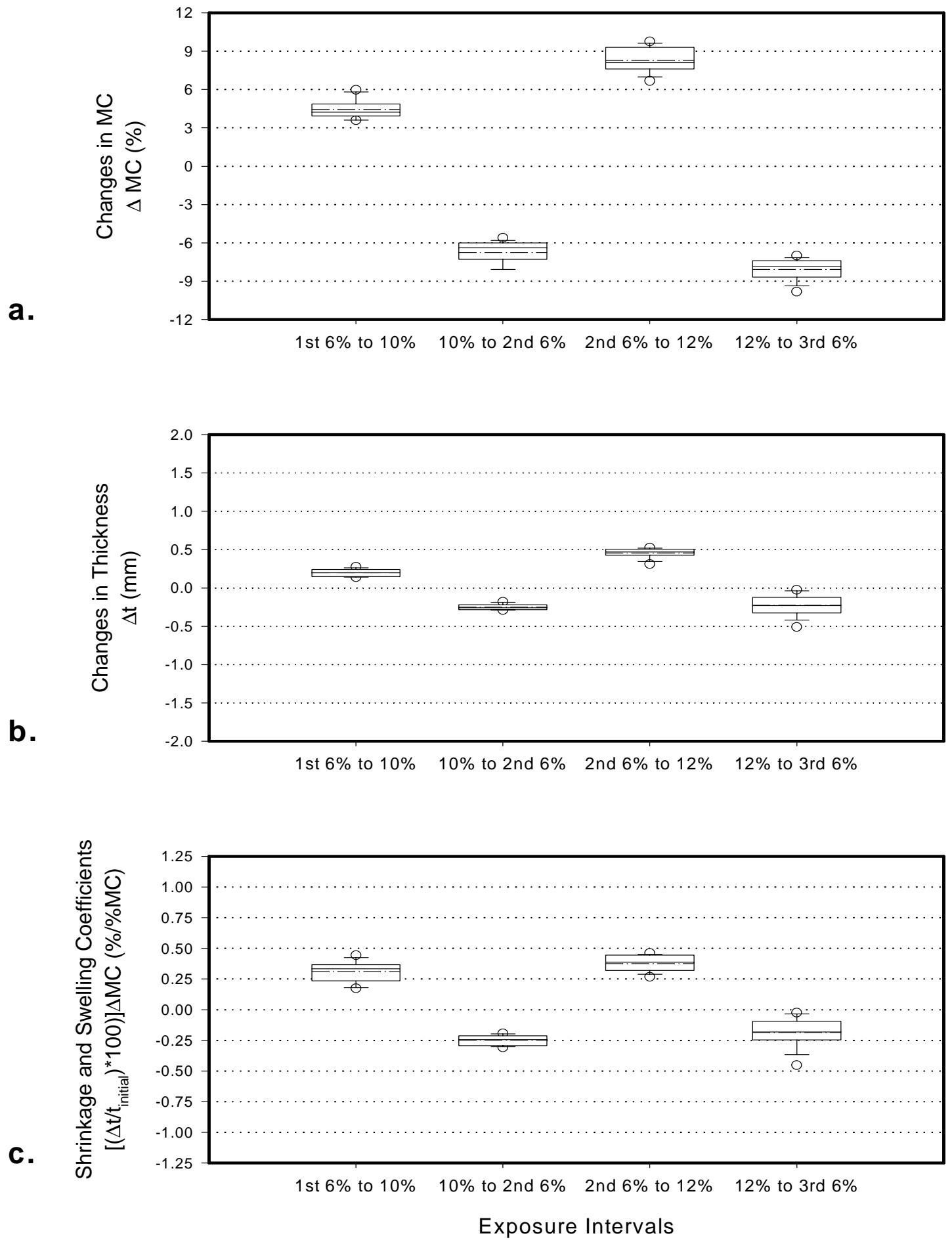

Figure 4.34 Moisture content change (a), thickness change (b), shrinkage and swelling ratios (c) of WP5 panels during exposure cycle. 
drying down intervals. Equation [3] approximated the shrinkage and swelling coefficients of the composite panels:

where:

$$
\beta=\left[\frac{\left(\frac{\Delta t}{t_{\text {initial }}}\right) x 100}{\Delta M C}\right]
$$

$\beta$ - shrinkage and swelling coefficients [\%/\%MC]

$\Delta \mathrm{t}$ - the change in thickness [mm]

$t_{\text {initial }}$ - the initial thickness $[\mathrm{mm}]$ and

$\Delta \mathrm{MC}$ - the change in moisture content [\%]

Shrinkage and swelling coefficients for OSB were approximately twice those found for plywood. This shows that OSB shrinks and swells more with changes in moisture content than does plywood. This may be best explained by the uniformity and homogeneity in the layers of the plywood products as compared to OSB. Due to the smaller relative size of the constituents in OSB as compared to plywood, there is a much greater chance in random variability within the panel. This may explain why OSB shrinks and swells to a greater degree than does plywood. However, coefficient values for WO3 experienced here $(0.65 \% / \% \mathrm{MC})$ are somewhat lower than published data for TS coefficients in WO3 (0.95\%/\%MC) (Wu and Suchsland 1997). 


\section{Chapter 5}

\section{Summary and Conclusions}

\subsection{Summary}

Fastener holding capacity was investigated for OSB and plywood material in relation to hardwood flooring performance in cyclic environmental conditions. The study involved the evaluation of composite panels from two geographic locations. The treatment was designed to simulate a two and one-half year moisture cycle that hardwood flooring would experience after installation. The main criterion for the evaluation was the fastener holding retention of the composite panels using 1.5 " long nails and staples. Supplemental fastener strength values were found by testing 2" long nails driven at an angle of $30^{\circ}$ as well as factory finished flooring with both 2" long nails and 1.5" long staples. Additionally, the thickness, swelling, and standard nail withdrawal strength of the panels were evaluated.

\subsection{Conclusions}

Based on the findings of the research outlined in this project, the following conclusions may be drawn:

1. Average strength loss for all panel types with both nails and staples over the entire moisture cycle was approximately $25 \%$.

2. Staples provided higher average strength values than did nails.

3. Plywood 3/4" thick provided the highest fastener holding capacity regardless of geographic location.

4. There is no significant correlation between fastener holding capacity and panel specific gravity for plywood panels while a positive correlation may exist between fastener holding capacity and panel specific gravity for OSB. 
5. Strength values for $\mathrm{O} 3, \mathrm{P} 3$, and P5 declined by an average of $30 \%$ over a ten-year period.

6. OSB proved to be more homogeneous than plywood based on mean horizontal density distribution values.

7. Shrinkage and swelling coefficients were higher in OSB than in plywood indicating that OSB tended to shrink and swell to a greater degree than did plywood.

8. The fastener holding capacity for standard nail withdrawal tests, for all panels, declined by an average of $77 \%$.

9. Coupon $f_{\max }$ values were similar for both standard nail withdrawal and flooring fastener withdrawal; standard nail withdrawal values declined at a much faster rate than did flooring fastener withdrawal values. 


\section{Recommendations}

In order to increase the knowledge in the area of composite panel products, flooring fastener withdrawal strength, and the effect of moisture cycling on hardwood flooring systems, several recommendations for further research may be made. These include:

- Continuing the simulated moisture cycle through one to several more phases in order to determine whether or not the current trend in fastener holding strength loss continues;

- Further investigating the relationship between fastener holding capacity and panel density;

- Increasing the number of replications to at least two for each panel/sub-floor combination;

- Performing fastener withdrawal tests utilizing 2" long nails and 2" long staples with all types of panels. 


\section{Literature Cited}

American Plywood Association. Residential and Commercial Design/Construction Guide. Form No. E3OQ. Tacoma, WA. November 1998.

American Society for Testing and Materials. 1996. Standard test methods for mechanical fasteners in wood. ASTM D 1761-88. ASTM, Philadelphia, PA.

American Society for Testing and Materials. 1996. Standard test methods for specific gravity of wood and wood-based materials. ASTM D 2395-93. ASTM, Philadelphia, PA.

American Society for Testing and Materials. 1996. Standard methods for use and calibration of hand-held moisture meters. ASTM D 4444-92. ASTM, Philadelphia, PA.

Atherton, George H., Kenneth E. Rowe, and Ken M. Bastendorff. 1980. Damping and slip of nailed joints. Wood Science, 15(1): 218-226.

Barnes, H. M. and D. E. Lyons. 1978. Fastener withdrawal loads for weathered and unweathered particleboard decking. Forest Prod. J. 28(4): 33-36.

Biblis, Evangelos J. 1989. Properties of commercial OSB from three southern pine mills. Forest Prod. J. 39(1):55-57.

Cassens, Daniel L. and William C. Feist. 1980. Finishing and maintaining wood floors. North Central Regional Extension Publication \#136. Forest Products Laboratory, Madison, WI.

Chou, Chun and Anton Polensek. 1987. Damping and stiffness of nailed joints in response to drying. Wood and Fiber Science, 19(1): 48-58.

Chow, Poo. 1976. Effects of moisture on the hardness of selected commercial woodbase panel materials. Forest Prod. J. 26(7): 41-44.

Chow, Poo, J. Dobbin McNatt, Steven J. Lambrechts and George Z. Gertner. 1988. Direct withdrawal and head pull-through performance of nails and staples in structural wood-based panel materials. Forest Prod. J. 38(6): 19-25.

Chow, Poo, J. Dobbin McNatt, John J. Janowiak and George Z. Gertner. 1985. Effects of test methods and exposure conditions on lateral nail and staple resistance of woodbase panel materials. Forest Prod. J. 35(9): 13-19.

DeBonis, A. Louis and J. Bodig. 1975. Nailed wood joints under combined loading. Wood Science and Technology, 9: 129-144.

Elias, Edward G. 1982. Performance-based testing for fastener holding. Report No. PT 82-5. American Plywood Association, Tacoma, Washington. 
Falk, Robert H., Daniel J. Vos, Steven M. Cramer, and Brent W. English. 2001. Performance of fasteners in wood flour-thermoplastic composite panels. Forest Prod. J. 51(1):55-61.

Feldborg, T. 1989. Timber joints in tension and nails in withdrawal under long-term loading and alternating humidity. Forest Prod. J. 39(11/12): 8-12.

Gromala, David S. 1985. Lateral nail resistance for ten common sheathing materials. Forest Prod. J. 35(9): 61-68.

Groom, Kevin M. and Robert J. Leichti. 1993. Load-withdrawal displacement characteristics of nails. Forest Prod. J. 43(1): 51-54.

Humphries, Micheal and Arno P. Schniewind. 1982. Behavior of wood columns under cyclic relative humidity. Wood Science 15(1): 44-48.

Jang, S. S., Y. Fujimoto and Y. Mataki. 1993. Fatigue behavior of framing-to-sheathing nailed joints. Forest Prod. J. 43(4): 63-69.

Kuklewski, Kenneth M., Paul R. Blakenhorn and Lester E. Rishel. 1985. Comparison of selected physical and mechanical properties of red maple (Acer Rubrum L.) and aspen (Populus Grandidentata Michx.) flakeboard. Wood and Fiber Science. 17(1): 11-21.

Lang, Elemer M., Joseph R. Loferski and J. Daniel Dolan. 1995. Hygroscopic deformation of wood-based composite panels. Forest Prod. J. 45(3): 67-70.

Lang, Elemer M., Joseph R. Loferski, Thomas E. McLain and Charles M. Moore. 1994. Performance of oak strip flooring systems under changing environmental conditions. Forest Prod. J. 44(5): 54-61.

Lang, Elemer M., Thomas E. McLain, and Joseph R. Loferski. 1992. Performance of wood floor systems under fluctuating moisture changes. Final Technical Report to the National Oak Flooring Manufacturers Association. Blackburg, VA.

Lehmann, W. F. 1978. Cyclic moisture conditions and their effect on strength and stability of structural flakeboards. Forest Prod. J. 28(6): 23-31.

Lu, Jing Ping and R. H. Leicester. 1997. Effect of cyclic humidity exposure on moisture diffusion in wood. Wood and Fiber Science 29(1): 68-74.

McLain, Thomas E. 1997. Design Axial withdrawal strength from wood: II. Plain-shank common wire nails. Forest Prod. J. 47(6): 103-109.

Milota, Micheal R. 1996. Calibration of moisture meters for western hardwood species. Forest Prod. J. 46(1):39-42. 
Milota, Micheal R. and Rakesh Gupta. 1996. Moisture meter correction factors for Dahurian Larch from the Russian Far East. Forest Prod. J. 46(6):91-93.

Mohammad, M. A. H. and lan Smith. 1996. Effects of multi-phase moisture conditioning on stiffness of nailed OSB-to-lumber connections. Forest Prod. J. 46(4): 76-83.

Palka, L. C. 1978. Effect of moisture content on the flexural properties of Douglas-fir plywood. Forest Prod. J. 28(11): 32-37.

Palka, L. C. and J. Hejjas. 1976. Calibration of moisture-meter readings for Douglas-fir plywood. Forest Prod. J. 26(12): 47-48.

Peralta, Perry N. 1995. Sorption of moisture by wood within a limited range of relative humidities. Wood and Fiber Science. 27(1): 13-21.

Polensek, Anton and Kenneth M. Bastendorff. 1987. Damping in nailed joints of lightframe wood buildings. Wood and Fiber Science, 19(2): 110-125.

Price, Eddie W. 1985. Creep behavior of flakeboards made with a mixture of southern species. Wood and Fiber Science, 17(1): 58-74.

Rammer, Douglas R. and Steve G. Winistorfer. 2001. Effect of moisture content on dowel-bearing strength. Wood and Fiber Science, 33(1): 126-139.

SAS. 1999. Version 8. SAS Institute Inc., Cary, NC.

SigmaPlot. 1997. Version 4.0. SPSS Inc., Chicago, III.

Suchland, Otto and Hong Xu. 1989. A simulation of the horizontal density distribution in a flakeboard. Forest Prod. J. 39(5): 29-33.

Wengert, Gene and Paul Bois. 1997. Evaluation of electric moisture meters in kiln-dried lumber. Forest Prod. J. 47(6):60-62.

Wu, Quinglin. 1997. Calibration of moisture meters for baldcypress (Taxodium Distichum). Forest Prod. J. 47(10): 77-78.

Wu, Quinglin. 1999. In-plane dimensional stability of oriented strand panel: effect of processing variables. Wood and Fiber Science. 31(1): 28-40.

Wu, Quinglin and Yukun Ren. 2000. Characterization of sorption behavior of oriented strandboard under long-term cyclic humidity exposure condition. Wood and Fiber Science. 32(4): 404-418. 
Wu, Quinglin and Otto Suchsland. 1997. Effect of moisture on the flexural properties of commercial oriented strandboards. Wood and Fiber Science. 29(1): 47-57.

Wu, Quinglin and Otto Suchsland. 1996. Linear expansion and its relationship to moisture content change for commercial oriented strandboards. Forest Prod. J. 46(11/12): 79-83.

Xu, Wei and Paul R. Steiner. 1995. A statistical characterization of the horizontal density distribution in flakeboard. Wood and Fiber Science. 27(2): 160-167.

Youngquist, John A. 1999. Wood-based composites and panel products. General Technical Report FPL-GTR-113. U.S. Department of Agriculture, Forest Service, FPL: 2-30/10. 
Appendices 


\section{Appendix I. Results of One-Way ANOVA for flooring fastener withdrawal and standard nail withdrawal.}

One Way Analysis of Variance

Thursday, March 15, 2001, 17:34:29

Data source: EO3N

Normality Test: $\quad$ Passed $\quad(P=0.420)$

Equal Variance Test: $\quad$ Passed $\quad(P=0.698)$

$\begin{array}{lcc}\text { Group } & \text { N } & \text { Missing } \\ \text { Coupon EO3N 29 } & 0 \\ \text { 10\% MC } & 24 & 0 \\ \text { 2nd 6\% MC } & 25 & 0 \\ \text { 12\% MC } & 25 & 0 \\ \text { 3rd 6\% MC } & 25 & 0\end{array}$

\begin{tabular}{lccc} 
Group & Mean & Std Dev & \multicolumn{1}{c}{ SEM } \\
Coupon EO3N76.924 & 14.270 & 2.650 \\
10\% MC & 77.833 & 17.756 & 3.624 \\
2nd 6\% MC & 68.200 & 13.481 & 2.696 \\
12\% MC & 68.400 & 15.740 & 3.148 \\
3rd 6\% MC & 65.440 & 17.614 & 3.523
\end{tabular}

Power of performed test with alpha $=0.050: 0.642$

The power of the performed test (0.642) is below the desired power of 0.800 .

You should interpret the negative findings cautiously.

$\begin{array}{lrrrrc}\text { Source of Variation } & \text { DF } & \text { SS } & \text { MS } & \text { F } & \text { P } \\ \text { Between Treatments } & 43246.436 & 811.609 & 3.251 & 0.014 \\ \text { Residual } & 12330707.206 & 249.652 & & \\ \text { Total } & 12733953.642 & & & \end{array}$

The differences in the mean values among the treatment groups are greater than would be expected by chance; there is a statistically significant difference $(P=0.014)$.

Multiple Comparisons versus Control Group (Tukey Test):

Comparisons for factor:

Comparison

Coupon EO3N vs. $10 \% \mathrm{MC}$

Coupon EO3N vs. $12 \% \mathrm{MC}$

Coupon EO3N vs. 2nd 6\% MC

Coupon EO3N vs. 3rd 6\% MC

$\begin{array}{cc}\text { Diff of Means } & \mathbf{p} \\ 0.909 & 5.000 \\ -8.524 & 5.000 \\ -8.724 & 5.000 \\ -11.484 & 5.000\end{array}$

$\mathbf{q}^{\prime}$

0.295

2.796

2.861

3.766

\section{$P<0.05$}

No

No

No

No 
Appendix I. (Cont.)

One Way Analysis of Variance

Thursday, March 15, 2001, 17:39:22

Data source: EO3S

Normality Test: $\quad$ Failed $(P=0.012)$

Test execution ended by user request, ANOVA on Ranks begun

Kruskal-Wallis One Way Analysis of Variance on RanksThursday, March 15, 2001, 17:39:23

Data source: EO3S

Group N Missing

Coupon EO3S $34 \quad 0$

$10 \%$ MC $25 \quad 0$

2nd $6 \%$ MC $25 \quad 0$

$12 \%$ MC $\quad 25 \quad 0$

3rd $6 \%$ MC $25 \quad 0$

Group Median 25\% $75 \%$

Coupon EO3S121.000113.800135.400

$10 \%$ MC $\quad 118.000104 .000126 .000$

2nd 6\% MC $\quad 99.00081 .750 \quad 111.750$

$12 \%$ MC $\quad 94.00072 .500 \quad 110.000$

3rd 6\% MC $\quad 99.00077 .750 \quad 111.000$

$\mathrm{H}=34.439$ with 4 degrees of freedom. $(\mathrm{P}=<0.001)$

The differences in the median values among the treatment groups are greater than would be expected by chance; there is a statistically significant difference $(P=<0.001)$

To isolate the group or groups that differ from the others use a multiple comparison procedure.

Multiple Comparisons versus Control Group (Dunn's Method) :

$\begin{array}{lrrr}\text { Comparison } & \text { Diff of Ranksp } & \mathbf{Q} & \mathbf{P}<\mathbf{0 . 0 5} \\ \text { 12\% MC vs Coupon EO3S } & 46.5025 & 4.546 & \text { Yes } \\ \text { 3rd 6\% MC vs Coupon EO3S } & 44.1024 & 4.312 & \text { Yes } \\ \text { 2nd 6\% MC vs Coupon EO3S } & 39.0623 & 3.819 & \text { Yes } \\ \text { 10\% MC vs Coupon EO3S } & 10.562 & 1.033 & \text { No }\end{array}$


Appendix I. (Cont.)

One Way Analysis of Variance

Thursday, March 15, 2001, 17:45:11

Data source: EP3N

Normality Test: $\quad$ Passed $\quad(P=0.659)$

Equal Variance Test: $\quad$ Passed $\quad(P=0.658)$

Group N Missing

CouponEP3N $34 \quad 0$

$10 \%$ MC $25 \quad 0$

2nd 6\% MC $25 \quad 0$

$12 \%$ MC $25 \quad 0$

3rd 6\% MC $25 \quad 0$

Group Mean Std Dev SEM

CouponEP3N92.118 $14.878 \quad 2.552$

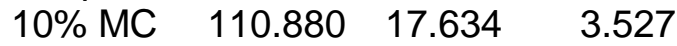

2nd 6\% MC $87.880 \quad 11.865 \quad 2.373$

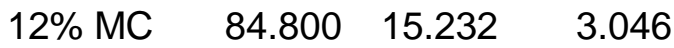

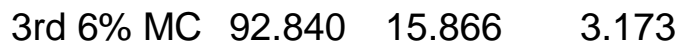

Power of performed test with alpha $=0.050: 1.000$

$\begin{array}{llllll}\text { Source of Variation } & \text { DF } & \text { SS } & \text { MS } & \text { F } & \text { P } \\ \text { Between Treatments } & 410308.069 & 2577.017 & 11.172 & <0.001 \\ \text { Residual } & 12929755.449 & 230.662 & & \\ \text { Total } & 13340063.519 & & & \end{array}$

The differences in the mean values among the treatment groups are greater than would be expected by chance; there is a statistically significant difference $(P=<0.001)$.

Multiple Comparisons versus Control Group (Dunnett's Method) :

Comparisons for factor:

Comparison

CouponEP3N vs. $10 \% \mathrm{MC}$

CouponEP3N vs. 3rd 6\% MC

CouponEP3N vs. 2nd $6 \% \mathrm{MC}$

CouponEP3N vs. $12 \% \mathrm{MC}$

$\begin{array}{cccc}\text { Diff of Means } & \mathbf{p} & \mathbf{q}^{\prime} & \mathbf{P}<\mathbf{0 . 0 5} \\ 18.762 & 5.000 & 4.689 & \text { Yes } \\ 0.722 & 4.000 & 0.181 & \text { No } \\ -4.238 & 3.000 & 1.059 & \text { No } \\ -7.318 & 2.000 & 1.829 & \text { No }\end{array}$


Appendix I. (Cont.)

t-test

Thursday, March 15, 2001, 17:47:32

Normality Test: $\quad$ Passed $\quad(P=0.277)$

Equal Variance Test: $\quad$ Passed $\quad(P=0.200)$

Group N Missing

CouponEP3N2 $35 \quad 0$

3rd 6\% MC $25 \quad 0$

Group Mean Std Dev SEM

CouponEP3N2 97.35414.987 2.533

3rd 6\% MC $\quad 91.68020 .081 \quad 4.016$

Difference $\quad 5.674$

$t=1.254$ with 58 degrees of freedom. $(P=0.215)$

95 percent confidence interval for difference of means: -3.382 to 14.731

The difference in the mean values of the two groups is not great enough to reject the possibility that the difference is due to random sampling variability. There is not a statistically significant difference between the i nput groups $(P=0.215)$.

Power of performed test with alpha $=0.050: 0.108$

The power of the performed test (0.108) is below the desired power of 0.800 .

You should interpret the negative findings cautiously. 
Appendix I. (Cont.)

One Way Analysis of Variance

Friday, March 16, 2001, 10:32:27

Data source: EP3S

Normality Test: $\quad$ Passed $\quad(P=0.810)$

Equal Variance Test: $\quad$ Failed $(P=0.010)$

Test execution ended by user request, ANOVA on Ranks begun

Kruskal-Wallis One Way Analysis of Variance on Ranks Friday, March 16, 2001, 10:32:27

Data source: EP3S

$\begin{array}{lcc}\text { Group } & \text { N } & \text { Missing } \\ \text { CouponEP3S } 34 & 0\end{array}$

$10 \%$ MC $25 \quad 0$

2nd 6\% MC $25 \quad 0$

$12 \%$ MC $25 \quad 0$

3rd 6\% MC $25 \quad 0$

Group Median 25\% 75\%

CouponEP3S117.400 107.600127.200

10\% MC $\quad 121.000105 .250130 .000$

2nd 6\% MC $\quad 91.70075 .650 \quad 107.575$

$12 \%$ MC $\quad 87.00076 .500 \quad 96.750$

3rd 6\% MC $\quad 68.00045 .250 \quad 91.250$

$H=73.427$ with 4 degrees of freedom. $(P=<0.001)$

The differences in the median values among the treatment groups are greater than would be expected by chance; there is a statistically significant difference $(P=<0.001)$

To isolate the group or groups that differ from the others use a multiple comparison procedure.

Multiple Comparisons versus Control Group (Dunn's Method) :

$\begin{array}{lclll}\text { Comparison } & \text { Diff of Ranks } & \mathbf{p} & \mathbf{Q} & \mathbf{P}<0.05 \\ \text { 3rd 6\% MC vs CouponEP3S } & 70.560 & 5 & 6.898 & \text { Yes } \\ \text { 12\% MC vs CouponEP3S } & 51.140 & 4 & 5.000 & \text { Yes } \\ \text { 2nd 6\% MC vs CouponEP3S } & 46.380 & 3 & 4.534 & \text { Yes } \\ \text { 10\% MC vs CouponEP3S } & 0.760 & 2 & 0.0743 & \text { No }\end{array}$


Appendix I. (Cont.)

One Way Analysis of Variance

Friday, March 16, 2001, 10:35:21

Data source: EP5N

Normality Test: $\quad$ Passed $\quad(P=0.599)$

Equal Variance Test: $\quad$ Passed $\quad(P=0.863)$

\begin{tabular}{|c|c|c|c|}
\hline Group & $\mathbf{N} \mathbf{M}$ & Missing & \\
\hline CouponEPs & $5 \mathrm{~N} 29$ & 0 & \\
\hline $10 \% \mathrm{MC}$ & 25 & 0 & \\
\hline 2nd $6 \% \mathrm{MC}$ & 25 & 0 & \\
\hline $12 \% \mathrm{MC}$ & 25 & 0 & \\
\hline 3rd 6\% MC & 25 & 0 & \\
\hline Group & Mean & Std Dev & SEM \\
\hline CouponEP & $5 \mathrm{~N} 74.317$ & $17 \quad 22.094$ & 4.103 \\
\hline $10 \% \mathrm{MC}$ & 84.720 & $\begin{array}{ll}0 & 17.482\end{array}$ & 3.496 \\
\hline 2nd 6\% MC & 62.560 & $\begin{array}{ll}0 & 16.472\end{array}$ & 3.294 \\
\hline $12 \% \mathrm{MC}$ & 75.200 & $0 \quad 21.637$ & 4.327 \\
\hline $3 \mathrm{rd} 6 \% \mathrm{MC}$ & 60.480 & $0 \quad 21.243$ & 4.249 \\
\hline
\end{tabular}

Power of performed test with alpha $=0.050: 0.973$

$\begin{array}{llllll}\text { Source of Variation } & \text { DF } & \text { SS } & \text { MS } & \text { F } & \text { P } \\ \text { Between Treatments } & 49975.477 & 2493.869 & 6.237 & <0.001 \\ \text { Residual } & 12449581.561 & 399.851 & & \\ \text { Total } & 12859557.038 & & & \end{array}$

The differences in the mean values among the treatment groups are greater than would be expected by chance; there is a statistically significant difference $(P=<0.001)$.

Multiple Comparisons versus Control Group (Dunnett's Method) :

Comparisons for factor:

Comparison

CouponEP5N vs. $10 \%$ MC

CouponEP5N vs. $12 \%$ MC

CouponEP5N vs. 2nd $6 \%$ MC

Diff of Means

10.403

0.883

p

q'

$P<0.05$

CouponEP5N vs. 3rd 6\% MC

$-11.757$

5.000

1.906

No

$-13.837$

4.000

0.162

No

2.154

No

3.000

2.536

Yes 
Appendix I. (Cont.)

t-test

Data Source: EP5N2f

Normality Test: $\quad$ Passed $\quad(P=0.154)$

Friday, March 16, 2001, 10:37:26

Equal Variance Test: $\quad$ Passed $\quad(P=0.945)$

Group N Missing

CoupEP5N2f $29 \quad 0$

3rd 6\% MC $25 \quad 0$

Group Mean Std Dev SEM

CoupEP5N2f $74.31722 .094 \quad 4.103$

3rd 6\% MC $105.96017 .451 \quad 3.490$

Difference $\quad-31.643$

$t=-5.773$ with 52 degrees of freedom. $(P=<0.001)$

95 percent confidence interval for difference of means: -42.642 to -20.643

The difference in the mean values of the two groups is greater than would be expected by chance; there is a statistically significant difference between the input groups $(P=<0.001)$.

Power of performed test with alpha $=0.050: 1.000$ 
Appendix I. (Cont.)

One Way Analysis of Variance

Friday, March 16, 2001, 10:40:02

Data source: EP5S

Normality Test: $\quad$ Passed $\quad(P=0.402)$

Equal Variance Test: $\quad$ Passed $\quad(P=0.688)$

Group N Missing

CouponEP5S $34 \quad 0$

$10 \%$ MC $26 \quad 0$

2nd $6 \%$ MC $25 \quad 0$

$12 \%$ MC $25 \quad 0$

3rd 6\% MC $25 \quad 0$

Group Mean Std Dev SEM

CouponEP5S100.588 14.126 2.423

$10 \%$ MC $\quad 101.385 \quad 19.661 \quad 3.856$

2nd 6\% MC $95.320 \quad 12.449 \quad 2.490$

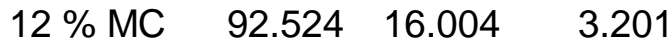

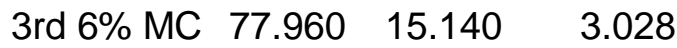

Power of performed test with alpha $=0.050: 1.000$

$\begin{array}{lllllc}\text { Source of Variation } & \text { DF } & \text { SS } & \text { MS } & \text { F } & \text { P } \\ \text { Between Treatments } & 49422.763 & 2355.691 & 9.686 & <0.001 \\ \text { Residual } & 13031616.075 & 243.201 & & \\ \text { Total } & 13441038.837 & & & \end{array}$

The differences in the mean values among the treatment groups are greater than would be expected by chance; there is a statistically significant difference $(P=<0.001)$.

Multiple Comparisons versus Control Group (Dunnett's Method) :

Comparisons for factor:

$\begin{array}{lrlll}\text { Comparison } & \text { Diff of Means p } & \mathbf{q}^{\prime} & \mathbf{P}<0.05 \\ \text { CouponEP5S vs. 10\% MC } & 0.796 & 5.000 & 0.196 & \text { No } \\ \text { CouponEP5S vs. 2nd 6\% MC } & -5.268 & 4.000 & 1.282 & \text { No } \\ \text { CouponEP5S vs. 12\% MC } & -8.064 & 3.000 & 1.963 & \text { No } \\ \text { CouponEP5S vs. 3rd 6\% MC } & -22.628 & 2.000 & 5.507 & \text { Yes }\end{array}$


Appendix I. (Cont.)

t-test

Data Source: EP5Sf

Normality Test: $\quad$ Passed $\quad(P=0.228)$

Friday, March 16, 2001, 10:41:50

Equal Variance Test: $\quad$ Passed $\quad(P=0.110)$

Group N Missing

CoupEP5Sf $34 \quad 0$

3rd $6 \%$ MC $25 \quad 0$

Group Mean Std Dev SEM

CoupEP5Sf100.588 $14.126 \quad 2.423$

3rd 6\% MC $79.880 \quad 16.969 \quad 3.394$

Difference $\quad 20.708$

$t=5.108$ with 57 degrees of freedom. $(P=<0.001)$

95 percent confidence interval for difference of means: 12.590 to 28.826

The difference in the mean values of the two groups is greater than would be expected by chance; there is a statistically significant difference between the input groups $(P=<0.001)$.

Power of performed test with alpha $=0.050: 1.000$ 
Appendix I. (Cont.)

One Way Analysis of Variance

Friday, March 16, 2001, 11:21:34

Data source: Standard Nail Coupon (All Pairwise Comparisons)

Normality Test: $\quad$ Passed $\quad(P=0.326)$

Equal Variance Test: $\quad$ Passed $\quad(P=0.307)$

$\begin{array}{lc}\text { Group } \quad \text { N } & \text { Missing } \\ \text { Coupon EO3 10 } & 0 \\ \text { Coupon EP3 10 } & 0 \\ \text { Coupon EP5 10 } & 0 \\ \text { Coupon WO3 10 } & 0 \\ \text { Coupon WP3 10 } & 0 \\ \text { Coupon WP5 10 } & 0\end{array}$

$\begin{array}{lrr}\text { Group Mean } & \text { Std Dev } & \text { SEM } \\ \text { Coupon EO381.100 } & 15.521 & 4.908 \\ \text { Coupon EP376.300 } & 15.702 & 4.965 \\ \text { Coupon EP538.230 } & 11.245 & 3.556 \\ \text { Coupon WO349.540 } & 12.841 & 4.061 \\ \text { Coupon WP356.560 } & 19.535 & 6.178 \\ \text { Coupon WP541.100 } & 17.296 & 5.470\end{array}$

Power of performed test with alpha $=0.050: 1.000$

$\begin{array}{lrrrrr}\text { Source of Variation } & \text { DF } & \text { SS } & \text { MS } & \text { F } & \text { P } \\ \text { Between Treatments } & 516141.533 & 3228.307 & 13.271 & <0.001 \\ \text { Residual } & 5413135.969 & 243.259 & & \\ \text { Total } & 5929277.502 & & & \end{array}$

The differences in the mean values among the treatment groups are greater than would be expected by chance; there is a statistically significant difference $(P=<0.001)$.

All Pairwise Multiple Comparison Procedures (Tukey Test):

Comparisons for factor:

Comparison

Coupon EO3 vs. Coupon EP5

Coupon EO3 vs. Coupon WP5

Diff of Means $p$

$42.870 \quad 6$

40.0006

Coupon EO3 vs. Coupon WO3

Coupon EO3 vs. Coupon WP3

Coupon EO3 vs. Coupon EP3

Coupon EP3 vs. Coupon EP5

Coupon EP3 vs. Coupon WP5

Coupon EP3 vs. Coupon WO3

Coupon EP3 vs. Coupon WP3

Coupon WP3 vs. Coupon EP5

Coupon WP3 vs. Coupon WP5

Coupon WP3 vs. Coupon WO3

Coupon WO3 vs. Coupon EP5

Coupon WO3 vs. Coupon WP5

Coupon WP5 vs. Coupon EP5

31.5606

$24.540 \quad 6$

4.8006

38.0706

35.2006

$26.760 \quad 6$

19.7406

18.3306

15.4606

7.0206

11.3106

$8.440 \quad 6$

$2.870 \quad 6$

$\begin{array}{ll}\mathbf{q} & \mathbf{P}<0.05 \\ 8.692 & \text { Yes } \\ 8.110 & \text { Yes } \\ 6.399 & \text { Yes } \\ 4.976 & \text { Yes } \\ 0.973 & \text { No } \\ 7.719 & \text { Yes } \\ 7.137 & \text { Yes } \\ 5.426 & \text { Yes } \\ 4.002 & \text { No } \\ 3.716 & \text { No } \\ 3.135 & \text { No } \\ 1.423 & \text { No } \\ 2.293 & \text { No } \\ 1.711 & \text { No } \\ 0.582 & \text { No }\end{array}$


Appendix I. (Cont.)

One Way Analysis of Variance

Friday, March 16, 2001, 11:06:07

Data source: Standard Nail EO3

Normality Test: $\quad$ Passed $\quad(P=0.632)$

Equal Variance Test: $\quad$ Passed $\quad(P=0.442)$

$\begin{array}{lrc}\text { Group } & \text { N } & \text { Missing } \\ \text { Coupon EO3 } 10 & 0 \\ \text { 10\% MC } & 10 & 0 \\ \text { 2nd 6\% MC } & 10 & 0 \\ \text { 12\% MC } & 10 & 0 \\ \text { 3rd 6\% MC } & 10 & 0\end{array}$

\begin{tabular}{lrrr} 
Group & Mean & Std Dev & \multicolumn{1}{c}{ SEM } \\
Coupon EO381.100 & 15.521 & 4.908 \\
10\% MC & 54.980 & 15.000 & 4.743 \\
2nd 6\% MC & 26.980 & 16.665 & 5.270 \\
12\% MC & 58.770 & 18.414 & 5.823 \\
3rd 6\% MC & 15.010 & 6.896 & 2.181
\end{tabular}

Power of performed test with alpha $=0.050: 1.000$

\begin{tabular}{|c|c|c|c|c|}
\hline $\begin{array}{l}\text { Source of Variation } \\
\text { Between Treatments }\end{array}$ & $\begin{array}{l}\text { DF SS } \\
427885.067\end{array}$ & $\begin{array}{c}\text { MS } \\
6971.267\end{array}$ & $\begin{array}{c}\mathbf{F} \\
30.840\end{array}$ & $\begin{array}{c}\mathbf{P} \\
<0.001\end{array}$ \\
\hline 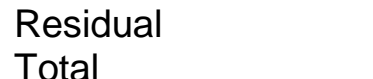 & $\begin{array}{l}4510172.222 \\
4938057289\end{array}$ & 226.049 & & \\
\hline
\end{tabular}

The differences in the mean values among the treatment groups are greater than would be expected by chance; there is a statistically significant difference $(P=<0.001)$.

Multiple Comparisons versus Control Group (Dunnett's Method) :

Comparisons for factor:

Comparison

Coupon EO3 vs. $12 \%$ MC

Coupon EO3 vs. 10\% MC

Coupon EO3 vs. 2nd 6\% MC

Coupon EO3 vs. 3rd 6\% MC

$\begin{array}{rlll}\text { Diff of Meansp } & \mathbf{q}^{\prime} & \mathbf{P}<\mathbf{0 . 0 5} \\ -22.330 & 5.000 & 3.321 & \text { Yes } \\ -26.120 & 4.000 & 3.885 & \text { Yes } \\ -54.120 & 3.000 & 8.049 & \text { Yes } \\ -66.090 & 2.000 & 9.829 & \text { Yes }\end{array}$


Appendix I. (Cont.)

One Way Analysis of Variance

Friday, March 16, 2001, 11:08:36

Data source: Standard Nail EP3

Normality Test: $\quad$ Passed $\quad(P=0.229)$

Equal Variance Test: $\quad$ Passed $\quad(P=0.052)$

$\begin{array}{lrc}\text { Group } & \mathbf{N} & \text { Missing } \\ \text { Coupon EP3 } 10 & 0 \\ \text { 10\% MC } & 10 & 0 \\ \text { 2nd 6\% MC } & 10 & 0 \\ \text { 12\% MC } & 10 & 0 \\ \text { 3rd 6\% MC } & 10 & 0\end{array}$

Group Mean Std Dev SEM

Coupon EP376.300 $15.702 \quad 4.965$

$\begin{array}{llll}10 \% & \text { MC } \quad 66.540 & 9.620 & 3.042\end{array}$

2nd 6\% MC $21.010 \quad 4.435 \quad 1.402$

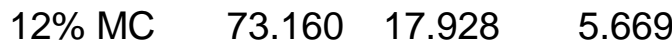

3rd 6\% MC $20.230 \quad 13.256 \quad 4.192$

Power of performed test with alpha $=0.050: 1.000$

$\begin{array}{llllll}\text { Source of Variation } & \text { DF } & \text { SS } & \text { MS } & \text { F } & \text { P } \\ \text { Between Treatments } & 432178.367 & 8044.592 & 46.996 & <0.001 \\ \text { Residual } & 457702.858 & 171.175 & & \\ \text { Total } & 4939881.225 & & & \end{array}$

The differences in the mean values among the treatment groups are greater than would be expected by chance; there is a statistically significant difference $(P=<0.001)$.

Multiple Comparisons versus Control Group (Dunnett's Method) :

Comparisons for factor:

Comparison

Coupon EP3 vs. 12\% MC

Coupon EP3 vs. $10 \% \mathrm{MC}$

Coupon EP3 vs. 2nd 6\% MC

Coupon EP3 vs. 3rd 6\% MC
Diff of Means p

$-3.140$

$-9.760$

$-55.290$

$-56.070$

5.000

$q^{\prime} \quad P<0.05$

0.537 No

1.668 No

9.450 Yes

9.583 Yes 
Appendix I. (Cont.)

One Way Analysis of Variance

Friday, March 16, 2001, 11:11:28

Data source: Standard Nail EP5

Normality Test: $\quad$ Passed $\quad(P=0.107)$

Equal Variance Test: $\quad$ Failed $(P=0.028)$

Test execution ended by user request, ANOVA on Ranks begun

Kruskal-Wallis One Way Analysis of Variance on Ranks Friday, March 16, 2001, 11:11:28

Data source: Data 1 in Notebook

$\begin{array}{lrc}\text { Group } & \mathbf{N} & \text { Missing } \\ \text { Coupon EP5 } 10 & 0 \\ \text { 10\% MC } & 10 & 0 \\ \text { 2nd 6\% MC } & 9 & 0 \\ \text { 12\% MC } & 10 & 0 \\ \text { 3rd 6\% MC } & 10 & 0\end{array}$

Group Median 25\% $75 \%$

Coupon EP5 $34.100 \quad 30.800 \quad 43.300$

$10 \%$ MC $\quad 37.800 \quad 27.000 \quad 47.600$

2nd 6\% MC $\quad 14.500 \quad 10.300 \quad 21.100$

$12 \%$ MC $\quad 56.250 \quad 45.900 \quad 67.000$

3rd 6\% MC $\quad 9.700 \quad 6.100 \quad 12.100$

$H=35.477$ with 4 degrees of freedom. $(P=<0.001)$

The differences in the median values among the treatment groups are greater than would be expected by chance; there is a statistically significant difference $(P=<0.001)$

To isolate the group or groups that differ from the others use a multiple comparison procedure.

Multiple Comparisons versus Control Group (Dunn's Method) :

Comparison

3 rd $6 \%$ MC vs Coupon EP5

2nd $6 \%$ MC vs Coupon EP5

$12 \% \mathrm{MC}$ vs Coupon EP5

$10 \%$ MC vs Coupon EP5

Test Needed

$\begin{array}{cl}\text { Diff of Ranks p } & \mathbf{Q} \\ 23.500 \quad 5 & 3.678 \\ 16.678 \quad 4 & 2.541 \\ 9.600 \quad 3 & 1.502 \\ 1.421 \mathrm{E}-015 & 2\end{array}$


Appendix I. (Cont.)

One Way Analysis of Variance

Data source: Standard Nail Phase VII (All Pairwise Comparisons)

Normality Test: Failed $(P=0.003)$

Test execution ended by user request, ANOVA on Ranks begun

Kruskal-Wallis One Way Analysis of Variance on Ranks Friday, March 16, 2001, 11:25:39

Data source: Standard Nail Phase VII

$\begin{array}{lcc}\text { Group } & \mathbf{N} & \text { Missing } \\ \text { EO3 } & 10 & 0 \\ \text { EP3 } & 10 & 0 \\ \text { EP5 } & 10 & 0 \\ \text { WO3 } & 10 & 0 \\ \text { WP3 } & 10 & 0 \\ \text { WP5 } & 10 & 0\end{array}$

$\begin{array}{lrrl}\text { Group Median } & \mathbf{2 5 \%} & \mathbf{7 5 \%} \\ \text { EO3 } & 13.050 & 9.500 & 19.600 \\ \text { EP3 } & 15.150 & 12.800 & 18.900 \\ \text { EP5 } & 9.700 & 6.100 & 12.100 \\ \text { WO3 } & 7.800 & 5.100 & 10.800 \\ \text { WP3 } & 10.550 & 6.200 & 14.700 \\ \text { WP5 } & 10.850 & 5.100 & 15.100\end{array}$

$H=13.154$ with 5 degrees of freedom. $(P=0.022)$

The differences in the median values among the treatment groups are greater than would be expected by chance; there is a statistically significant difference $(P=0.022)$

To isolate the group or groups that differ from the others use a multiple comparison procedure.

All Pairwise Multiple Comparison Procedures (Student-Newman-Keuls Method) :

$\begin{array}{lrlll}\text { Comparison } & \text { Diff of Ranksp } & \mathbf{q} & \text { P }<.05 \\ \text { EP3 vs WO3 } & 241.5006 & 4.373 & \text { Yes } \\ \text { EP3 vs EP5 } & 201.500 & 5 & 4.371 & \text { Yes } \\ \text { EP3 vs WP3 } & 173.500 & 4 & 4.693 & \text { Yes } \\ \text { EP3 vs WP5 } & 162.000 & 3 & 5.819 & \text { Yes } \\ \text { EP3 vs EO3 } & 70.500 & 2 & 3.768 & \text { Yes } \\ \text { EO3 vs WO3 } & 171.000 & 5 & 3.710 & \text { No } \\ \text { EO3 vs EP5 } & 131.000 & 4 & 3.544 \text { No Test Needed } \\ \text { EO3 vs WP3 } & 103.000 & 3 & 3.700 \text { No Test Needed } \\ \text { EO3 vs WP5 } & 91.500 & 2 & 4.891 \text { No Test Needed } \\ \text { WP5 vs WO3 } & 79.500 & 4 & 2.150 \text { No Test Needed } \\ \text { WP5 vs EP5 } & 39.500 & 3 & 1.419 \text { No Test Needed } \\ \text { WP5 vs WP3 } & 11.500 & 2 & \text { 0.615No Test Needed } \\ \text { WP3 vs WO3 } & 68.0003 & 2.443 \text { No Test Needed } \\ \text { WP3 vs EP5 } & 28.000 & 2 & 1.497 \text { No Test Needed } \\ \text { EP5 vs WO3 } & 40.000 & 2 & & 2.138 \text { No Test Needed }\end{array}$


Appendix I. (Cont.)

One Way Analysis of Variance

Friday, March 16, 2001, 11:13:59

Data source: Standard Nail WO3

Normality Test: $\quad$ Passed $\quad(P=0.234)$

Equal Variance Test: $\quad$ Failed $(P=0.024)$

Test execution ended by user request, ANOVA on Ranks begun

Kruskal-Wallis One Way Analysis of Variance on Ranks Friday, March 16, 2001, 11:13:59

Data source: Standard Nail WO3

$\begin{array}{lcc}\text { Group } & \mathbf{N} & \text { Missing } \\ \text { Coupon WO3 } 10 & 0 \\ \text { 10\% MC } & 10 & 0 \\ \text { 2nd 6\% MC } & 10 & 0 \\ \text { 12\% MC } & 10 & 0 \\ \text { 3rd 6\% MC } & 10 & 0\end{array}$

$\begin{array}{lrll}\text { Group } & \text { Median } & \mathbf{2 5 \%} & \mathbf{7 5 \%} \\ \text { Coupon WO348.800 } & 37.400 & 56.000 \\ \text { 10\% MC } & 29.000 & 27.400 & 35.200 \\ \text { 2nd 6\% MC } & 13.050 & 11.100 & 21.900 \\ \text { 12\% MC } & 31.350 & 18.500 & 39.200 \\ \text { 3rd 6\% MC } & 7.800 & 5.100 & 10.800\end{array}$

$H=37.974$ with 4 degrees of freedom. $(P=<0.001)$

The differences in the median values among the treatment groups are greater than would be expected by chance; there is a statistically significant difference $(P=<0.001)$

To isolate the group or groups that differ from the others use a multiple comparison procedure.

All Pairwise Multiple Comparison Procedures (Dunnett's Method) :

$\begin{array}{lrlll} & \text { Comparison } & \text { Diff of Ranksp } & \mathbf{q}^{\prime} & \text { P<0.05 } \\ \text { 3rd 6\% MC vs Coupon WO3 } & 355.000 & 5 & 5.445 & \text { Yes } \\ \text { 2nd 6\% MC vs Coupon WO3 } & 288.500 & 4 & 5.518 & \text { Yes } \\ \text { 10\% MC vs Coupon WO3 } & 126.000 & 3 & 3.200 & \text { Yes } \\ \text { 12\% MC vs Coupon WO3 } & 125.500 & 2 & 4.743 & \text { Yes }\end{array}$


Appendix I. (Cont.)

One Way Analysis of Variance

Friday, March 16, 2001, 11:16:03

Data source: Standard Nail WP3

Normality Test: $\quad$ Passed $\quad(P=0.226)$

Equal Variance Test: $\quad$ Failed $(P=0.037)$

Test execution ended by user request, ANOVA on Ranks begun

Kruskal-Wallis One Way Analysis of Variance on Ranks Friday, March 16, 2001, 11:16:03

Data source: Standard Nail WP3

$\begin{array}{lrc}\text { Group } & \mathbf{N} & \text { Missing } \\ \text { Coupon WP3 } 10 & 0 \\ \text { 10\% MC } & 10 & 0 \\ \text { 2nd 6\% MC } & 10 & 0 \\ \text { 12\% MC } & 10 & 0 \\ \text { 3rd 6\% MC } & 10 & 0\end{array}$

Group Median $25 \% \quad 75 \%$

Coupon WP3 55.00041.200 72.200

$10 \%$ MC $\quad 58.40043 .600 \quad 70.000$

2nd $6 \%$ MC $\quad 13.65012 .000 \quad 18.100$

$12 \%$ MC $\quad 53.40043 .800 \quad 76.700$

3rd 6\% MC $\quad 10.550 \quad 6.200 \quad 14.700$

$H=34.913$ with 4 degrees of freedom. $(P=<0.001)$

The differences in the median values among the treatment groups are greater than would be expected by chance; there is a statistically significant difference $(P=<0.001)$

To isolate the group or groups that differ from the others use a multiple comparison procedure.

All Pairwise Multiple Comparison Procedures (Dunnett's Method) :

\begin{tabular}{lrrll} 
& \multicolumn{2}{c}{ Diff of Ranks p } & $\mathbf{q}^{\prime}$ & $\mathbf{P}<\mathbf{0 . 0 5}$ \\
3rd 6\% MC vs Coupon WP3 & 262.000 & 5 & 4.019 & Yes \\
2nd 6\% MC vs Coupon WP3 & 216.000 & 4 & 4.131 & Yes \\
12\% MC vs Coupon WP3 & 15.000 & 3 & 0.381 & No \\
10\% MC vs Coupon WP3 & 8.000 & 2 & & 0.302 No Test Needed
\end{tabular}


Appendix I. (Cont.)

One Way Analysis of Variance

Friday, March 16, 2001, 11:18:19

Data source: Standard Nail WP5

Normality Test: $\quad$ Passed $\quad(P=0.312)$

Equal Variance Test: $\quad$ Failed $(P=<0.001)$

Test execution ended by user request, ANOVA on Ranks begun

Kruskal-Wallis One Way Analysis of Variance on Ranks Friday, March 16, 2001, 11:18:19

Data source: Standard Nail WP5

$\begin{array}{lrc}\text { Group } & \mathbf{N} & \text { Missing } \\ \text { Coupon WP5 } & 10 & 0 \\ \text { 10\% MC } & 10 & 0 \\ \text { 2nd 6\% MC } & 10 & 0 \\ \text { 12\% MC } & 10 & 0 \\ \text { 3rd 6\% MC } & 10 & 0\end{array}$

Group Median $25 \% \quad 75 \%$

Coupon WP5 $35.00027 .000 \quad 59.800$

$\begin{array}{lll}10 \% & \text { MC } \quad 43.50039 .800 \quad 54.000\end{array}$

2nd $6 \%$ MC $\quad 14.85012 .000 \quad 18.800$

$12 \%$ MC $\quad 51.55044 .400 \quad 60.600$

3rd 6\% MC $\quad 10.850 \quad 5.100 \quad 15.100$

$H=34.729$ with 4 degrees of freedom. $(P=<0.001)$

The differences in the median values among the treatment groups are greater than would be expected by chance; there is a statistically significant difference $(P=<0.001)$

To isolate the group or groups that differ from the others use a multiple comparison procedure.

All Pairwise Multiple Comparison Procedures (Dunnett's Method) :

$\begin{array}{lrlll}\text { Comparison } & \text { Diff of Ranksp } & \mathbf{q}^{\prime} & \mathbf{P}<\mathbf{0 . 0 5} \\ \text { 3rd 6\% MC vs Coupon WP5 } & 227.500 & 5 & 3.490 & \text { Yes } \\ \text { 2nd 6\% MC vs Coupon WP5 } & 193.500 & 4 & 3.701 & \text { Yes } \\ \text { 12\% MC vs Coupon WP5 } & 71.500 & 3 & 1.816 & \text { No } \\ \text { 10\% MC vs Coupon WP5 } & 24.500 & 2 & & 0.926 \text { No Test Needed }\end{array}$


Appendix I. (Cont.)

One Way Analysis of Variance

Friday, March 16, 2001, 10:45:06

Data source: WO3N

Normality Test: $\quad$ Passed $\quad(P=0.133)$

Equal Variance Test: $\quad$ Passed $\quad(P=0.837)$

Group N Missing

CouponWO3N 310

$10 \%$ MC $25 \quad 0$

2nd $6 \%$ MC $25 \quad 0$

$12 \%$ MC $25 \quad 0$

3rd 6\% MC $25 \quad 0$

Group Mean Std Dev SEM

CouponWO3N58.542 $12.985 \quad 2.332$

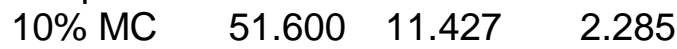

2nd 6\% MC $61.040 \quad 13.572 \quad 2.714$

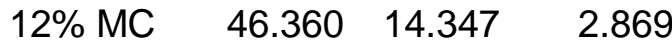

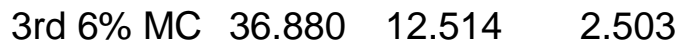

Power of performed test with alpha $=0.050: 1.000$

$\begin{array}{llcccc}\text { Source of Variation } & \text { DF } & \text { SS } & \text { MS } & \text { F } & \text { P } \\ \text { Between Treatments } & 49807.703 & 2451.926 & 14.496 & <0.001 \\ \text { Residual } & 12621311.695 & 169.140 & & \\ \text { Total } & 13031119.398 & & & \end{array}$

The differences in the mean values among the treatment groups are greater than would be expected by chance; there is a statistically significant difference $(P=<0.001)$.

Multiple Comparisons versus Control Group (Dunnett's Method) :

Comparisons for factor:

\begin{tabular}{lrrrr} 
& Diff of Means p & $\mathbf{q}^{\prime}$ & \multicolumn{1}{c}{$\mathbf{P}<\mathbf{0 . 0 5}$} \\
Comparison & 2.498 & 5.000 & 0.715 & No \\
CouponWO3N vs. 2nd 6\% MC & -6.942 & 4.000 & 1.986 & No \\
CouponWO3N vs. 10\% MC & -12.182 & 3.000 & 3.485 & Yes \\
CouponWO3N vs. 12\% MC & -21.662 & 2.000 & 6.196 & Yes
\end{tabular}


Appendix I. (Cont.)

One Way Analysis of Variance

Friday, March 16, 2001, 10:47:12

Data source: WO3S

Normality Test: $\quad$ Passed $\quad(P=0.362)$

Equal Variance Test: $\quad$ Passed $\quad(P=0.124)$

Group N Missing

CouponWO3S 330

$10 \%$ MC $25 \quad 0$

2nd 6\% MC $25 \quad 0$

$12 \%$ MC $25 \quad 0$

3rd 6\% MC $25 \quad 0$

Group Mean Std Dev SEM

CouponWO3S87.279 19.904 3.465

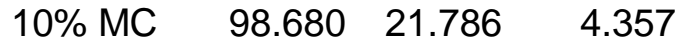

2nd 6\% MC $82.080 \quad 24.737 \quad 4.947$

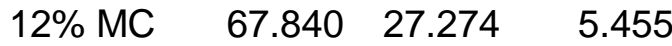

3rd 6\% MC $63.360 \quad 28.595 \quad 5.719$

Power of performed test with alpha $=0.050: 0.999$

$\begin{array}{llllll}\text { Source of Variation } & \text { DF } & \text { SS } & \text { MS } & \text { F } & \text { P } \\ \text { Between Treatments } & 421187.411 & 5296.853 & 8.894 & <0.001 \\ \text { Residual } & 12876232.315 & 595.565 & & \\ \text { Total } & 13297419.726 & & & \end{array}$

The differences in the mean values among the treatment groups are greater than would be expected by chance; there is a statistically significant difference $(P=<0.001)$.

Multiple Comparisons versus Control Group (Dunnett's Method) :

Comparisons for factor:

Comparison

CouponWO3S vs. $10 \% \mathrm{MC}$

CouponWO3S vs. 2nd $6 \% \mathrm{MC}$

CouponWO3S vs. $12 \% \mathrm{MC}$

CouponWO3S vs. 3rd 6\% MC
Diff of Means $p$

$11.401 \quad 5.000$

$-5.199 \quad 4.000$

$-19.439 \quad 3.000$

$\begin{array}{ll}-23.919 & 2.000\end{array}$ $q^{\prime} \quad P<0.05$

1.762 No

0.803 No

3.004 Yes

3.696 Yes 
Appendix I. (Cont.)

One Way Analysis of Variance

Friday, March 16, 2001, 10:49:05

Data source: WP3N

Normality Test: $\quad$ Passed $\quad(P=0.579)$

Equal Variance Test: $\quad$ Passed $\quad(P=0.404)$

Group N Missing

CouponWP3N 350

$10 \%$ MC $25 \quad 0$

2nd $6 \%$ MC $25 \quad 0$

$12 \%$ MC $25 \quad 0$

3rd 6\% MC $25 \quad 0$

Group Mean Std Dev SEM

CouponWP3N95.166 $16.908 \quad 2.858$

$10 \%$ MC $\quad 104.800 \quad 21.545 \quad 4.309$

2nd 6\% MC $71.200 \quad 15.825 \quad 3.165$

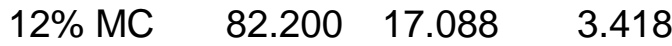

3rd 6\% MC $\quad 69.720 \quad 20.229 \quad 4.046$

Power of performed test with alpha $=0.050: 1.000$

$\begin{array}{lrrrrr}\text { Source of Variation } & \text { DF } & \text { SS } & \text { MS } & \text { F } & \text { P } \\ \text { Between Treatments } & 424190.481 & 6047.620 & 17.991 & <0.001 \\ \text { Residual } & 13043698.919 & 336.146 & & \\ \text { Total } & 13467889.400 & & & \end{array}$

The differences in the mean values among the treatment groups are greater than would be expected by chance; there is a statistically significant difference $(P=<0.001)$.

Multiple Comparisons versus Control Group (Dunnett's Method) :

Comparisons for factor:

Comparison

CouponWP3N vs. $10 \%$ MC

CouponWP3N vs. $12 \%$ MC

CouponWP3N vs. 2nd 6\% MC

CouponWP3N vs. 3 rd $6 \%$ MC
Diff of Means $p$

$9.634 \quad 5.000$

$-12.966 \quad 4.000$

\begin{tabular}{ll}
$-23.966 \quad 3.000$ \\
\hline
\end{tabular}

$-25.446 \quad 2.000$ $q^{\prime} \quad P<0.05$

2.007 No

2.701 Yes

4.992 Yes

5.300 Yes 
Appendix I. (Cont.)

t-test

Friday, March 16, 2001, 10:51:21

Data Source: WP3N2

Normality Test: $\quad$ Passed $\quad(P=0.210)$

Equal Variance Test: $\quad$ Passed $\quad(P=0.838)$

Group N Missing

CouponWP3N2 350

3rd 6\% MC $25 \quad 0$

Group Mean Std Dev SEM

CouponWP3N2101.31421.503 3.635

3rd 6\% MC $103.800 \quad 21.040 \quad 4.208$

Difference $\quad-2.486$

$t=-0.445$ with 58 degrees of freedom. $(P=0.658)$

95 percent confidence interval for difference of means: -13.657 to 8.686

The difference in the mean values of the two groups is not great enough to reject the possibility that the difference is due to random sampling variability. There is not a statistically significant difference between the i nput groups $(P=0.658)$.

Power of performed test with alpha $=0.050: 0.050$

The power of the performed test $(0.050)$ is below the desired power of 0.800 .

You should interpret the negative findings cautiously. 
Appendix I. (Cont.)

One Way Analysis of Variance

Friday, March 16, 2001, 10:54:02

Data source: WP3S

Normality Test: $\quad$ Passed $\quad(P=0.413)$

Equal Variance Test: $\quad$ Failed $(P=0.033)$

Test execution ended by user request, ANOVA on Ranks begun

Kruskal-Wallis One Way Analysis of Variance on Ranks Friday, March 16, 2001, 10:54:02

Data source: WP3S

Group N Missing

CouponWP3S 350

$10 \%$ MC $25 \quad 0$

2nd 6\% MC $25 \quad 0$

$12 \%$ MC $25 \quad 0$

3rd 6\% MC $26 \quad 0$

Group Median 25\% 75\%

CouponWP3S125.000115.150134.950

$10 \%$ MC $\quad 111.00099 .500 \quad 117.250$

2nd 6\% MC 115.000112.500 131.000

$12 \%$ MC $\quad 92.00071 .000 \quad 110.500$

3rd 6\% MC $100.50097 .000 \quad 118.000$

$H=42.998$ with 4 degrees of freedom. $(P=<0.001)$

The differences in the median values among the treatment groups are greater than would be expected by chance; there is a statistically significant difference $(P=<0.001)$

To isolate the group or groups that differ from the others use a multiple comparison procedure.

Multiple Comparisons versus Control Group (Dunn's Method) :

$\begin{array}{lrrrr} & \text { Comparison } & \text { Diff of Ranksp } & \mathbf{Q} & \mathbf{P}<\mathbf{0 . 0 5} \\ \text { 12\% MC vs CouponWP3S } & 61.7095 & 5.981 & \text { Yes } \\ \text { 3rd 6\% MC vs CouponWP3S } & 40.340 & 4 & 3.955 & \text { Yes } \\ \text { 10\% MC vs CouponWP3S } & 32.1693 & 3.118 & \text { Yes } \\ \text { 2nd 6\% MC vs CouponWP3S } & 11.7492 & 1.139 & \text { No }\end{array}$


Appendix I. (Cont.)

One Way Analysis of Variance

Friday, March 16, 2001, 10:56:29

Data source: WP5N

Normality Test: $\quad$ Passed $\quad(P=0.720)$

Equal Variance Test: $\quad$ Passed $\quad(P=0.117)$

Group N Missing

CouponWP5N $31 \quad 0$

$10 \%$ MC $25 \quad 0$

2nd 6\% MC $25 \quad 0$

$12 \% \mathrm{MC} \quad 25 \quad 0$

3rd 6\% MC $25 \quad 0$

Group Mean Std Dev SEM

CouponWP5N62.645 $13.026 \quad 2.340$

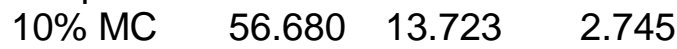

2nd 6\% MC $63.360 \quad 19.350 \quad 3.870$

$12 \%$ MC $\quad 77.280 \quad 19.930 \quad 3.986$

3rd 6\% MC $\quad 41.880 \quad 15.878 \quad 3.176$

Power of performed test with alpha $=0.050: 1.000$

$\begin{array}{lccccc}\text { Source of Variation } & \text { DF } & \text { SS } & \text { MS } & \text { F } & \text { P } \\ \text { Between Treatments } & 416418.680 & 4104.670 & 15.132 & <0.001 \\ \text { Residual } & 12634179.257 & 271.264 & & \\ \text { Total } & 13050597.936 & & & \end{array}$

The differences in the mean values among the treatment groups are greater than would be expected by chance; there is a statistically significant difference $(P=<0.001)$.

Multiple Comparisons versus Control Group (Dunnett's Method) :

Comparisons for factor:

Comparison

$\begin{array}{cccc}\text { Diff of Means } & \mathbf{p} & \mathbf{q}^{\prime} & \mathbf{P}<\mathbf{0 . 0 5} \\ 14.635 & 5.000 & 3.306 & \text { Yes } \\ 0.715 & 4.000 & 0.161 & \text { No } \\ -5.965 & 3.000 & 1.347 & \text { No } \\ -20.765 & 2.000 & 4.690 & \text { Yes }\end{array}$

CouponWP5N vs. $12 \% \mathrm{MC}$

CouponWP5N vs. 2nd 6\% MC

CouponWP5N vs. $10 \%$ MC

CouponWP5N vs. 3rd 6\% MC

$-20.765 \quad 2.000$

4.690 Yes 
Appendix I. (Cont.)

t-test

Friday, March 16, 2001, 10:58:10

Data Source: WP5N2f

Normality Test: $\quad$ Passed $\quad(P=0.151)$

Equal Variance Test: $\quad$ Passed $\quad(P=0.327)$

Group N Missing

CoupWP5N2f $31 \quad 0$

3rd 6\% MC $25 \quad 0$

Group Mean Std Dev SEM

CoupWP5N2f62.645 $13.026 \quad 2.340$

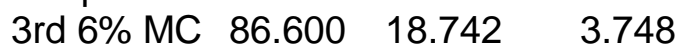

Difference $\quad-23.955$

$t=-5.632$ with 54 degrees of freedom. $(P=<0.001)$

95 percent confidence interval for difference of means: -32.482 to -15.427

The difference in the mean values of the two groups is greater than would be expected by chance; there is a statistically significant difference between the input groups $(P=<0.001)$.

Power of performed test with alpha $=0.050: 1.000$ 
Appendix I. (Cont.)

One Way Analysis of Variance

Friday, March 16, 2001, 11:00:40

Data source: WP5S

Normality Test: $\quad$ Passed $\quad(P=0.272)$

Equal Variance Test: $\quad$ Passed $\quad(P=0.475)$

Group N Missing

CouponWP5S 310

$10 \%$ MC $25 \quad 0$

2nd 6\% MC $25 \quad 0$

$12 \%$ MC $25 \quad 0$

3rd 6\% MC $25 \quad 0$

Group Mean Std Dev SEM

CouponWP5S100.24514.134 2.538

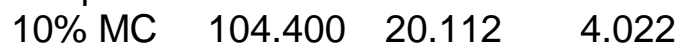

2nd 6\% MC $79.096 \quad 17.261 \quad 3.452$

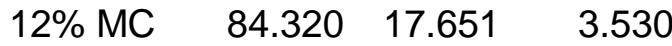

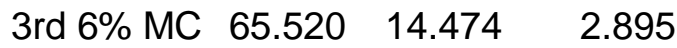

Power of performed test with alpha $=0.050: 1.000$

$\begin{array}{lllllc}\text { Source of Variation } & \text { DF } & \text { SS } & \text { MS } & \text { F } & \text { P } \\ \text { Between Treatments } & 426268.835 & 6567.209 & 23.403 & <0.001 \\ \text { Residual } & 12635357.186 & 280.613 & & \\ \text { Total } & 13061626.021 & & & \end{array}$

The differences in the mean values among the treatment groups are greater than would be expected by chance; there is a statistically significant difference $(P=<0.001)$.

Multiple Comparisons versus Control Group (Dunnett's Method) :

Comparisons for factor:

Comparison

CouponWP5S vs. $10 \% \mathrm{MC}$

CouponWP5S vs. $12 \%$ MC

CouponWP5S vs. 2nd 6\% MC

CouponWP5S vs. 3rd 6\% MC
Diff of Means $p$

$4.155 \quad 5.000$

$-15.925 \quad 4.000$

$-21.149 \quad 3.000$

$-34.725 \quad 2.000$ $q^{\prime} \quad P<0.05$

0.923 No

3.537 Yes

4.697 Yes

7.712 Yes 
Appendix I. (Cont.)

t-test

Friday, March 16, 2001, 11:02:26

Data source: WP5Sf

Normality Test: $\quad$ Failed $(P=0.004)$

Test execution ended by user request, Rank Sum Test begun

Mann-Whitney Rank Sum Test

Friday, March 16, 2001, 11:02:26

Data source: WP5Sf

Group N Missing

CoupWP5Sf $31 \quad 0$

3rd 6\% MC $25 \quad 0$

Group Median 25\% 75\%

CoupWP5Sf 98.80090.100 108.050

3rd 6\% MC $100.00095 .750 \quad 115.000$

$\mathrm{T}=797.500 \mathrm{n}(\mathrm{small})=25 \mathrm{n}(\mathrm{big})=31 \quad(\mathrm{P}=0.164)$

The differences in the median values among the two groups are not great enough to exclude the possibility that the difference is due to random sampling variability; there is not a statistically significant difference $(P=0.164)$ 
Appendix II. SAS output for the General Linear Model Procedure and Means Procedure for fastener withdrawal tests.

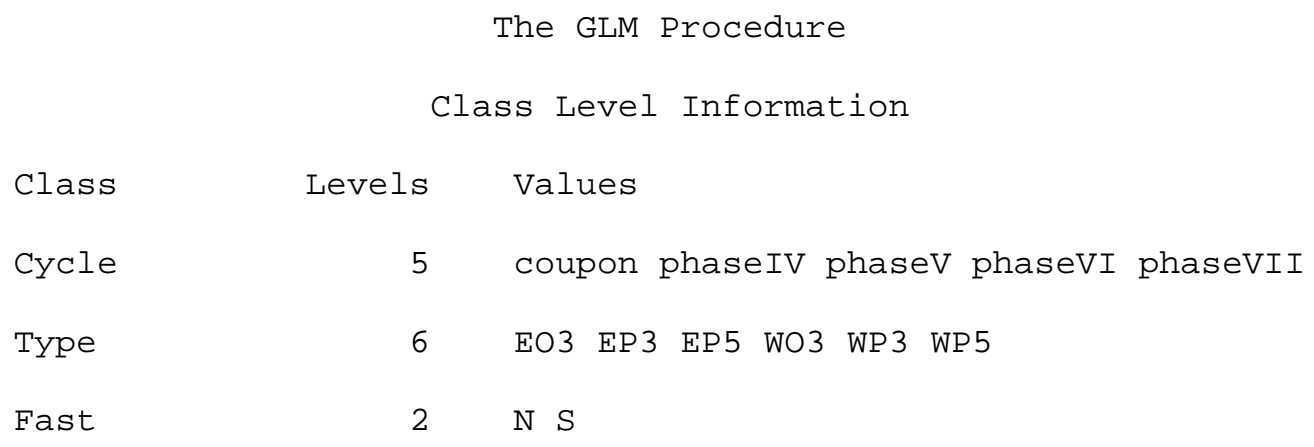




\section{Appendix II. (Cont.)}

The GLM Procedure

Dependent Variable: Value

\begin{tabular}{|c|c|c|c|c|c|c|}
\hline Source & $\mathrm{DF}$ & $\begin{array}{c}\text { Sum } \\
\text { Squares }\end{array}$ & Mean Square & $\mathrm{F}$ & Value & $\operatorname{Pr}>\mathrm{F}$ \\
\hline Model & 59 & 688375.718 & 11667.385 & & 34.44 & $<.0001$ \\
\hline Error & 1531 & 518603.701 & 338.735 & & & \\
\hline Corrected Total & 1590 & 1206979.419 & & & & \\
\hline
\end{tabular}

$\begin{array}{llrr}\text { R-Square } & \text { Coeff Var } & \text { Root MSE } & \text { Value Mean } \\ 0.570329 & 21.82486 & 18.40476 & 84.32935\end{array}$

Source

$\mathrm{DF}$

Type I SS

Mean Square

F Value $\operatorname{Pr}>\mathrm{F}$

Cycle

Type

Fast

Cycle*Type

Cycle*Fast

Type*Fast

Cycle*Type*Fast

138526.8749
207599.8559
216480.8268
30218.3607
18542.4184
33430.4978
43576.8839

$$
34631.7187
$$

102.24

122.57

$<.0001$

41519.9712

639.09

$<.0001$

216480.8268

1510.9180

4.46

$<.0001$

4635.6046

13.69

$<.0001$

6686.0996

19.74

$<.0001$

2178.8442

6.43

$<.0001$

20

Source

$\mathrm{DF}$

Type III SS

Mean Square

F Value

$\operatorname{Pr}>\mathrm{F}$

Cycle

Type

Fast

Cycle*type

Cycle*Fast

Type*Fast

Cycle*Type ${ }^{*}$ Fast

32989.7809

40205.1897

205504.6572

1498.1953

4713.8172

7137.4080

2178.8442
$97.39<.0001$

$118.69<.0001$

$606.68<.0001$

$4.42<.0001$

$13.92<.0001$

$21.07<.0001$

$6.43<.0001$ 


\section{Appendix II. (Cont.)}

The GLM Procedure

Level of

cycle

coupon

phaseIV

phaseV

phaseVI

phaseVII

Level of

Type

$\mathrm{EO} 3$

EP 3

EP 5

WO 3

WP 3

WP 5

Level of

Fast

$\mathrm{N}$
$\mathrm{S}$
$\mathrm{N}$

390

300

300

300

301

$\mathrm{N}$

262

268

264

264

271

262

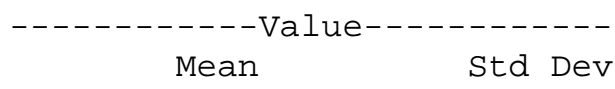

93.8307692

94.5333333

81.4433333

78.9200000

70.1162791

26.7110999

27.8199338

24.1564048

23.0652760

27.4439386

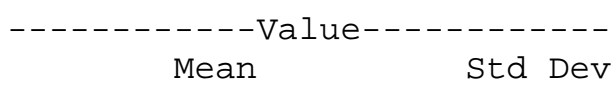

88.3396947

28.0675681

95.7388060

83.0643939

66.0000000

22.9526231

98.3357934

22.5658231

73.9045802

26.5130716

25.2720342

24.7290772

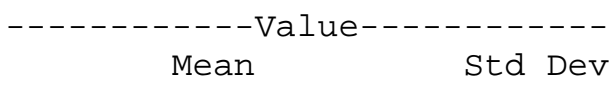

72.4847716

23.7467263

95.9526775

26.0477741

$\begin{array}{ll}\begin{array}{l}\text { Level of } \\ \text { Type }\end{array} & \begin{array}{l}\text { Level of } \\ \text { Fast }\end{array} \\ \text { EO3 } & \text { N } \\ \text { EO3 } & \text { S } \\ \text { EP3 } & \text { N } \\ \text { EP3 } & \text { S } \\ \text { EP5 } & \text { N } \\ \text { EP 5 } & \text { S } \\ \text { WO3 } & \text { N } \\ \text { WO3 } & \text { S } \\ \text { WP3 } & \text { N } \\ \text { WP3 } & \text { S } \\ \text { WP 5 } & \text { N } \\ \text { WP 5 } & \text { S }\end{array}$

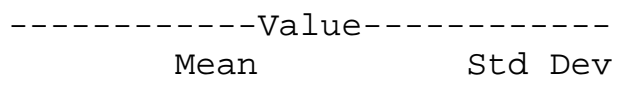

128

134

134

134

129

135

131

133

135

136

131

131

16.3370002

27.5136187

17.3508295

27.3393575

21.5565778

17.5017112

15.8246780

27.1703884

22.5097657

20.9994294

19.7247441

21.7782261 


\section{Appendix II. (Cont.)}

The GLM Procedure

\begin{tabular}{|c|c|c|c|c|c|c|c|}
\hline $\begin{array}{l}\text { Tests of Hypotheses } \\
\text { Term }\end{array}$ & Using & the & Type III MS & for & Cycle*Type*Fast & $t$ as an & Error \\
\hline Source & & $\mathrm{DF}$ & Type III & SS & Mean Square & F Value & $\operatorname{Pr}>\mathrm{F}$ \\
\hline Cycle & & 4 & 131959.1235 & & 32989.7809 & 15.14 & $<.0001$ \\
\hline Type & & 5 & 201025.9483 & & 40205.1897 & 18.45 & $<.0001$ \\
\hline Fast & & 1 & 205504.6572 & & 205504.6572 & 94.32 & $<.0001$ \\
\hline Cycle*Type & & 20 & 29963.9057 & & 1498.1953 & 0.69 & 0.7952 \\
\hline Cycle*Fast & & 4 & 18855.2688 & & 4713.8172 & 2.16 & 0.1103 \\
\hline Type Fast & & 5 & 35687.0400 & & 7137.4080 & 3.28 & 0.0254 \\
\hline $\begin{array}{l}\text { Tests of Hypotheses } \\
\text { Term }\end{array}$ & Using & the & Type III MS & for & Cycle*Type*Fast & $t$ as an & Error \\
\hline Contrast & & $\mathrm{DF}$ & Contrast SS & & Mean Square & F Value & $\operatorname{Pr}>F$ \\
\hline east vs west & & 1 & 35390.15861 & & 35390.15861 & 16.24 & 0.0007 \\
\hline sboard vs pwood & & 1 & 40146.68924 & & 40146.68924 & 18.43 & 0.0004 \\
\hline pwood 3 vs pwood 5 & & 1 & 86916.93441 & & 86916.93441 & 39.89 & $<.0001$ \\
\hline e vs $\mathrm{w} \times \mathrm{s}$ vs $\mathrm{p}$ & & 1 & 29737.85402 & & 29737.85402 & 13.65 & 0.0014 \\
\hline e vs $w \times p 3$ vs $p 5$ & & 1 & 8336.97088 & & 8336.97088 & 3.83 & 0.0646 \\
\hline comparison 1 x fast & & 1 & 6317.38704 & & 6317.38704 & 2.90 & 0.1041 \\
\hline comparison $2 \mathrm{x}$ fast & & 1 & 10830.99106 & & 10830.99106 & 4.97 & 0.0374 \\
\hline comparison $3 \mathrm{x}$ fast & & 1 & 6767.45884 & & 6767.45884 & 3.11 & 0.0933 \\
\hline comparison $4 \mathrm{x}$ fast & & 1 & 6002.34276 & & 6002.34276 & 2.75 & 0.1126 \\
\hline comparison $5 \mathrm{x}$ fast & & 1 & 5620.86437 & & 5620.86437 & 2.58 & 0.1239 \\
\hline
\end{tabular}




\section{Appendix II. (Cont.)}

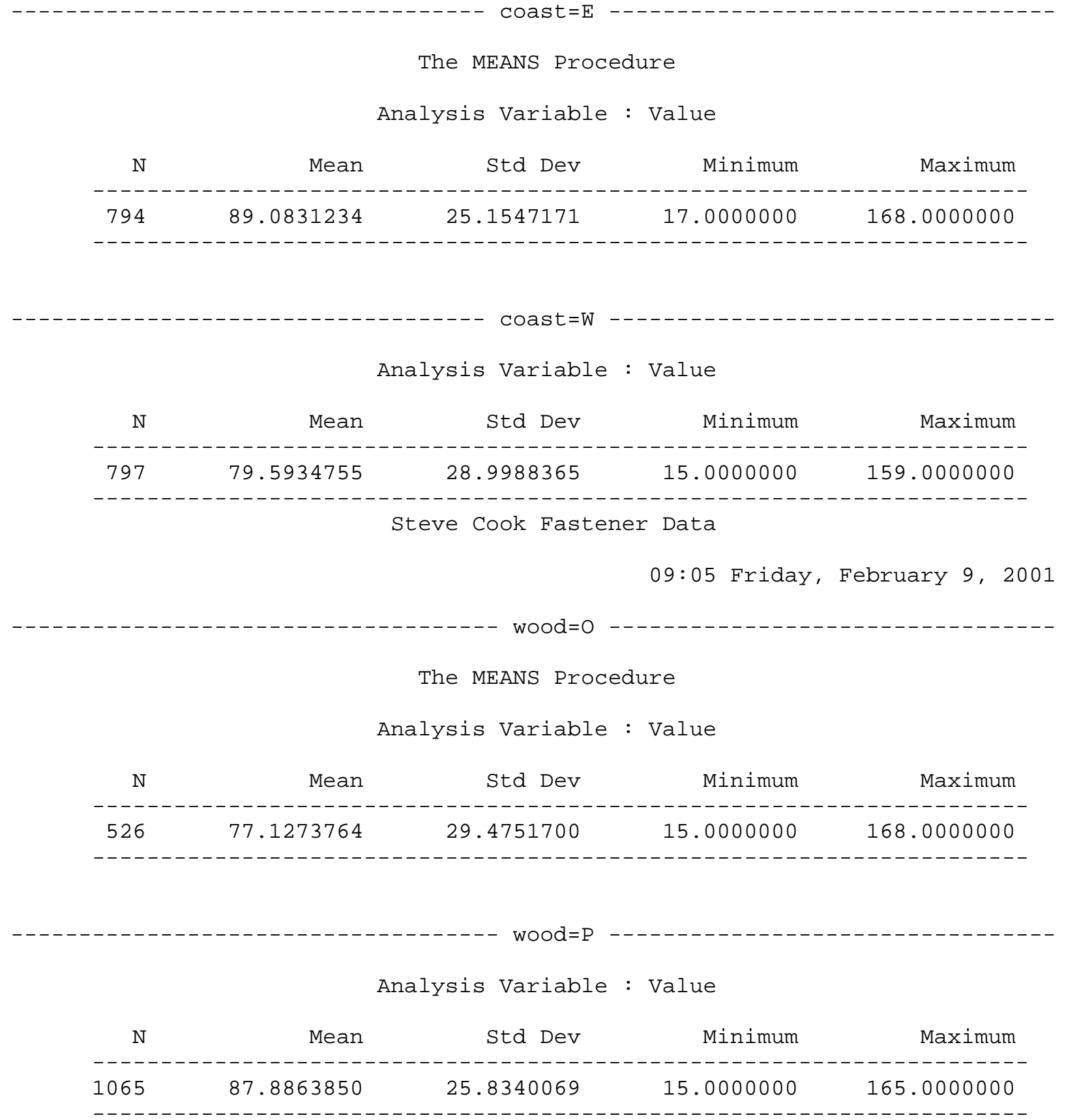




\section{Appendix II. (Cont.)}

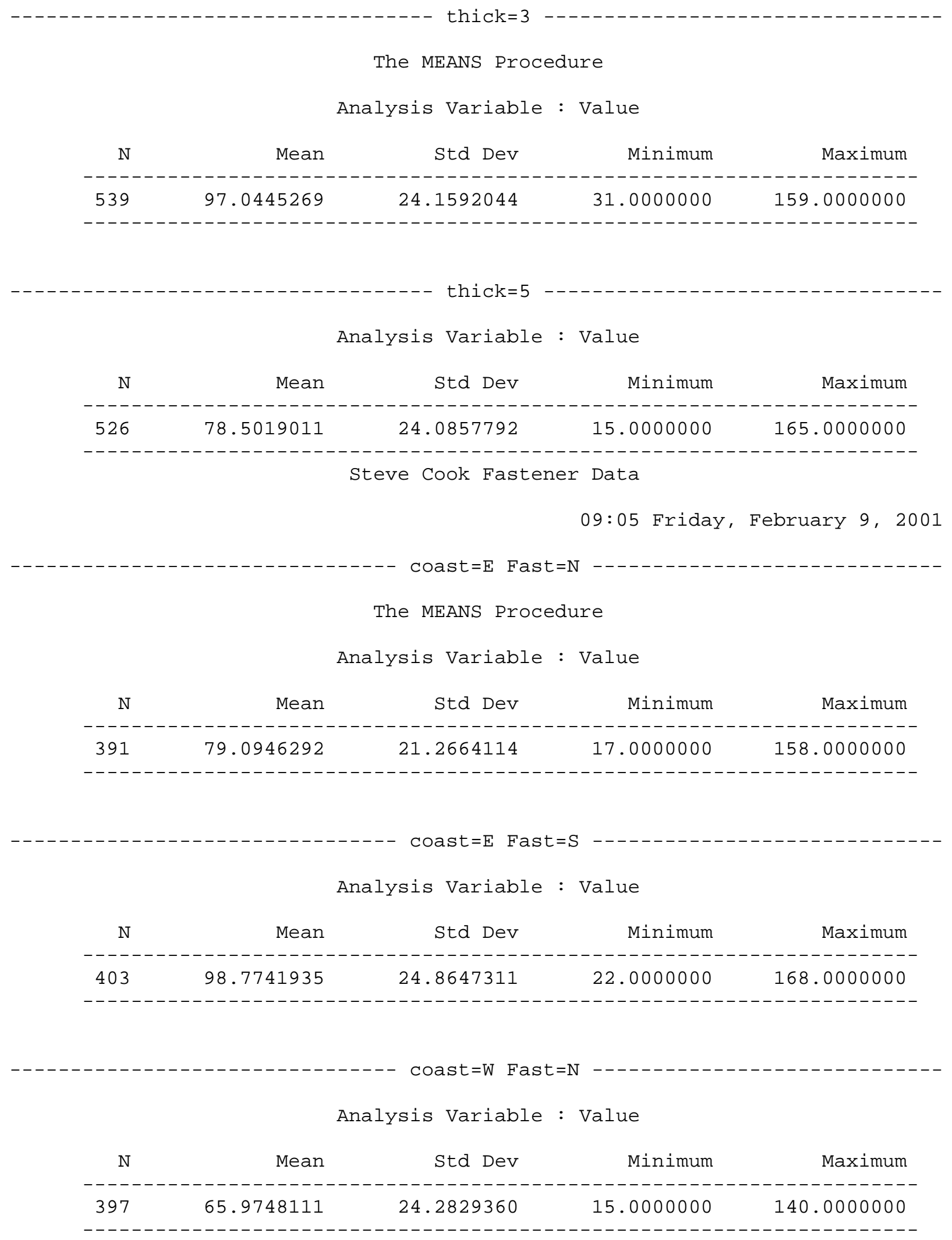




\section{Appendix II. (Cont.)}

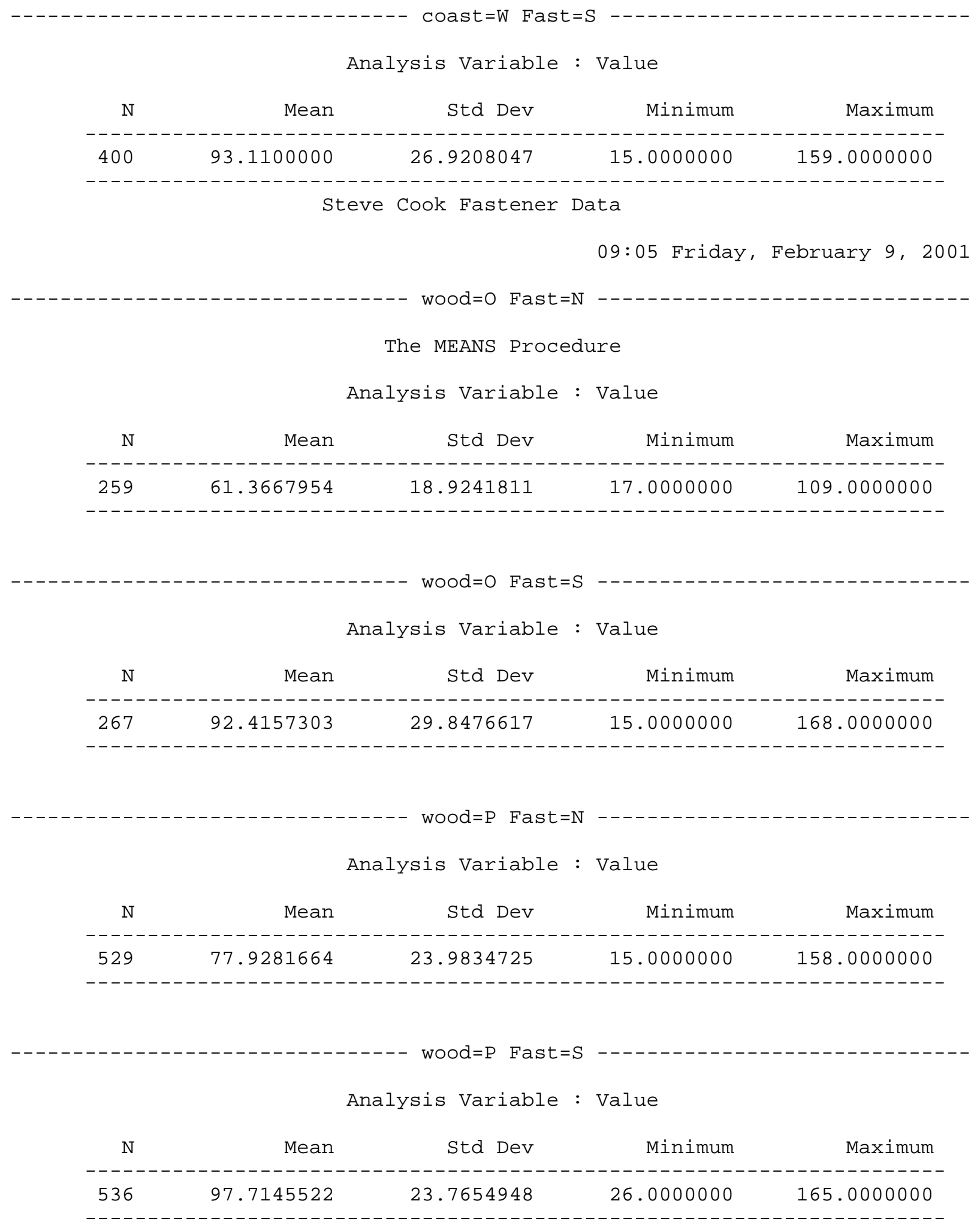




\section{Appendix II. (Cont.)}

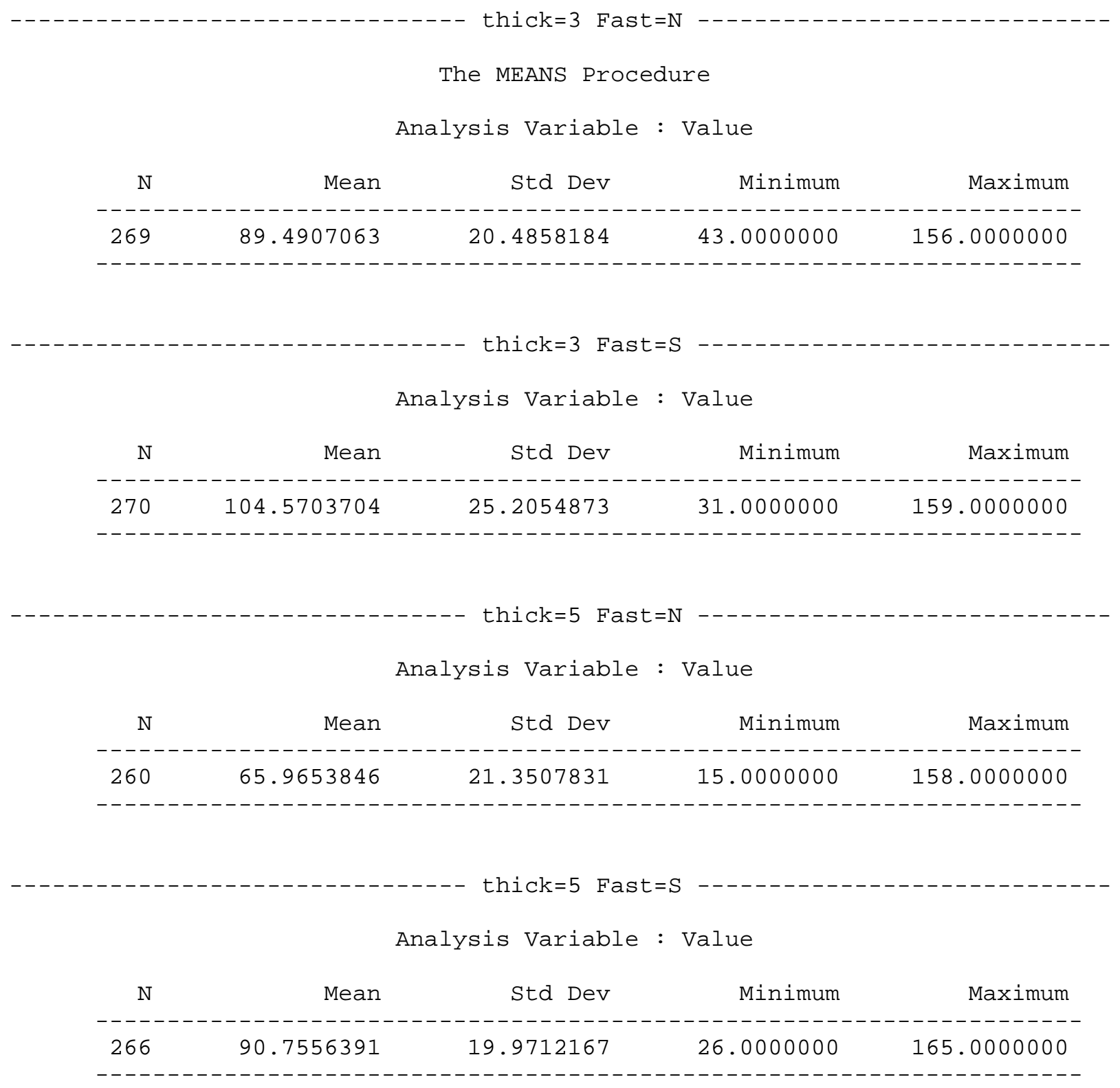

